\title{
Die (Un)Abhängigkeit der Richter unter der austrofaschistischen und nationalsozialistischen Herrschaft
}

\author{
The (In)Dependence of Judges Under Austrofascist and National Socialist Rule
}

Following the dissolution of parliament in Austria in March 1933, the Dollfuß government massively stripped back the rule of law. Government decrees were used first to limit the independence of the judges and, ultimately, to make it obsolete. In this article, these government measures will be examined within the context of party political power relations in Austria and the constitutional framework of their implementation, as well as in reference to discussions in the council of ministers. Furthermore, for the first time, the actual sanctions against individual judges will be documented in order to illustrate the effects of this government policy in practice. Finally, the claim of a 'national state of emergency', used to justify these measures, will be placed in relation to contemporary discussions of 'national emergency law'. The final chapter will then sketch the conceptual reformulation of judicial independence within National Socialist ideology and demonstrate the formal ending of traditional guarantees of unremovability and non-transferability of professional judges in the 'Third Reich' and consequently, in the wake of the 'Annexation' in 1938, in Austria as well.

Keywords: Dollfuß government - independance of judge -National Socialism - state of emergency

Nach der Ausschaltung des Parlaments in Österreich im März 1933 wurden mittels Regierungsverordnungen sukzessive „Säulen, die das Gebäude des Rechtsstaates getragen hatten, umgelegt" ${ }^{\prime \prime}$, darunter die 1934 zunächst zurückgebaute und schließlich de facto obsolet gemachte Unabhängigkeit der Richter. Im Folgenden werden diese Maßnahmen im Kontext der parteipolitischen Kräfteverhältnisse in Österreich und der verfassungsrechtlichen Rahmenbedingungen ihres Zustandekommens sowie anhand der Diskussionen im Ministerrat (MR) behandelt. Darüber hinaus dokumentiert der Beitrag erstmals konkrete Maßregelungen einzelner Richter, um die Auswirkungen dieser
Regierungspolitik in der Praxis zu illustrieren. Schließlich wird der zur Rechtfertigung dieser Maßnahmen behauptete "Staatsnotstand" in Bezug zu den zeitgenössischen Diskussionen um das „Staatsnotrecht" gesetzt. Das Schlusskapitel skizziert sodann die begriffliche Neufassung von richterlicher Unabhängigkeit durch die NSIdeologie und zeigt das formelle Ende der traditionellen Garantien der Unabsetzbarkeit und Unversetzbarkeit der Berufsrichter im „Dritten Reich" und somit infolge des "Anschlusses" 1938 auch im „Land Österreich“ auf.

\footnotetext{
${ }^{1}$ LEICHTER, Glanz 199.
} 


\section{Die Anfänge der richterlichen Unabhängigkeit in Österreich}

Die Umsetzung der Forderung nach Unabhängigkeit der Berufsrichter begann in Österreich erst mit der Trennung der Justiz von der Verwaltung durch die Verfassung von 1867. Die Unabhängigkeit der Richter, wie sie das Staatsgrundgesetz über die richterliche Gewalt garantierte, ${ }^{2}$ war aber "keineswegs eine besonders ausgeprägte Zäsur, sondern trug eher dazu bei, Defizite in der Rechtsstellung der Richter deutlicher spürbar zu machen". ${ }^{3}$ Richter im Sinne des Staatsgrundgesetzes über die richterliche Gewalt waren nämlich zunächst nur die "selbstständigen richterlichen Beamten", also nach dem Richterdisziplinargesetz vom 21. Mai $1868^{4}$ Präsidenten, Vizepräsidenten und Räte der Gerichtshöfe sowie die Bezirksrichter, von denen es jedoch - im Sinne der überkommenen monokratischen Behördenorganisation - bei jedem Bezirksgericht (BG) nur einen gab, nämlich den heute als Vorsteher des BG bezeichneten Funktionär. Das übrige Personal war, selbst wenn es richterliche Funktion ausübte, nur als Hilfspersonal eingestuft. Diese Situation wurde erst mit dem Gerichtsorganisationsgesetz von $1896^{5}$ geändert, das die Gruppe der selbstständigen richterlichen Beamten um die bei den BG angestellten Einzelrichter erweiterte, sodass nun die richterliche Unabhängigkeit prinzipiell jedem Richter im funktionalen Sinn zukam. ${ }^{6}$

Nachdem 1918 der neue Staat „Deutschösterreich“ die Rechtsgrundlagen für die Stellung der Richterschaft rezipiert hatte, legte in weiterer

\footnotetext{
${ }^{2}$ RGBl. 144/1867, Art. 6: „Die Richter sind in Ausübung ihres richterlichen Amtes selbstständig und unabhängig."

${ }^{3}$ Vgl. m.w.N. KOHL, Entwicklung 19ff; AuBIN, Entwicklung $17 \mathrm{f}$.

${ }^{4}$ RGBl. 46/1868, Vgl. LEHNER, Kabinettsjustiz 23f.

${ }^{5}$ RGBl. 217/1896.

${ }^{6} \mathrm{KOHL}$, Entwicklung 24f.
}

Folge Art. 87 des Bundesverfassungs-Gesetzes vom 1. Oktober 1920 (B-VG) fest, dass die Richter „in Ausübung ihres richterlichen Amtes unabhängig" sind, wobei sich ein Richter bei der „Besorgung aller ihm nach dem Gesetz und der Geschäftsverteilung zustehenden gerichtlichen Geschäfte" in Ausübung seines richterlichen Amtes befindet.7 Die Geschäfte sind „unter die Richter eines Gerichts für die in der Gerichtsverfassung bestimmte Zeit im voraus zu verteilen", und eine "nach dieser Einteilung einem Richter zufallende Sache dar ihm durch Verfügung der Justizverwaltung nur im Fall seiner Behinderung abgenommen werden". Garantiert wird die richterliche Unabhängigkeit durch die grundsätzliche Unversetzbarkeit und Unabsetzbarkeit der Richter, die in Art. 88 B-VG festgelegt ist: Außer bei Versetzung in den dauernden Ruhestand nach Erreichen der in der Gerichtsverfassung bestimmten Altersgrenze können Richter „nur in den vom Gesetz vorgeschriebenen Fällen und Formen und auf Grund eines förmlichen richterlichen Erkenntnisses ihres Amtes entsetzt oder wider ihren Willen an eine andere Stelle oder in den Ruhestand versetzt werden“, ausgenommen Fälle, „die durch Veränderungen in der Verfassung der Gerichte nötig werden." Eine zeitweise Enthebung der Richter vom Amt darf „nur durch Verfügung des Gerichtsvorstandes oder der höheren Gerichtsbehörde bei gleichzeitiger Verweisung der Sache an das zuständige Gericht stattfinden." So war auf verfassungsrechtlicher Ebene der Schutz der richterlichen Unabhängigkeit vor einem Eingreifen der Regierung und der Justizverwaltung in der Ersten Republik umfassend verankert und institutionell garantiert.

Freilich kann eine institutionelle Absicherung der „äußeren“ Unabhängigkeit der Berufsrichter nicht auch schon deren „innere Unabhängig-

${ }^{7}$ BGBl. 1/1920. 
keit" ${ }^{\text {"8 }}$ bewirken, denn auch sie werden von ihrem sozialen und kulturellen Umfeld mehr oder weniger stark geprägt. ${ }^{9}$ So waren die „fast ausschließlich aus den oberen Bereichen der sozialen Hierarchie stamm[end]en" Richter auch in der Ersten Republik, "[s]elbst in der festen Absicht, unparteiisch Recht zu sprechen, [...] meist nicht imstande, ihre konservative Weltanschauung oder deutschnationale Gesinnung zu überwinden. " 10 Bereits in der Zeit zwischen 1923 und 1932 lagen bei politisch motivierten Straftaten die über „Marxisten“ verhängten Strafen „mehr als doppelt so hoch" im Vergleich zu ähnlich gelagerten Verfahren gegen Nichtmarxisten. ${ }^{11}$ Der "großteils konservativ geprägten Richterschaft" ${ }^{\prime \prime 2}$ werden daher bereits vor 1933/34 ,auffallend milde Urteile [...] in politischen Prozessen gegen rechtsradikale Gewalttäter" zugeschrieben. ${ }^{13}$ Der mit Freisprüchen der Angeklagten endende Hochverratsprozess von 1931 gegen den Heimwehrführer Walter Pfriemer und sieben weitere Putschisten stellte dann einen vorläufigen Höhepunkt "politisch einseitiger Rechtsprechung" dar. ${ }^{14}$ Die Richter galten somit 1933 als „nicht besonders arbeiterfreundlich, noch weniger aber [...] regierungsfreundlich", und viele von ihnen waren jedenfalls „durchaus nicht für das Dollfuß-Regime“. ${ }^{15}$

\footnotetext{
${ }^{8}$ Vgl. dazu etwa NiEBLER, Unabhängigkeit 21.

${ }^{9}$ HeLIGE, Richteramt $145 \mathrm{f}$.

${ }^{10}$ BotZ, Gewalt 251.

${ }^{11}$ BotZ, Verhältnis 160.

12 HoltmanN, Unterdrückung 1f., vgl. auch MATTL, Beiträge; MATTL, Sozialgeschichte; RATHKOLB, Anmerkungen 81; SZONTAGH, Richtervereinigung 58f.

${ }^{13}$ HOLTMANN, Unterdrückung 1f.

${ }^{14}$ Ebd.

${ }^{15}$ Diskussionsbeitrag Robert Kann, JEDLICKA, NECK, 12. Februar 155.
}

\section{2. "Austrofaschismus"}

\subsection{Politische Hintergründe}

Bereits bald nach dem Ende der Regierungskoalition am Beginn der Ersten Republik traten die ideologischen Gegensätze zwischen Christlichsozialen und Sozialdemokraten (wieder) klar zu Tage und manifestierten sich auch in gewalttätigen Ausschreitungen ihrer paramilitärischen Verbände, den „Heimwehren“ und dem "Republikanischen Schutzbund“. Seit 1923 machte dann die SA einen fixen Bestandteil des "antimarxistischen" Straßenkampfes aus, ${ }^{16}$ und 1932 waren die Nationalsozialisten bereits an $90 \%$ aller politischen Gewaltakte beteiligt. ${ }^{17}$ Trotzdem legten in dieser Phase des "latenten Bürgerkriegs" die konservativen Regierungen ihr Hauptaugenmerk auf die Bekämpfung der linken Opposition, die sich ihrerseits v.a. durch Verbalradikalismus auszeichnete, aber auch vor aktiver, in der Regel jedoch defensiver Gewaltanwendung nicht zurückschreckte. ${ }^{18}$ Prinzipiell war die Linie der Sozialdemokratie entsprechend dem Linzer Parteiprogramm von 1926 jedoch: „demokratisch, so lange wir können: Diktatur nur, wenn man uns dazu zwingt, und nicht weiter als unbedingt notwendig" (Otto Bauer). ${ }^{19}$ Seit den Wahlerfolgen der Nationalsozialisten, insbesondere bei den Landtagswahlen im April 1932, nahm die seit 20. Mai 1932 amtierende Regierung unter Engelbert Dollfuß dann den "Zweifrontenkrieg" sowohl gegen Marxisten als auch Nationalsozialisten auf,20 wobei die NSDAP allerdings mehr als "terroristische Organisation ${ }^{\prime 21}$ und weniger als politische Opposi-

\footnotetext{
${ }^{16}$ Botz, Gewalt 186ff.

17 Ausführlich GARSCHA, Nationalsozialisten.

${ }^{18}$ BoTZ, Gewalt 1616ff., 317, 277.

${ }^{19}$ Zit.n. GULICK, Österreich 18; vgl. dazu auch REITER-

ZATLOUKAL, Parlamentarismus 25ff.

${ }^{20} \mathrm{Vgl}$. zum Folgenden etwa ReITER-ZATLOUKAL, Radikalisierung 273ff.

${ }^{21}$ GARSCHA, Nationalsozialisten $10 \mathrm{ff}$.
} 
tion agierte. Hauptgegner der Regierung blieb dennoch weiterhin die linke Opposition, war doch die SDAPÖ nach wie vor eine Massenpartei, während die Nationalsozialisten 1933 bundesweit erst etwa $10 \%$ der sozialdemokratischen Mitgliederstärke erreichen konnten. ${ }^{22}$ In Wien hatten jedenfalls bei den Wahlen 1932 der politische Arm der Heimwehren, der „Heimatblock", sowie die "Großdeutsche Volkspartei" eine vollständige Niederlage erlitten und die Christlichsozialen deutlich Stimmen verloren (22 \% 1930, $18 \%$ 1932). ${ }^{23}$ Die SDAPÖ hatte dagegen nur geringe Verluste erlitten ( $55 \% 1930$, $52,5 \%$ 1932), die KPÖ ihren Stimmenanteil sogar mehr als verdoppelt $(0,8 \% 1930,1,7 \% 1932),{ }^{24}$ und die NSDAP war zur drittstärksten Partei aufgestiegen (2\% 1930, 15,5\% 1932). ${ }^{25}$ Ange-

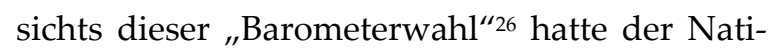
onalrat auch (auf Antrag der SDAPÖ) im Mai 1932 die Ausschreibung von Neuwahlen beschlossen, welche die neue Regierung allerdings unbedingt verhindern musste, wollte sie ihre Einstimmenmehrheit im Nationalrat nicht verlieren und die Christlichsozialen nicht zur „drittstärksten Partei“ herabsinken lassen, wie dies Parteiobmann Carl Vaugoin auch klar aussprach. ${ }^{27}$ Der Kärntner Christlichsoziale Sylvester Leer brachte dies im Parteivorstand am 9. März 1933 deutlich auf den Punkt: „Neuwahlen bedeuten heute ein Debakel ${ }^{\prime,}{ }^{28}$ und der dem Landbund zugehörige Vizekanzler Franz Winkler ${ }^{29}$ konstatierte wenige Tage später lapidar:

${ }^{22}$ KONRAD, Werben 74f.; BOTZ, Strukturwandlungen 175ff; WILTSCHEGG, Heimwehr 31.

${ }^{23}$ Vgl. etwa StAUDINGER, Partei 266f.

${ }^{24}$ STEINER, Partei 322.

${ }^{25} \mathrm{HÄNISCH}$, Wahlentwicklung 491.

${ }^{26}$ KREISSLER, Revolution 186.

${ }_{27}$ Zit.n. Huemer, Sektionschef Hecht 109, 195.

${ }^{28}$ Parteivorstand 9.3.1933, Goldinger, Protokolle 151, 156.

${ }^{29}$ Winkler war Parteiobmann des Landbundes, der sich zum Antimarxismus und Ständegedanken, nicht aber zur Heimwehr bekannte, und ab 1930 mit den Großdeutschen die Wahlgemeinschaft „Nationaler
„Wir haben 60 Prozent der Bevölkerung gegen uns". 30

Ausschlaggebend für die weitere Entwicklung waren dann die Ereignisse am 4. März 1933, ${ }^{31}$ als der Nationalrat durch die Rücktritte der Nationalratspräsidenten in den Zustand einer - allerdings rein formalen - Handlungsunfähigkeit geraten war und die Regierung, von der "Selbstausschaltung" des Nationalrates sprechend, dessen erneutes Zusammentreten mittels Polizeieinsatzes verhinderte. Dollfuß nützte nun die Gelegenheit, ein „straffes Autoritätsregime“ unter Ausschaltung der Oppositionsparteien zu errichten. Die Regierung besaß damals freilich noch „keineswegs ein klares Programm in Richtung Etablierung einer neuen Herrschaftsform ", ${ }^{32}$ sondern sah zunächst den durch sie geschaffenen Zustand als nur einen „vorübergehenden“ mit dem Ziel einer „Verfassungs- und Parlamentsreform ". ${ }^{33}$ Allerdings lotete sie in weiterer Folge die Grenzen der Ermächtigungsgesetzgebung ohne Parlament aus und erließ grundrechtseinschränkende Versammlungs- sowie Aufmarschverbote.

Die Regierung stützte sich dafür zunächst auf das Kriegswirtschaftliche Ermächtigungsgesetz (KwEG) von 1917, das der Regierung die Befugnis eingeräumt hatte, „während der Dauer der durch den Krieg hervorgerufenen außerordentlichen Verhältnisse durch Verordnung die notwendigen Verfügungen zur Förderung und

Wirtschaftsblock" bildete. Er war zwischen 1930 und Mai 1933 BMI bzw. als Vizekanzler (29. 1. 1932) mit der Leitung der Angelegenheiten der inneren Verwaltung betraut, danach bis 10.5.1933 mit der Leitung der wirtschaftspolitischen Angelegenheiten. 1934 emigrierte er nach Deutschland, trat der NSDAP bei und wurde 1935 aus Österreich ausgebürgert.

30 Parteivorstand 9.3.1933, GOLDINGER, Protokolle 182.

${ }^{31}$ FRÖSCHL, ZOITL, März 1933.

32 TÁlOS, MANOSCHEK, Konstituierungsprozess 12.

33 Parteivorstand 14.3. 1933, GolDINGER, Protokolle 184. 
Wiederaufrichtung des wirtschaftlichen Lebens, zur Abwehr wirtschaftlicher Schädigungen und zur Versorgung der Bevölkerung mit Nahrungsmitteln und anderen Bedarfsgegenständen zu treffen." Das KwEG war 1918 übergeleitet und 1920 mit dem Verfassungsüberleitungsgesetz explizit in Kraft belassen worden, ${ }^{34}$ und zwar trotz bereits damals vorhandener Missbrauchsbedenken. ${ }^{35}$ Wie die Ereignisse seit dem 4. März 1933 zeigten, war hinfort die gesamte Rechtspolitik der Regierung dem Grundprinzip geschuldet, ,jeden offen revolutionären Schritt zu vermeiden, Wahrung der Rechtskontinuität unter allen Umständen", was in der Praxis eben auch nur „vorgebliche Wahrung der Rechtskontinuität" bedeutete. ${ }^{36}$

Eine Überprüfung dieser Regierungspraxis durch den Verfassungsgerichtshof (VfGH) verunmöglichte die Regierung durch Ausschaltung desselben im Mai 1933 mittels KwEG-Verordnung, ${ }^{37}$ als dessen Entscheidung über einige von der „roten“ Wiener Landesregierung angefochtene KwEG-Verordnungen anstand, wodurch dieser Regierungspraxis zweifellos der Boden entzogen worden wäre. "So wie sich Baron Münchhausen [...] einst am eigenen Schopf aus dem Sumpf zog", so rettete sich nun auch die Regierung mit einer weiteren verfassungswidrigen Verordnung ",aus dem Sumpf der Illegalität“. ${ }^{38}$ Dem von der Verfassung 1934 anstelle von VfGH und Verwaltungsgerichtshof eingerichteten BGH war dann das Prüfungsrecht für Verordnungen vor dem Juli 1934 überhaupt generell entzogen, ${ }^{39}$ womit eine rechtsstaatliche Kontrolle der KwEG-Rechtspraxis weiterhin unmöglich war. Ab Ende April ersetzte dann ein

\footnotetext{
${ }^{4}$ StGB1. 1/1918, StGB1. 451/1920, BGB1. 2/1920.

${ }^{35} \mathrm{Vgl}$. HuEMER, Sektionschef Hecht 140.

${ }^{36}$ Ebd. 301.

${ }^{37}$ BGBl. 1933/191.

${ }^{38}$ GRAF, Rechtslehre 62.

${ }^{39}$ BGBl. II 75/1934; Vgl. zu diesem ReITER-ZATLOUKAL, Bundesgerichtshof.
}

Ermächtigungsgesetz auf bundesverfassungsgesetzlicher Ebene ${ }^{40}$ das KwEG.

Nachdem bereits Ende März 1933 die Auflösung des Republikanischen Schutzbundes auf vereinsrechtlicher Ebene erfolgt war ${ }^{41}$ setzte die Regierung ihr "little legal dictatorship“, ${ }^{42}$ so damals der amerikanische Gesandte, dann damit fort, auf der Grundlage des KwEG die oppositionellen Parteien zu verbieten und generell den Rechtsstaat abzubauen. So wurde am 26. Mai jegliche Betätigung für die KPÖ verboten, ${ }^{43}$ am 19. Juni 1933 auch für die NSDAP. ${ }^{44}$ War die Politik gegen die Nationalsozialisten nämlich zwar anfänglich durchaus noch schonend, weil man hoffte, sie vielleicht für die Regierungslinie gewinnen zu können, wenn man in entschiedener Weise den „Weg der Faschisierung des österreichischen Staates" einschlage, ${ }^{45}$ so hatten die Ernennung Hitlers zum deutschen Reichskanzler im Jänner 1933 und die Reichstagswahlen vom März 1933 „die führenden Kreise der österreichischen Politik in schwerste Bestürzung gesetzt“". ${ }^{46}$ Dazu kamen die Abkühlung des Klimas zwischen der österreichischen und deutschen Regierung sowie die sich seit Juni 1933 in besonderem Maße manifestierende „Sprengstoffpolitik“47 der österreichischen Nationalsozialisten. Nun sagte die österreichische Regierung auch den Nationalsozialisten den Kampf an freilich ohne den Kampf gegen den „Bolschewismus" im Geringsten einzuschränken, denn so erklärte etwa Richard Schmitz, der Bundesminister (BM) für soziale Verwaltung: „Mit den Sozialdemokraten zusammengehen, um die NS-

\footnotetext{
${ }^{40}$ BGB1. I 255/1934.

${ }^{41}$ VLCEK, Schutzbund; ROTHLÄNDER, Vermögensbeschlagnahme.

42 Zit.n. GOLDNER, Dollfuss 41.

43 BGBl. 200/1933.

${ }^{44}$ BGBl. 240/1933.

${ }^{45}$ Brief Mussolinis an Dollfuß, 9. 9. 1933, MADERTHA-

NER, Briefwechsel 37.

46 WINKLER, Diktatur 44f.

${ }^{47}$ SCHUSCHNIGG, Österreich 219.
} 
Welle aufzuhalten, [da] bringt man sich um", ${ }^{48}$ und Staatssekretär Odo Neustädter-Stürmer war der Ansicht, nur auf diese Weise die Nationalsozialisten „überhitlern“ zu können. ${ }^{49}$ Dollfuß wiederum war davon überzeugt, ${ }^{50}$ die „,braune Welle [...] nur auffangen“ zu können, wenn man "das, was die Nazi versprechen und in Deutschland getan haben, was ohnehin gemildert wird durch verschiedene Richtungen bei uns, selber mache“. Nur dann werde es gelingen, einem "Großteil der Sozi-Mitglieder beizubringen, daß sie keine Macht mehr haben", und sie würden „weggehen von den Sozi“.

Die Nationalsozialisten freilich waren mit dieser Regierungspolitik zufrieden, "weil“- so Theo Habicht, der NS-,„Landesinspekteur“ - „die abgefallenen Sozi Nazi werden“, was Dollfuß im Mai 1933 auf folgende Weise kommentierte: „Ich bin so Antimarxist, daß ich auch das in Kauf nehme ". ${ }^{51}$ Außerdem intensivierte Benito Mussolini im Juli 1933 den Druck auf Dollfuß, forderte ihn auf, 52 ",in der energischsten Weise“ zu reagieren und die "notwendigen Maßnahmen“ zu ergreifen, was auch einen allfälligen „Belagerungszustand" einschließe. Der Kampf gegen die Sozialdemokraten müsse verstärkt werden, denn es dürfe nicht den „Nazi die Waffe des Antimarxismus in die Hand gegeben werden", da sie sich sonst "in einem gegebenen Moment als Retter der Lage" aufspielen könnten.

Die weiteren Aktivitäten der illegalen Nationalsozialisten gipfelten dann im Juliputsch 1934, ${ }^{53}$ bei dem Bundeskanzler Dollfuß ermordet wurde. Im Zuge des Schutzbundaufstandes am 12. Februar 1934 erfolgte schließlich auch das

\footnotetext{
${ }^{48}$ Zit.n. WeINZIERL, Notizen 119.

49 STAUdinger, Partei 72.

50 Parteivorstand 25.3. 1933, GoldINGER, Protokolle 212.

51 Parteivorstand 3. 5. 1933, ebd. 241.

52 Brief 1.7. 1933, MADERTHANER, Briefwechsel 19; auch Ross, Hitler 77.

53 JAGSCHITZ, Putsch; BAUER, Elementar-Ereignis.
}

Parteiverbot für die SDAPÖ, ${ }^{54}$ weil sie, so Leopold Kunschak, "gegen den Staat und seine Unabhängigkeit revoltiert" hätte, weshalb sie der "Staat" im "Zustand der Notwehr [...] ausgeschaltet" habe. ${ }^{55}$ Damit war nun endgültig der Umbruch in die Diktatur vollzogen.

\subsection{Eingriffe der Regierung in die Justiz}

\subsubsection{Etablierungsphase $1933 / 34$}

Erste Eingriffe in die Justiz, die ein tiefes Misstrauen der Regierung gegenüber derselben zum Ausdruck brachten, erfolgten bereits unmittelbar nach der von der Regierung so bezeichneten Selbstausschaltung des Nationalrats am 4. März 1933.56 Schon Ende März 1933 hatte Dollfuß aufgrund der aus seiner Sicht unbefriedigenden Beschlagnahmepraxis betreffend oppositionelle Zeitungen verlangt, dass die "staatsanwaltlichen Funktionäre ganz besonders angehalten werden müssten, eine mit der Regierungspolitik übereinstimmende Praxis zu üben", ${ }^{57}$ und nach ersten Abänderungen der Geschwornengerichtsbarkeit Ende März $1933^{58}$ sollte nun auch die Berufsrichterschaft möglichst eng an die Regierungslinie gebunden werden. Dies erfolgte aber anfänglich durchaus verschleiert und unter Vermeidung von gröberen Repressalien. ${ }^{59}$

So wurde etwa bereits am 7. April 1933 auf Beschluss des Ministerrates (MR) vom 31. März für alle Bundesbeamten durch Erlass mit Strafan-

\footnotetext{
${ }^{54}$ BGBl. 78/1934.

${ }^{55}$ Parteivorstand 15. 2. 1933, GoldingER, Protokolle 355.

${ }^{56}$ NeUgeBAuER, Repressionsapparat 301ff.; die Ausführungen unter 2.2.1. und 2.2.2. stützen sich weitgehend auf REITER, Unabhängigkeit.

${ }^{57}$ MRP 863, 31. 3. 1933, NECK, WANDRUSZKA, Protokolle VIII/3, 68 .

${ }^{58}$ Siehe dazu ReITER, Unabhängigkeit m.w.N.

${ }^{59} \mathrm{Vgl}$. dazu HOLTMANN, Unterdrückung 56.
} 
drohung verfügt, ${ }^{60}$ dass diesen nicht nur innerhalb, sondern nun auch außerhalb des Dienstes jede ,abfällige Kritik am Staat und an den verantwortlichen obersten Staatsorganen in Wort oder Schrift" untersagt sei und jeder Beamte zur Hintanhaltung solcher Vorkommisse über "Wahrnehmungen in dieser Richtung" der

${ }^{60}$ BMJ, GZ 1.475/33, ÖStA, AVA, Justiz JM, Allgemein Pers.Ger., G. 5a, Kart. 4465. Außerdem waren ihnen eine parteipolitische Betätigung, das Tragen von Abzeichen im Amt sowie die Verbreitung von parteipolitischen Druckschriften und die Einhebung von Spenden und Beiträgen für politische Zwecke im Amt verboten. Bereits der Erlass vom 20.11. 1931 monierte, dass nicht von allen Bundesbediensteten „bei ihrem außerdienstlichen Verhalten die ihnen durch ihre Dienstpflichten vorgeschriebene Zurückhaltung gewahrt" werde. Sie hätten ,in und ausser Dienst alles zu vermeiden, was die Achtung und das Vertrauen, die ihre Stellung erfordert - vor allem das Vertrauen in ihre unparteiische dienstliche Haltung - schmälern könnte“. Es war ihnen daher „besonders eine Betätigung im Vereinsleben, die den Pflichten eines Beamten widerstreitet, verboten sowie das Eingehen von Verbindungen mit dem Zweck der Herbeiführung von Störungen oder Hemmungen des Dienstbetriebes“. Der Beamte hatte daher ,jede ausserdienstliche Betätigung - insbesondere im politischen und Vereinsleben - zu unterlassen, die wegen der Art der Betätigung an sich oder wegen der Ziele, die ihr zu Grunde liegen, zu den vorbezeichneten Dienstpflichten in unmittelbarem Widerspruch steht oder geeignet ist, ihn in einen solchen Widerspruch zu verwickeln“. Auch war das Tragen von politischen Abzeichen, welcher Art auch immer, im Dienst unzulässig, vgl. BMJ GZ 5189-3/31: BKA, betreffend die Erinnerung der Bundesangestellten an ihre Dienstpflichten. Da allerdings dieser Erlass „nicht von allen Richtern entsprechend gewürdigt" wurde, musste er zu Jahresbeginn 1932 erneut eingeschärft werden. Als der BMJ den Auftrag erteilte, „dass die Richter neuerdings an die gebotene Zurückhaltung bei der politischen Tätigkeit erinnert" werden sollten, hagelte es Proteste von Richtern, die sich bei den Landtagswahlen von 1932 für die NSDAP engagierten und nun behaupteten, das BMJ habe den richterlichen Beamten verboten, auf Versammlungen $\mathrm{zu}$ sprechen und in Zeitungen zu schreiben, vgl. BMJ Amtserinnerung betreffend die Erinnerung der Richter an ihre Dienstpflichten bei ihrer politischen Betätigung, GZ 9013/32, ebd.
Dienstbehörde sofort Meldung zu erstatten habe. ${ }^{61}$ Dieser Erlass verursachte eine „,bedeutende Erregung" unter den Richtern, die im Zusammenhang mit der ihnen auferlegten Anzeigepflicht eine "Schmälerung des Vertrauens, der Eintracht und reibungslosen Zusammenarbeitens" befürchteten. ${ }^{62}$ Einige Richter legten Verwahrung gegen die nach ihrer Ansicht mit den verfassungsmäßigen Staatsbürgerrechten und den Vorschriften des Richterdienstrechts unvereinbaren Bestimmungen des Erlasses ein. Der Gerichtsvorsteher in Villach lehnte es darüber hinaus "aus Standesrücksichten“ explizit ab, „die ,Wahrnehmungen' durch Richter und Beamte gegen Kollegen entgegenzunehmen", und tat kund, dass wer immer sich bewogen fühle, solche Anzeigen zu erstatten, dies „bei der übergeordneten Stelle oder bei der StA. oder bei der Polizei" tun möge. ${ }^{63}$

Mit Verordnung vom 10. Mai $1933^{64}$ wurden, nachdem 1919 der religiös formulierte Diensteid der Monarchie durch eine Vereidigung durch Handschlag ersetzt worden war, eine neue Eidesformel vorgeschrieben und die neuerliche Vereidigung aller Beamten angeordnet. Hatten die Richter in der Republik „die Erfüllung ihrer Pflichten, insbesondere die unverbrüchliche Beobachtung der Grundgesetze und Gesetze zu geloben", 65 so lautete der neue „Richtereid“ nun:66

\footnotetext{
${ }^{61}$ Äußerung des BG Feldkirchen 2. 5. 1933, übermittelt durch OLG-Präs. Graz an BMJ, GZ 2070-3/33, ebd. ${ }^{62}$ LG-Präs. Klagenfurt an das OLG-Präs. Graz, 28. 4. 1933, GZ 1992-3/33, ebd.

${ }^{63}$ Er wurde daraufhin allerdings sofort auf Anordnung des BMJ befragt, ob diese Erklärung eine Weigerung darstelle, „über Wahrnehmungen jeder Beeinträchtigung der öffentlichen Interessen oder des geordneten Ganges der Verwaltung der Dienstbehörde sofort Meldung zu erstatten“, OLG-Präs. Graz, 26. 5. 1933, ebd.

${ }^{64}$ BGBl. 173/1933; vgl. auch MRP 872, 10. 5. 1933, NeCK, WANDRUSZKA, Protokolle VIII/3, 290.

${ }^{65}$ StGBl. 38/1918; übernommen durch RGBl. 217/1896; BGBl. 422/1921.
} 
„Sie werden einen Eid zu Gott dem Allmächtigen schwören und bei Ihrer Ehre und Ihrem Gewissen geloben, dem Bundestaate Österreich treu und gehorsam zu sein und die Gesetze der Republik unverbrüchlich $\mathrm{zu}$ beobachten. Sie werden ferner schwören, sich mit aller Kraft und mit allem Eifer dem Dienste zu widmen und in jeder Diensteseigenschaft die Pflicht Ihres Amtes gewissenhaft, unparteiisch und uneigennützig zu erfüllen, jederzeit auf die Wahrung der öffentlichen Interessen bedacht zu sein, und alles $\mathrm{zu}$ vermeiden $[\ldots]$, was diesen abträglich sein oder den geordneten Gang der Verwaltung beeinträchtigen könnte [...]. Insbesondere werden Sie schwören, der vom Bundespräsidenten bestellten Regierung treu und gehorsam zu sein". Die Verweigerung der Eidesleistung wurde als Austritt aus dem Dienstverhältnis gesehen, der den Verlust aller aus dem Dienstverhältnis erfließenden Rechte und Ansprüche nach sich zog. Für die "Wiener Zeitung" ${ }^{67}$ war es "wohl naheliegend, daß auch die Richter, die einen Grundpfeiler im staatlichen Gebäude darstellen, die unverbrüchliche Beobachtung der Gesetze in der besonders feierlichen Form eines Eides zu versprechen" hätten, und der Inhalt des Eides entspreche ohnedies „vollkommen dem bisherigen Gelöbnisse“ - was allerdings nicht zutraf. Daher betonte die "Arbeiter-Zeitung“ (AZ), ${ }^{68}$ dass der neue Diensteid "manches Auffällige“ enthalte. So sollten die Beamten dem „Bundesstaat Österreich treu und gehorsam" sein, und nicht, „wie doch der offizielle Titel lautet, der ,Republik Österreich' “ - was freilich der Distanzierung der Regierung von der parlamentarischen Demokratie der „Republik Österreich“ geschuldet war. Was die Treue gegenüber der Regierung anbelangt, so kommentierte die AZ, dass der Beamte „selbstverständlich im Treue-

\footnotetext{
${ }^{66}$ WrZ, Nr. 110 v. 12. 5. 1933, 3, siehe dazu auch SEDLAK, Sanktionen 72.

${ }^{67}$ WrZ, Nr. 110 v. 12. 5. 1933, 2.

${ }^{68}$ AZ, Nr. 130 v. 12. 5. 1933, 1f.
}

verhältnis zum Staat" stehe, "aber nur im Dienst, nicht außerhalb des Dienstes“, da Art. 7 B-VG „die ungeschmälerte Ausübung seiner politischen Rechte" sichere, „wozu selbstverständlich auch das Recht auf oppositionelle Stellungnahme zu der jeweiligen Regierung gehört". Dass der Beamte „außerhalb des Dienstes ein freier Bürger des Staates sei, frei wie jeder andere Bürger", stelle nicht nur die "Grundlage jedes demokratischen Beamtenrechtes" dar, sondern sei „ein Erfordernis der Demokratie überhaupt“, und: „Man schützt die Demokratie nicht gegen den Fascismus, sondern man gefährdet sie, wenn man diesen Grundsatz verletzt oder seine Geltung einschränkt.“ Darüber hinaus wies die AZ darauf hin, dass die Regierung, die von den Beamten die "gewissenhafteste Beobachtung aller Gesetze" fordere, diesen mit gutem Beispiel vorangehen und "selbst vor allem die Verfassung $[. .$.$] gewissenhaft beobachten" müsse.$

Die in dieser Verordnung geregelte Verschärfung des Disziplinarrechts für Beamte betraf die Richter allerdings nicht, denn für sie galt weiterhin das Richterdisziplinargesetz von 1868.69 Dieses normierte als Strafe für Ordnungswidrigkeiten die "Mahnung" und den "Verweis", der in den "Personal-Standesausweis" einzutragen war, für Dienstvergehen jedoch die Disziplinarstrafen der Versetzung mit gleichen Rang an einen anderen Dienstort ohne Anspruch auf die Übersiedlungskosten, was im Fall einer Verschärfung mit einer Minderung der Dienstbezüge verbunden werden konnte, weiters die Versetzung in den Ruhestand auf unbestimmte Zeit mit Verminderung der Ruhegenusszahlungen sowie die Dienstentlassung bei Verlust des Pensionsanspruches. Die Verhängung solcher Disziplinarstrafen war nur durch Erkenntnis des zuständigen Disziplinargerichtes möglich, also je nach Anstellung des betroffenen Richters des Oberlandesgerichtes (OLG) bzw. Obersten Ge-

${ }^{69}$ RGB1. 46/1868. 
richtshofes (OGH). Gegen Erkenntnisse eines Disziplinarsenates der OLG konnte an den Disziplinarsenat des OGH berufen werden, kein Rechtsmittel bestand gegen Erkenntnisse des Disziplinarsenats des OGH.

Maßnahmen zur Kontrolle der Richter bildeten in weiterer Folge auch einen Gegenstand der Diskussionen im MR im Juli 1933.70 Odo Neustädter-Stürmer, Staatssekretär für Arbeitsbeschaffung seit der Regierungsumbildung im Mai, forderte etwa eine Änderung der Gerichtsorganisation zwecks Schaffung von Möglichkeiten, eine „notwendige Auswechslung von Richtern durchzuführen, ohne an die sonst vorgeschriebenen Förmlichkeiten gebunden zu sein", weil „,bei vielen ländlichen Gerichten die Richter nicht nach Recht und Gesetz entscheiden, sondern sich bei ihren Erkenntnissen von politischen Gesichtspunkten leiten lassen“. Dollfuß unterstützte dies nicht nur, sondern schlug darüber hinaus vor, ",gewisse Angelegenheiten politischer Natur an einen Sondergerichtshof zu verweisen", denn die richterliche Unabhängigkeit würde derzeit „unter Verfälschung ihres Sinnes so vielfach missbraucht, daß sie in dieser Form nicht mehr aufrecht bleiben könne." Diese Erkenntnis habe auch im Deutschen Reich platzgegriffen, „wo die richterliche Unabhängigkeit praktisch so gut wie außer Kraft gesetzt sei.“ Justizminister Kurt Schuschnigg wies freilich auf die Bestimmungen der Bundesverfassung hin, die solche "Reformen großen Stiles" nicht erlaubten, berichtete aber über Aktivitäten seines Ressorts, „die Jurisdiktion in politischen Delikten den Bezirksgerichten im allgemeinen abzunehmen und in einer Abteilung beim BG am Sitze des Landesgerichts (LG) zu vereinigen, auf deren Besetzung im Wege der Geschäftsverteilung durch den Gerichtshofpräsidenten Einfluß genommen werden könnte." Außerdem denke

\footnotetext{
${ }^{70}$ Die folgenden Zitate MRP 893, 26. 7. 1933, NECK, WANDRUSZKA, Protokolle VIII/4, 250ff.
}

er daran, "gewisse Bezirksgerichte durch die Abnahme der Strafgerichtsbarkeit zu strafen". In diesen Fällen wären „auch Versetzungen und Pensionierungen von Richtern auf der Grundlage von Organisationsänderungen möglich." Wenngleich Schuschnigg also noch die Schranken der geltenden Bundesverfassung 1920 ansprach, so vertrat auch er die grundsätzliche Position, dass sich die „Unabsetzbarkeit der Richter [...] aus Gründen der Wahrnehmung der Staatsautorität und des Ansehens der Gerichte heute ebenso wenig aufrechterhalten" ließe wie „die Autonomie der Gerichte in der Festsetzung der Geschäftseinteilung“. Jedenfalls müssten diejenigen "Richter, die Politik und Rechtsprechung mit einander verwechseln, $[\ldots]$ aus der Rechtspflege entfernt werden können." Er sprach sich aber dafür aus, ,[z]u starke Eingriffe in die Rechtsprechung“ zu vermeiden, "damit Österreich nicht auf die Stufe des Deutschen Reiches gerate" - wobei allerdings das Deutsche Reich selbst zunächst die Fassade des Rechtsstaates und auch die Unabhängigkeit der Richter nach der "Machtergreifung" der Nationalsozialisten in formeller Hinsicht aufrecht erhalten hatte, wie noch zu zeigen sein wird.

Bereits im Jänner 1934 nahm die Diskussion im MR dann insofern konkretere Formen an, als nun eine "Reform des Gerichtswesens" geplant wurde, die auch das Ende des eigenen Richterdisziplinarrechts bringen sollte. So regte Neustädter-Stürmer an, ${ }^{71}$ mit einer Justizreform die Möglichkeit zu schaffen, über das Richterdisziplinarrecht hinaus „Richter, die sich im Sinne einer verbotenen Partei betätigt hätten oder betätigten, zu amovieren." Der Landbund-Politiker Franz Glas, Staatssekretär im Justizministerium (BMJ) bis Juli 1934, warnte allerdings vor einer derartigen Maßnahme, zumal die österreichische Justiz „bis vor Kurzem in der ganzen

\footnotetext{
${ }^{71}$ Die folgenden Zitate MRP 918, 26. 1. 1934, NECK, WANDRUSZKA, Protokolle VIII/5, 452ff.
} 
Welt hochangesehen gewesen" sei. Eine solche Maßnahme würde „vom Ausland dahin ausgelegt werden“, dass „Österreich [...] nunmehr in eine derart schwierige Lage geraten [sei], daß es sogar gegenüber den eigenen [...] Richtern die schärfsten Maßnahmen ergreifen müsse“. Dass die tatsächliche Bedrohung offenbar geringer war, als man selbst glauben machen wollte, gab Schuschnigg im MR selbst zu. Es sei nämlich die Reform „an sich gewiß nicht so dringend, wenn die Bevölkerung das Bewusstsein hätte, bei Gericht immer ihren Schutz zu finden", wobei hier „auch eine Rolle spiele, dass die sogenannte öffentliche Meinung nur zu leicht bereit sei, ein Pauschalurteil zu fällen." Er gestand $\mathrm{zu}$, dass „die Mehrzahl der Gerichte, insbesondere in Wien, [...] absolut ihre Pflicht" erfülle, aber in anderen Gerichtssprengeln seien „schwere Verstöße vorgekommen", gegen die „zweifellos Remedur geschaffen werden“ müsse. Die „überwiegende Zahl der Richter" war Schuschnigg zufolge ohnedies „staatstreu und objektiv“, aber es genüge eben, „daß bei einem Kreisgericht mit einem Stand von 30 Richtern 3 Richter nicht ganz loyal seien, um das ganze Kreisgericht nach diesen 3 unverläßlichen Beamten zu beurteilen." Einzelne Vorkommnisse seien „sehr ernst" $^{\prime \prime} \mathrm{zu}$ nehmen und für „einen geordneten Staat untragbar, denn die Verfassung und das Recht hoch in Ehren, aber wenn das Letztere bloßes Buchstabenrecht geworden sei und seinem eigentlichen Sinn, Ordnung im Staat $\mathrm{zu}$ schaffen, nicht mehr genüge, dann verliere auch der Staat seinen Sinn.“ Ziel müsse sein, „so bald wie möglich zur neuen Verfassung $\mathrm{zu}$ kommen", aber solange "die alte noch bestehe, müsse man auch an ihr festhalten". Daher dürften auch die Richter weiterhin nicht dem Disziplinarrecht der Verwaltungsbeamten unterstellt werden, sondern man müsse ,andere Möglichkeiten suchen“. Es sei aber klar, „dass da Ordnung gemacht werden müsse, [...] zumal sonst alles [...] sabotiert würde." Man müsse daher wohl zunächst das Gerichtsorganisationsgesetz so ändern, dass „im Effekt das Ansehen der österreichischen Rechtsprechung gewahrt werde" $^{\prime}$, da bislang eben die "Justizverwaltung keine Möglichkeit habe, auf die Geschäftsverteilung bei den Gerichten Einfluß zu nehmen und damit bestimmte Richter von bestimmten Geschäftsgruppen zu entfernen."

Nachdem mit einer weiteren Reform der Schwurgerichtsbarkeit Ende Jänner 1934 Befugnisse der Geschworenenbank zugunsten der Richterbank verschoben worden waren, ${ }^{72}$ entzog dann eine Regierungsverordnung vom 9. Februar $1934^{73}$ den richterlichen Selbstverwaltungskörpern die ihnen bisher zustehende jährliche Geschäftseinteilung. Hinkünftig wurden die Richter des Gerichtshofes 1. Instanz durch den Präsidenten des Gerichtshofes, der auch die jährliche Geschäftsverteilung festsetzte, auf die dem Gerichtshof zugeordneten Senate verteilt. Diese Geschäfts- und Personalverteilung unterlag der Genehmigung des OLG-Präsidenten, die Geschäftsverteilung des OLG der des BMJ. Bei den BG ,hatte nun der Gerichtsvorsteher die Geschäftseinteilung vorzunehmen und diese dem Präsidenten des übergeordneten Gerichtshofes anzuzeigen, wobei sich der Präsident des Gerichtshofes 1. oder 2. Instanz die Genehmigung der beabsichtigten Geschäftseinteilung vorbehalten konnte, um - wie aus den Ministerratsprotokollen (MRP) hervorgeht ${ }^{74}$ - besonders die Bezirksgerichte in Gegenden „mit politisch unsicheren Verhältnissen“ im Auge zu behalten. Während des Jahres konnte der Präsident des Gerichtshofes oder der BG-Vorsteher die Geschäftsverteilung (unter Anzeigepflicht an den übergeordneten Gerichtspräsidenten) aus „wichtigen Gründen“ ändern. Dieses Recht wurde dem OLG-Präsidenten hinsichtlich aller ihm unterstehenden Gerichte zugesprochen. Darüber

\footnotetext{
72 BGBl. I 61/1934.

${ }^{73}$ BGBl. I 83/1934; vgl. auch WÄCHTER, Politik 75ff.

${ }_{74}$ MRP 921, 9. 2. 1934, NECK, WANDRUSZKA, Protokolle VIII/5, 548.
} 
hinaus erhielt das BMJ das Recht, die Geschäftsverteilung aller Gerichte jederzeit zu ändern. Damit waren nun tatsächlich, wie es die Sozialdemokratie kritisierte, „tiefe Eingriffe in die Gerichtsverfassung vorgenommen worden $[\ldots]$, die es ermöglichten, ausgewählte Richter mit ausgewählten Prozessen zu betrauen“ ${ }^{.75}$

Außerdem konnten aufgrund dieser Verordnung nun auch Richter durch Verfügung des BMJ oder des OLG-Präsidenten gegen ihren Willen „aus wichtigen dienstlichen Rücksichten“ bis zu einem Jahr „außerhalb ihres Amtssitzes verwendet werden“. Die Verordnung vom 9. Februar 1934 änderte nämlich auch das Richterdisziplinargesetz von 1868, das ursprünglich vorgesehen hatte, dass eine zeitweise Verwendung richterlicher Beamter außerhalb ihres Amtssitzes zur Supplierung und Aushilfsleistung (gegen die gesetzliche zustehende Entschädigung) einer unfreiwilligen Versetzung an einen anderen Dienstposten nicht gleichzuhalten war, und eine solche zeitweise Verwendung gegen den Willen des betreffenden Beamten nur innerhalb des eigenen OLG-Sprengels und nicht über 6 Monate verfügt werden durfte. Hinkünftig konnte jedoch ein Richter "aus wichtigen dienstlichen Rücksichten zeitweise" durch Verfügung des OLG-Präsidenten oder nach dessen Anhörung durch Verfügung des BMJ gegen die zustehende Entschädigung ,"selbst wider seinen Willen, aber höchstens auf die Dauer eines Jahres", auch außerhalb seines Amtssitzes verwendet werden. Eine solche Verwendung war nun der unfreiwilligen Versetzung an einen anderen Dienstposten gleichzusetzen. Bei Verwendung in einem anderen OLG-Sprengel war, wenn keine Verfügung des BMJ vorlag, das Einvernehmen der beiden OLG-Präsidenten herzustellen.

\footnotetext{
${ }^{75}$ LEICHTER, Schwarzbuch 97.
}

In der Diskussion zu dieser Verordnung im $\mathrm{MR}^{76}$ sprach sich Staatssekretär Glas dafür aus, dass „auch die Fälle einer politisch untragbaren Einstellung eines Richters" erfasst sein müssten. Robert Kerber, selbst Jurist, Christlichsozialer und Innenminister (BMI) bis Anfang 1934, kritisierte, dass die Beurteilung, ob „wichtige dienstliche Rücksichten“ vorlägen, der "Administrativinstanz" zukäme, was ihm verfassungsrechtlich bedenklich erschien. Es würde ,jedenfalls optisch besser wirken, wenn in dem Falle, als ein Richter zu unliebsamen Wahrnehmungen Anlaß gebe", das Vorhandensein der gesetzlichen Voraussetzungen für eine derartige Maßnahme vom richterlichen Personalsenat festgestellt würde, um nicht "das Vertrauen der Bevölkerung in die Objektivität der Rechtsprechung zu erschüttern". Schuschnigg hingegen betonte, dass das, „was in der Verordnung verarbeitet worden sei, das Minimum dessen darstelle, was aufgrund der geltenden verfassungsrechtlichen Bestimmungen erreicht werden könne und auch erreicht werden müsse, wenn auf dem Gebiet des Gerichtswesens jene durchgreifende Ordnung erzielt werden solle, die gegenwärtig zweifellos unbedingt erforderlich sei“. Von der Verwendung des Begriffes „Versetzung" der Richter habe man Abstand genommen, da eine solche Maßnahme verfassungswidrig gewesen wäre. Eine derartige Beschränkung sei ja auch schon nach den geltenden Bestimmungen zulässig, allerdings nur auf den OLGSprengel beschränkt, wodurch „gewisse Gerichte" eines OLG-Sprengels geradezu "lahmgelegt" worden seien. Eine Bindung an die Personalsenate lehnte Schuschnigg ab, weil dadurch der Zweck der Bestimmung "vollkommen vereitelt" würde, da "die Justizverwaltung in diesen Personalsenaten aus zum Teil menschlich begreiflichen Gründen für die in Aussicht genommene Personalverfügung nie die Mehrheit fände“. Er

${ }^{76}$ MRP 921, 9. 2. 1934, NECK, WANDRUSZKA, Protokolle VIII/5, 549ff. 
versicherte gleichzeitig, dass zu einer derartigen Verfügung nur dann gegriffen werde, wenn sie „im Interesse des Dienstes und der Autorität des Staates unbedingt notwendig sei“. Sie habe auch nur einen Sinn, wenn sie „in einem gewissen zeitlichen Zusammenhang [...] mit dem ihr zugrunde liegenden Verhalten" stehe und mit der „entsprechenden Raschheit" erfolge. Eine Entschädigung könne man den betroffenen Richtern deshalb nicht zubilligen, weil diese eine „zu große Belastung“ darstellen würde. Eine „weitergehende Verfügung", die Schuschnigg für "zweckmäßig“ erachtet hatte, nämlich die Einführung eines "Zwangsurlaubes" in der Dauer eines Jahres sei von den OLG-Präsidenten aus verfassungsrechtlichen Gründen abgelehnt worden, allerdings aufgrund des Berichts der „fliegenden Gerichtsinspektoren“ eine "Reihe von Verfügungen in den Landgerichtssprengeln Innsbruck und Klagenfurt erforderlich". Staatssekretär Glas betonte in der weiteren Diskussion, dass bei derartigen Maßnahmen jedenfalls der Eindruck vermieden werden sollte, "daß es sich um eine Strafverfügung handle", da in einem solchen Fall ein Disziplinarverfahren eingeleitet werden müsse. Er sprach sich auch für die Gewährung einer Entschädigung aus, weil der versetzte Richter in der Regel seinen Wohnsitz im früheren Verwendungsort behielte und dort für seine Familie zu sorgen habe, aber auch am neuen Verwendungsort Lebenshaltungskosten entstünden. Man dürfe daher nicht eine derartig „drakonische Strafmaßregel“ vorsehen.

Schuschnigg betonte im weiteren Verlauf der Diskussion, dass der BMJ jedenfalls, unbedingt auch gegen einen "eventuellen Widerstand“ des OLG-Präsidenten, „die vorübergehende Zuteilung" eines Richters auf ein Jahr "erzwingen“ können müsse, da "sonst die ganze Maßnahme wertlos" sei. Der BMJ habe die Verantwortung für das „Funktionieren der Justiz“ zu tragen und brauche eine „verläßliche Handhabe“. Glas betonte dagegen, dass die Staatsgrundgesetze nicht nur die Unabhängigkeit, sondern auch die
Unversetzbarkeit der Richter normierten, weshalb er sich dagegen aussprach, dass der BMJ derartige Verfügungen vornehmen könne. Die Entscheidung sollte vielmehr den OLG-Präsidenten vorbehalten werden, allenfalls könne dem BMJ ein Zustimmungsrecht eingeräumt werden, weil damit „das Verfassungsgesetz am wenigsten beeinträchtigt" werde. Der BMJ müsse sich auf die OLG-Präsidenten verlassen können, sonst wäre es „um die Justiz traurig bestellt“. Dann müsse man sich auch fragen, „ob es überhaupt zweckmäßig wäre, wenn der Justizminister ein derartiges Odium auf sich nehmen sollte“. Bundeskanzler Dollfuß wies darüber hinaus darauf hin, dass „in Deutschland in die richterliche Selbstverwaltung viel mehr eingegriffen worden sei" und die "hier vorliegende Maßnahme [...] aus dem Bestreben solange aufgeschoben worden [sei], die Unabhängigkeit der Richter solange als möglich aufrechtzuerhalten“. Sie „richte sich gegen jene Leute, die in ihrer Eigenschaft als Richter gesinnungsgemäß sonderbarer Weise ein System anstreben, bei dem dem Richter jede Selbstverwaltung genommen worden sei." Schuschnigg betonte abschließend, dass bei der "Bekämpfung der vorhandenen Missstände“ Disziplinarverfahren „keineswegs ausreichen" würden. Die Disziplinargerichte könnten „vielleicht für normale Zeiten genügen, nicht aber für die gegenwärtigen“. Außerdem gäbe es Fälle, „die überhaupt nicht disziplinär erfassbar seien". Ein Kompromiss sei daher erforderlich, und überdies solle die Verordnung ganz grundsätzlich und allgemein „ein Aviso an die Richter sein, daß sie auf das Palladium der Unverantwortlichkeit und Unabsetzbarkeit nicht unter allen Umständen rechnen“ könnten.

Schmitz wies darauf hin, „daß [...] die Stimmung in der Bevölkerung, auch in bürgerlich ruhigen Kreisen, gegen die Zustände in der Justizverwaltung nachgerade gemeingefährlich werde und die Gefahr bestehe, daß die Leute sich das Recht selbst holen würden, wenn sie sähen, daß Recht und Gerechtigkeit in den Händen partei- 
politisch eingestellter Richter zu Schanden würden. Wenn man Mißstände, die zweifellos vorhanden seien, nicht rechtzeitig behebe, würde eine Welle kommen, die dann auch viel Gutes wegreißen würde. Wolle man einer revolutionären Bewegung, deren Tendenzen sich auch bereits innerhalb der konservativen Volkskreise zeigten, zuvorkommen, müsse man sich entschließen, rechtzeitig einzugreifen." Es sei das "Vertrauen in die Justiz [...] in der Bevölkerung untergraben", und diese verstehe nicht, dass der BMJ „,in die Zustände nichts dreinzureden habe“, denn "[s]chließlich und endlich habe der Justizminister eine Verantwortung vor der Bevölkerung und den verfassungsmäßigen Instanzen dafür, daß die Justiz richtig funktioniere". Wenn die Richter „nicht in sich selbst den Mut aufbrächten, vaterlandsfeindliche Elemente aus ihren Kreisen auszustoßen - und bis heute fehle jede diesbezügliche Erklärung, während auf der anderen Seite versteckte Solidaritätserklärungen vorlägen", dann müsse eben die Regierung aktiv werden, um zu verhindern, dass es zur "Selbsthilfe" käme. Versage die Regierung, dann werde „die Selbsthilfe kommen, und aus dem Jahr 1918 müßte man wissen, dass eine Revolution mehr zerstöre als sie Gutes bringe."

Die Einstufung der Richterschaft als politisch unzuverlässig im Sinne der Regierungsdiktatur kam ebenfalls in der konkreten Besetzung der Standgerichte zum Ausdruck, die infolge der von der Regierung beschlossenen bundesweiten Verhängung des Standrechts (für Mord, Brandlegung und öffentliche Gewalttätigkeit durch boshafte Beschädigung fremden Eigentums) im November 1933 (in weiterer Folge 1934 sukzessive erweitert um verschiedene Sprengstoffdelikte und im Zuge des Februaraufstandes 1934 auch auf Fälle des Aufruhrs) erforderlich war. ${ }^{77}$ Trotz Standrechts und Todesstrafe erachtete es die Regierung dennoch als „bedenklich“, dass -

\footnotetext{
77 Vgl. ReITER-ZATLOUKAL, Radikalisierung 315.
}

wie Vizekanzler Emil Fey ${ }^{78}$ im MR zu bedenken gab - das Urteil auch bei den Standgerichten „in die Hände der ordentlichen Richter gelegt" war, "denn ein vom Standgericht gefällter Freispruch wäre eine schwere Erschütterung der Autorität der Regierung“. Um nun die Loyalität der Richter an diesem Sondergericht abzusichern, wurde einerseits das LG für Strafsachen Wien I als ausschließliches Standgericht eingerichtet, das als "fliegender Senat [...] am jeweiligen Tatort verhandeln" sollte, andererseits erklärte Schuschnigg, dass bezüglich der Besetzung des Standgerichts bzw. der Auswahl der Personen ohnedies „bereits Fühlung“ mit dem Präsidenten des LG für Strafsachen Wien I genommen worden sei. ${ }^{79}$ Fey meinte in der MR-Sitzung am 12. Februar, dass man sich „überhaupt nicht bloß auf die Abwehr beschränken, sondern [...] offensiv vorgehen [müsse], sonst werde man nicht durchkommen können." Man solle folglich die Staatsanwaltschaften "entsprechend anweisen und könne überzeugt sein, dass die Richter sicher ihre Pflicht tun würden" ${ }^{80}$ Mit der von der Regierung gesteuerten Auswahl der Richter der Standgerichte war die Justiz nun - Wolfgang Neugebauer zufolge - „zum Kampfmittel der sich etablierenden austrofaschistischen Diktatur" geworden, v.a. „im bevorstehenden Bürgerkrieg gegen die Sozialdemokratie“. ${ }^{81}$ Die „vom liberalen Rechtsstaat überkommene Unabhängigkeit" der Richter konnte also letztlich im Dollfußregime nicht weiterbestehen, gehört doch die „Handhabung der Justiz als eines der Instrumente der Herrschaft“ zum „Wesenszug eines diktatorischen Systems, das auf die Ausschaltung und Unterdrückung politischer Gegner abzielt" ${ }^{\prime \prime}{ }^{82}$ Die richterliche Unabhängigkeit

\footnotetext{
78 MRP 906, 10. 11. 1933, NeCK, WANDRUSZKA, Protokolle VIII/5, 52 .

${ }^{79}$ Ebd. 60.

${ }^{80}$ SAFRIAN, Standgerichte 273.

${ }^{81}$ NEUGEBAUER, Unabhängigkeit 113.

${ }^{82}$ Ebd. 106.
} 
blieb daher nur mehr ,als ein verbaler Anspruch" (auch) in der (neuen) Verfassung bestehen, dem aber "keine praktische Bedeutung mehr" zukam.

\subsubsection{Verfassungsordnung 1934}

Die richterliche Unabhängigkeit wurde in weiterer Folge in diesem Sinne auch in die „Verfassung des Bundesstaates Österreich“ $1934^{83}$ aufgenommen, ${ }^{84}$ und BMJ Schuschnigg hatte anlässlich einer Rede vor der Fachgruppe Justiz der „Vaterländischen Front" (VF) im März 1934 betont, dass „in der neuen Ständeverfassung [...] selbstverständlich [...] die Unabhängigkeit der Rechtsprechung und daher die Unabhängigkeit der Richter in Ausübung ihres richterlichen Amtes und alles, was damit zusammenhängt", verankert sein werde. ${ }^{85}$ Nach Art. 101 waren also ,[a]lle Richter [...] in Ausübung ihres richterlichen Amtes unabhängig", wobei sich in "Ausübung seines richterlichen Amtes" der Richter „bei Besorgung aller ihm nach dem Gesetz zustehenden gerichtlichen Geschäfte" befand, „mit Ausschluß der Justizverwaltungssachen, die nicht nach dem Gesetze durch Senate oder Kommissionen zu erledigen sind" (Abs. 1). Ausnahmsgerichte waren „nur in den von den Gesetzen im voraus bestimmten Fällen zulässig“ (Abs. 3).

Im MR war freilich die Aufnahme der richterlichen Unabhängigkeit und insbesondere deren institutioneller Garantien in die Verfassung nicht unumstritten gewesen. ${ }^{86}$ So stellte Neustädter-Stürmer grundsätzlich zur Diskussion, ob überhaupt „,an der Unabhängigkeit und Unabsetzbarkeit der Richter festgehalten werden solle". Schuschnigg hingegen sprach sich gegen

\footnotetext{
${ }^{83}$ BGBl. II 1/1934.

${ }^{84} \mathrm{Vgl}$. zu den folgenden Ausführungen bereits REITER, Unabhängigkeit.

${ }^{85}$ Bericht über die Rede des BM 66.

${ }^{86}$ Siehe MRP 930, 20.-29. 3. 1934, NECK, WANDRUSZKA, Protokolle VIII/6, 179ff
}

eine Streichung und dafür aus, sich mit den „aus dem Staatsnotrecht ergebenden Möglichkeiten“ zu begnügen, „wenn man die Unabhängigkeit der Rechtsprechung nicht beeinträchtigen wol$1 e^{\prime \prime}$, wobei hier freilich eine staats- und regierungstreue Haltung der Richter von Schuschnigg bereits vorausgesetzt erscheint. Auch Dollfuß trat für die Unabhängigkeit der Richter ein, allerdings unter der Voraussetzung, dass durch die „Einschaltung eines Übergangsstadiums" die Möglichkeit geschaffen werde, eine „Reinigung im Richterstand" durchzuführen. Glas wiederum erachtete es als „hinreichend, die Gerichtsverfassung so $\mathrm{zu}$ konstruieren, als ob in Österreich tatsächlich nichts vorgefallen sei", und „für die Übergangszeit, bis volle Beruhigung eingetreten sei, einen provisorischen $\mathrm{Zu}$ stand zu schaffen“. Es wäre dann „der Grundsatz gerettet und auch den Zeitverhältnissen Rechnung getragen." Der MR einigte sich folglich auf die Gewährleistung der Unabhängigkeit der Rechtsprechung und der Trennung der Justiz von der Verwaltung als „unbedingtes Erfordernis“, was aber "nicht hindere, daß man in einer Übergangsbestimmung abweichende Verfügungen treffe".

Massive Kontroversen gab es im $\mathrm{MR}^{87}$ allerdings zur Frage, ob in der Verfassung an der bisherigen Notwendigkeit eines förmlichen richterlichen Erkenntnisses für die Ab- bzw. Versetzung von Richtern festgehalten werden sollte. Glas verwies darauf, dass alle europäischen Staaten den „Richtern [...] solche Konzessionen gemacht“ hätten, so dass „Österreich nicht zurückbleiben könne", weil der Richterstand „eben ein unentbehrliches Fundament für jedes Staatswesen" sei, und schlug daher vor, "die alte Gerichtsverfassung zu übernehmen." Mit der Verordnung vom 9. Februar 1934 sei ohnedies die Regierung in die Lage versetzt worden, „Ent-

${ }^{87}$ MRP 938, 14.-18. 4. 1934, NECK, WANDRUSZKA, Protokolle VIII/6, 459ff. 
gleisungen von Richtern wirksam zu begegnen", und diese Bestimmung verhindere, "daß irgendwie unliebsame Erscheinungen in der Rechtsprechung zutage treten könnten." Für Schuschnigg war hingegen die Beibehaltung eines förmlichen richterlichen Erkenntnisses, wofür sich nicht nur Glas, sondern auch der Präsident des bisherigen VfGH, Ernst Durig, ausgesprochen hatte, bzw. die von der "Richterorganisation" geforderte „Wiederherstellung des früheren Textes“ völlig „untragbar und mit seiner Verantwortung als Chef der Justiz nicht zu vereinbaren." Vielmehr sei es „zwingend geboten, ein Ventil offenzulassen“, sonst "wäre man gegenüber gewissen Erscheinungen machtlos." Es möge zwar "richtig sein, daß nur eine Minderheit unter den Richtern solche Verfügungen notwendig mache, aber ein einziger Fall genüge vollkommen." Im Vordergrund habe zu stehen, dass "sofort Ordnung gemacht werden“ müsse. Es sei „unbedingt notwendig [...], die Richter, die im Inneren staatsfeindlich eingestellt seien, aus der Rechtsprechung ausschalten zu können" - wobei hier auch wieder die typische Gleichsetzung von Regierungs- und Staatsfeindlichkeit vorgenommen wurde. Letztlich setzte sich in dieser Debatte aber Glas weitgehend mit seiner Ansicht durch, ${ }^{88}$ dass man "die alte Bestimmung der Gerichtsverfassung [...] aufrecht [lassen]", aber „in das Übergangsgesetz etwas hinein[nehmen]“ solle, das "die Handhabe gibt, gegen die Richter, wenn sie sich nicht gebessert haben, frei vorzugehen." Man möge also zunächst die Gerichtsverfassung ,in der alten Fassung belassen und damit nach außen hin die Stellung der Richter in einer Form festlegen, die den Wünschen des Richterstandes entspreche." Schließlich erklärte sich Schuschnigg mit dem Kompromiss einverstanden, „daß man aus optischen Gründen das volle Recht zugestehe und in der Übergangsverfassung die erforderlichen Bestimmun-

\footnotetext{
${ }^{88}$ Ebd., Anm. LXXVIII, 464ff.
}

gen treffe“, die Frist dürfe allerdings nicht zu kurz bemessen sein.

Als Ergebnis dieser Diskussion waren die Richter nach der Verfassung 1934 gemäß Art. 102 mit Erreichen einer in der Gerichtsverfassung festgelegten Altersgrenze in den dauernden Ruhestand zu versetzen (Abs. 3), im Übrigen durften sie „nur in den vom Gesetz vorgeschriebenen Fällen auf Grund eines gerichtlichen Erkenntnisses ihres Amtes entsetzt oder wider ihren Willen an eine andere Stelle oder in den Ruhestand versetzt werden“. Diese Bestimmungen sollten jedoch auf solche "Übersetzungen und Versetzungen in den Ruhestand" keine Anwendung finden, "die durch Veränderungen in der Verfassung der Gerichte nötig werden“. In einem derartigen Fall war durch Gesetz festzustellen, „innerhalb welchen Zeitraumes Richter ohne die sonst vorgeschriebenen Förmlichkeiten übersetzt und in den Ruhestand versetzt werden können" (Abs. 4) - womit hier also eine inhaltlich völlig undeterminierte verfassungsrechtliche Grundlage für eine Suspendierung der richterlichen Unabhängigkeit durch eine gesetzliche Veränderung der Gerichtsverfassung geschaffen wurde. Eine "zeitweise Enthebung der Richter vom Amt“ durfte „nur durch Verfügung des Gerichtsvorstehers oder der höheren Gerichtsbehörde bei gleichzeitiger Verweisung der Sache an das zuständige Gericht stattfinden“ (Abs. 4).

Weiters waren nach Art. 103 die „Geschäfte [...] unter die Richter eines Gerichtes für die in der Gerichtsverfassung bestimmte Zeit im voraus zu verteilen“. Im Unterschied zum B-VG war nun allerdings, wie Adolf Merkl 1935 hervorhob, ${ }^{89}$ die "Gewähr für den in der Geschäftsverteilung festgesetzten Wirkungskreis des einzelnen Richters, wonach eine nach dieser Einteilung einem Richter zufallende Sache ihm durch Verfügung der Justizverwaltung nur im Falle seiner Verhinderung abgenommen werden darf, in der

${ }^{89}$ MERKL, Verfassung 91. 
Verfassung 1934 nicht mehr enthalten." Ob diese Bestimmung (,,in Anbetracht der verbleibenden Vorschrift, dass die Geschäfte unter die Richter eines Gerichts für die in der Gerichtsverfassung bestimmte Zeit im Voraus zu verteilen“ waren) „für überflüssig erachtet wurde, oder ob Eingriffen der Justizverwaltung in die Geschäftsverteilung Raum gegeben werden sollte", schien Merkl damals allerdings fraglich. Ebenfalls 1935 wies Ludwig Adamovich ${ }^{90}$ darauf hin, dass die geltende Gerichtsverfassung ohnedies bereits eine Änderung der Geschäftseinteilung während des Jahres durch Verfügung der Gerichtsvorstände wie auch aus wichtigen Gründen durch Verfügung des BMJ vorsah.

Nach Inkrafttreten der Verfassung hob dann der 1933/34 für die Verfassungs- und Verwaltungsreform zuständige BM Otto Ender in seiner Textausgabe der Verfassung 1934 hervor, ${ }^{91}$ dass sich in der neuen Verfassung bezüglich „der Gerichtsbarkeit $[\ldots]$ gegenüber der früheren Verfassung wenig geändert" habe. Es sei in der neuen Verfassung "selbstverständlich [...] an der richterlichen Unabhängigkeit festgehalten" worden, „die ja nicht im Interesse der Richter aufgestellt wurde, sondern im Interesse der Bevölkerung und zur Wahrung des Ansehens und Vertrauens des Staates gegenüber anderen Staaten und deren Bürgern“. Für Merkl² war 1935 die "grundsätzliche Beibehaltung der richterlichen Unabhängigkeit samt deren Rechtsgarantien [...] um so bemerkenswerter, als es sich um ein typisches Requisit liberaler Staatsdoktrin, nämlich um eine rechtliche Konsequenz der im Namen der bürgerlichen Freiheit geforderten Trennung der Staatsgewalten handelt." Was Merkl in diesem Kontext freilich nicht erwähnt, ist, dass zu diesem Zeitpunkt die in der Verfassung verankerte Unabhängigkeit ohnedies bereits infolge

\footnotetext{
${ }^{90}$ ADAMOVICH, Grundriss 163.

${ }^{91}$ ENDER, Verfassung 16.

${ }^{92}$ MerKL, Verfassung 90f.
}

der Bestimmungen des Verfassungs-Übergangsgesetzes (V-ÜG) 1934 obsolet war.

Mit dem V-ÜG vom Juni $1934^{93}$ war nämlich entsprechend den schon im MR artikulierten Vorstellungen der Regierung die richterliche Unabund Unversetzbarkeit auf die Dauer eines Jahres suspendiert worden: Nach $\S 28$ konnten „in der Zeit bis 30. Juni 1935 [...] Richter, ohne dass es eines gerichtlichen Erkenntnisses bedarf, von Amts wegen an eine andere Stelle oder in den zeitlichen oder dauernden Ruhestand versetzt werden", "wenn ihr Verbleiben auf ihrem Dienstposten oder im richterlichen Dienste überhaupt dem Ansehen der Rechtspflege offenbar zum Abbruch gereichen, insbesondere die Unparteilichkeit der Rechtsprechung nicht mehr gewährleisten würde". Derartige Verfügungen waren vom BMJ nach Anhörung des Präsidenten des OGH oder des jeweiligen OLG zu treffen. Die Versetzung eines Richters auf einen anderen Dienstposten oder in den Ruhestand war also nunmehr „unter Voraussetzungen, die dem Ermessen der Dienstbehörde weitesten Raum lassen, nicht durch ein richterliches Disziplinarerkenntnis bedingt, sondern durch formlose Verfügung der Dienstbehörde möglich“. ${ }^{94}$

Während ein „Verfassungsjurist" in der „Neuen Freien Presse" betonte, ${ }^{95}$ dass diese Bestimmung „den außerordentlichen Zeitverhältnissen entsprungen“ sei und dazu dienen sollte, "das Ansehen der Rechtspflege“ und die "Unparteilichkeit der Rechtsprechung" zu wahren, war hingegen für die (damals bereits illegalen) Sozialdemokraten dieser "entscheidende Schlag gegen die Richter" ein Zeichen dafür, dass „die Klerikofaschisten aus dem letzten Loch pfeifen“. Das „Dollfuss-Österreichertum“ könne es „nicht mehr ertragen“, dass die Richter "weiter nur Recht sprechen", sie bräuchten allein den

\footnotetext{
${ }^{93}$ BGBl. II 75/1934.

${ }^{94}$ MERKL, Verfassungsübergangsgesetz 381.

${ }^{95}$ NFP, Nr. 25064 v. 24. 6. 1934, 6.
} 
"Schein der Rechtsprechung“ bzw. die „Form des ordentlichen Gerichtsverfahrens [...], um vor der Welt gerechtfertigt zu sein“. Im Übrigen aber müsse „nach der Meinung der Autoritären auch jeder Richter so tanzen, wie der Despot pfeift". Stehe dem eine verfassungsrechtliche Bindung entgegen, „so dekretiert der Klerikofaschismus einfach: das ist altes Gerümpel“, der Richter sei „nur ein Teil der Exekutive des jeweils Herrschenden [...], der nach den Befehlen von oben amtszuhandeln hat, der also jetzt an Stelle des Rechtes die Barbarei zu setzen hat". „Wenn Österreichs Richter sich beugen“, so die $A Z$, „dann muß ab 1. Juli von oben befohlener $\mathrm{Ha}$ und Wut den politischen Gegner zermalmen. [...] Blieben aber die Richter fest, beantworteten sie die verfassungs- und gesetzwidrige Verfügung der gewalttätigen Verderber Österreichs mit ihrem autoritären ,Nein', dann würden die Klerikofaschisten auf Granit beißen. Ist soviel Stärke von den Richtern zu erwarten? ${ }^{\prime \prime 96}$ Auch in späteren Nummern prangerte die AZ an, dass nun jeder Richter abgesetzt werden könne, „wenn er nicht so judiziert, wie es die Regierung verlangt“. Man „erniedrigt die Richter zu Bütteln der Diktatoren, die auf Befehl ihre Urteile zu fällen haben!“ Die „Heimwehrbestien“ hätten geschrieen, "dass die Richter zu ,milde‘ Strafen verhängen“, und die "Dollfuß und Schuschnigg, die Fey und Starhemberg haben einen Regierungsfeldzug gegen die Richter begonnen, um sie zur Verhängung noch bestialischerer Strafen zu zwingen". ${ }^{77}$ Die AZ stellte Ende Juli 1934 auch fest, dass der Durchschnitt des Strafausmaßes auf über ein Jahr für jeden Februarkämpfer gestiegen sei, seitdem „die Dollfuss, Starhemberg und Schuschnigg die Unabhängigkeit der Richter aufgehoben" hätten.98 Im November $1934^{99}$ berichtete sie über lange

\footnotetext{
${ }^{96}$ AZ, Nr. 18 v. 24. 6. 1934, 3.

${ }^{97}$ AZ, Nr. 19 v. 1. 7. 1934, 1f.

${ }^{98}$ AZ, Nr. 23, 29. 7. 1934, 5.

${ }^{99}$ AZ, Nr. 37 v. $4.11 .1934,2$.
}

Untersuchungshaftzeiten von Schutzbündlern und kritisierte die Richter, die sich "dazu her[geben], dieses Verbrechen zu begehen“, aber „[j]eder Richter zittert jetzt um Amt und Stelle", seitdem die Regierung die Unabhängigkeit suspendiert habe, weshalb „er auf Befehl der Regierung Männer in Haft [hält], von denen er sehr gut weiß, daß er sie nach Recht und Gesetz längst hätte in Freiheit setzen müssen“.

Auch von Seiten der rechten politischen Opposition wurde naturgemäß Kritik geübt. So verlangte der bekannte Wiener NSDAP-Anwalt und SS-Hauptsturmführer Erich Führer in seiner an Bundeskanzler Dollfuß gerichteten Denkschrift "Justitia Fundamentum Regnorum" vom Juni 1937100 u.a. die „volle Wiederherstellung der richterlichen Unabhängigkeit durch Aufhebung des [§] 28 des Verfassungsübergangsgesetzes". Weiters wurde in einer Berliner Publikation aus 1936 die Begründung der im V-ÜG verankerten Maßnahme mit einer Gefährdung der „Unparteilichkeit der Rechtsprechung“ angesichts der „tatsächlich nur gegen politisch missliebige Richter nach rein parteilichen Gesichtspunkten gerichteten Anwendung des Gesetzes" als „derart zynisch“ bezeichnet, "dass kein Wort mehr darüber verloren werden" sollte. ${ }^{101}$

Ender verteidigte hingegen diese Eingriffe in die richterliche Unabhängigkeit in seiner Ausgabe des V-ÜG nachträglich, ${ }^{102}$ denn die Unabsetzbarkeit und Unversetzbarkeit der Richter habe trotz Aufrechterhaltung dieser Grundsätze in der Verfassung 1934 für „eine Übergangszeit [...] aufgehoben werden" müssen. Der österreichische Richterstand habe sich zwar "gewiß in seiner großen, überwiegenden Mehrzahl auch in den politisch aufgewühlten Tagen seit dem gewaltsamen Vorstoßen des Nationalsozialismus [...] in der Objektivität bei der Rechtsprechung

\footnotetext{
${ }^{100}$ Abgedruckt in PUTSCHEK, Verfassung 288.

101 RIEDLER, Ausnahmegesetzgebung 22.

102 ENDER, Übergangsbestimmungen 11.
} 
nicht beirren lassen und außerhalb des Amtes das Ansehen und die Würde des Richters gewahrt", es gäbe aber „Ausnahmefälle, wo Richter zum Ärgernis der vaterlandstreuen Bevölkerung geworden sind und deren Vertrauen bezüglich der unparteiischen Rechtsprechung verloren“ hätten. Da in diesen Fällen das Disziplinarrecht nicht immer gegriffen habe, müsse nun „Abhilfe geschaffen werden, wenn das Volk im Vertrauen auf die Staatsführung am Aufbau des neuen Staates arbeiten und wenn es das so wichtige Vertrauen auf seine Richter wieder gewinnen" solle. Daher habe der BMJ das Recht bekommen, „in solchen Fällen Richter von Amts wegen, ohne daß es eines Disziplinarerkenntnisses bedarf, zu versetzen, auch auf Zeit oder dauernd zu pensionieren".

Über diese Maßnahmen der Zwangspensionierung und -versetzung hinaus konnte in weiterer Folge aufgrund einer von der Bundesregierung auf der Grundlage des Ermächtigungsgesetzes $1934^{103}$ im August desselben Jahres erlassenen Novelle ${ }^{104}$ des V-ÜG auch ,ausnahmsweise aus besonders wichtigen dienstlichen Rücksichten“ verfügt werden, dass Richter, die in den Jahren 1934 oder 1935 das 65. Lebensjahr vollendeten, erst später „aufgrund einer besonderen Anordnung" in den dauernden Ruhestand treten sollten. Wie Schuschniggs Nachfolger in der Funktion des BMJ, Egon Berger-Waldenegg, im MR erläuterte, konnten nun also Richter „auch über das 65. Lebensjahr hinaus so lange im Dienste belassen werden $[\ldots]$, solange es dienstliche Interessen erforderten, ${ }^{\prime 105}$ wobei zu dieser Maßnahme insbesondere deshalb gegriffen werden müsse, weil mehrere leitende Richterposten neu zu besetzen waren und man es für möglich hielt, dass in einzelnen Fällen nur ein Bewerber (aus Regierungssicht) geeignet erschien, der kurz vor

\footnotetext{
${ }^{103}$ BGBl. I 255/1934

${ }^{104}$ BGB1. I 230/1934.

${ }^{105}$ MRP 964, 31. 8. 1934, NeCK, WANDRUSZKA, Protokolle IX/1, 214.
}

der gesetzlichen Altersgrenze stand. ${ }^{106}$ Darüber hinaus wurde seit November 1934 bei Neuaufnahmen von Richtern nun auch gefordert, "dass in Hinkunft die Personalsenate bei Erstattung von Besetzungsvorschlägen stets auch zur Frage des bisherigen politischen Verhaltens der Bewerber Stellung nehmen" sollten. Im Hinblick auf Art. 16 Abs. 3 der Verfassung 1934, der die gleiche Ämterfähigkeit aller „vaterlandstreuen Bundesbürger" festlege, müsse „,auch diese Frage bei allen Besetzungsvorschlägen geklärt" sein. ${ }^{107}$

In weiterer Folge wurden sowohl der Aufschub für die Pensionierung von Richtern als auch die Aufhebung der Unversetzbarkeit und Unabsetzbarkeit von der Regierung immer wieder verlängert. ${ }^{108}$ So blieb schließlich der in der Verfassung formal garantierte Ab- und Versetzungsschutz der Richter bis zum "Anschluss“ Österreichs an das Deutsche Reich tatsächlich aufgehoben.

Trotz all dieser genannten Veränderungen fehlte der Regierung aber offenbar weiterhin sowohl das Vertrauen in die ordentlichen Gerichte als auch in die Standgerichte, denn für die Aburteilung der nationalsozialistischen Juliputschisten 1934 wurde für das ganze Bundesgebiet ein neues Gericht geschaffen, ${ }^{109}$ der Militärgerichtshof in Wien, dessen Richter alle vom BMJ bzw. Verteidigungsminister bestimmt wurden und in „Ausübung ihres richterlichen Amtes unabhängig" sein sollten. Wie BMJ Berger-Waldenegg später berichtete, wurde der Präsident des Militärgerichtshofs allerdings direkt von ihm mit Weisungen versehen. ${ }^{110}$

\footnotetext{
106 Ebd. Anm. 15, 213.

${ }^{107}$ Erl. des OLG-Präs. Wien v. 8.11.1934, zit.n. WÄCHTER, Politik 71.

108 Siehe REITER, Unabhängigkeit 107.

${ }^{109}$ BGBl. II 152/1934.

${ }^{110}$ NeUGebauer, Justiz 117.
} 
Wenngleich also die Justiz in der Verfassung 1934 in ihrer äußeren Struktur auf den ersten Blick als wenig verändert wahrgenommen werden konnte, so war sie doch unter dem Schlagwort der „Entpolitisierung“, das vielmehr „Umpolitisierung" im "vaterländischen“ Sinne bedeutete, ${ }^{111}$ sukzessive ihrer Unabhängigkeit beraubt worden, die verfassungsrechtlichen Garantien der Unabsetzbarkeit und Unversetzbarkeit waren zu reinen Leerformeln verkommen. Auch die Richterschaft sollte der Regierung nun als "verlängerter Arm ihrer Politik"112 dienen, eine systematische ideologische Indoktrinierung wie im Nationalsozialismus unterblieb aber.

\subsection{Konkrete Maßregelungen von Richtern}

Im Fokus der Regierungsmaßnahmen stand die angeblich mangelnde Regimetreue der Richter, waren diese doch nach den bisherigen Forschungen auch in der Ersten Republik überwiegend dem Lager der Großdeutschen Volkspartei, aus dem sich im Übrigen durch lange Jahre hindurch auch die Justizminister rekrutiert hatten, oder dem konservativen Katholizismus zuzurechnen. ${ }^{113}$ Jedenfalls stammten sie aus sozialen Schichten, die „von vornherein in einem bewußtseinsmäßigen Distanzverhältnis zur Arbeiterschaft und zur Sozialdemokratie standen". ${ }^{114}$ Auch wenn die Richter überwiegend „keineswegs Nationalsozialisten oder Heimwehrmänner" waren, so scheinen diese doch, so Gerhard Botz, „wenn sie etwa der , antimarxistische' StraBenkampf vor die Schranken des Gerichtes brachte, von vielen Richtern als, geistige Söhne' betrachtet worden $\mathrm{zu}$ sein, die den richtigen Gegner, wenn auch nicht mit ganz gebilligten

\footnotetext{
${ }^{111}$ HoltmanN, Autoritätsprinzip 219.

112 Ebd. 49.

${ }^{113}$ BotZ, Politik 162; JeDLICKA, NECK, 12. Februar 155.

${ }^{114}$ BOTZ, Politik 162.
}

Methoden, bekämpften.“115 Daher konnten NSStraftäter bei vielen Richtern mit Milde rechnen, während bei sozialistischen oder kommunistischen Angeklagten der Strafrahmen in der Regel ausgeschöpft wurde.116 Diese Nachsichtigkeit gegenüber Nationalsozialisten brachte die Richter nun im Dollfuß-Schuschnigg-Regime unter den Pauschalverdacht der mangelnden Regierungsloyalität.

Wie viele Richter nun österreichweit tatsächlich gemaßregelt wurden, ist bislang nicht bekannt. ${ }^{117}$ Einige konkrete Fälle, die ausschließlich für den Nationalsozialismus aktive Richter betreffen, können allerdings auf Grundlage der Forschungsliteratur ${ }^{118}$ und ersten Archivrecherchen bereits aufgezeigt werden, ${ }^{119}$ eine umfassende systematische Erhebung steht jedoch noch aus. ${ }^{120}$ Neben vereinzelten Fällen von strafweisen Ruhestandsversetzungen ${ }^{121}$ war jedenfalls die offenbar häufigste Maßnahme der Maßregelung politisch unliebsamer Richter deren Versetzung an einen anderen Dienstort (z.T. nach vorheriger Suspendierung), und zwar sowohl aufgrund eines Disziplinarerkenntnisses als auch aufgrund von $\S 28$ des V-ÜG von 1934. Darüber hinaus wurde gegen Richter die Strafe des disziplinarrechtlichen Verweises in Anwendung gebracht. Außerdem kam es auch zu zeitweiligen

\footnotetext{
115 Ebd.

${ }^{116}$ HOLTMANN, Unterdrückung 262.

117 In den Personalakten wird zwar immer wieder ein Sammelbericht des OLG-Präs. betreffend illegale Richter und Staatsanwälte Zl. 200-255 vom 9. 6. 1943 erwähnt, dieser konnte aber bislang weder im ÖStA noch in den Beständen des OLG Wien aufgefunden werden. OLG-Präs. Gerhard Jelinek sei für seine Bemühungen herzlichst gedankt.

118 STADLER, Verfahren.

${ }^{119}$ Für Hinweise auf weitere gemaßregelte Richter danke ich Ursula Schwarz.

${ }^{120}$ Ein Projekt dazu ist in Vorbereitung.

${ }^{121}$ Siehe MuLLEY, Gleichschaltung 267.
} 
Internierungen nach der Anhalteverordnung ${ }^{122}$ oder zur Stellung unter Polizeiaufsicht.

Aber nicht nur Richter waren von Maßregelungen betroffen, sondern auch Richteramtsanwärter, wie etwa der Fall von Friedrich Kraus zeigt, der 1932 in den Gerichtsdienst und in die NSDAP eintrat. Wegen seiner politischen Einstellung wurde er „ein Jahr später als üblich in den Gerichtsdienst übernommen", im Jänner 1934 erfolgte seine „Verhaftung wegen natsoz. Betätigung mit nachfolgender gerichtlicher und verwaltungsbehördlicher Bestrafung“. 1937 kam es zur Verurteilung wegen eines Verbrechens nach dem Staatsschutzgesetz ${ }^{123}$ zu zwei Monaten schweren Kerkers, was auch seine Entfernung aus dem Gerichtsdienst ohne Disziplinarverhandlung zur Folge hatte. ${ }^{124}$

\subsubsection{Ruhestandsversetzungen}

Zwangsweise in den Ruhestand versetzt wurden im OLG-Sprengel Wien ${ }^{125}$ wegen NS-Einstellung etwa Herbert Paul und Emil Schindler. Herbert Paul126 war NSDAP-Parteimitglied von 1922 bis 1924, dann wieder seit Mai 1930, u.a. seit 1932 Bezirksleiter der NSDAP in Wien Hietzing. ${ }^{127}$ Er wurde nach dem Juliputsch zunächst vom Dienst suspendiert und Mitte Dezember 1934 „wegen verschiedener Disziplinarvergehen (Betätigung für den Nationalsozialismus) zur Disziplinarstrafe der Versetzung in den dauern-

122 BGBl. 431/1933.

${ }^{123}$ BGBl. 223/1936.

124 Geb. 1909. Nach der „Machtergreifung“ wurde er in den öffentlichen Dienst als Staatsanwalt übernommen, ÖStA, AdR Justiz BMJ VP Liqu Kraus, Friedrich. ${ }^{125}$ Für den OLG-Sprengel Wien existiert ein Verzeichnis von Justizangestellten, die wegen ihrer Zugehörigkeit zur NSDAP entlassen oder pensioniert und 1938 wieder eingestellt wurden, das insgesamt 20 Namen enthält, ÖStA, AVA, BMJ, OStA Wien 1938 Pers. Varia, Kart. 5045.

${ }^{126}$ Geb. 1903, ÖStA, AdR, Justiz, BMJ, VP Liqu Paul, Herbert.

${ }^{127}$ Daher wurde er auch 1938 als „Alter Kämpfer“ anerkannt. den Ruhestand auf unbestimmte Zeit unter Verminderung des Ruhegenusses auf zwei Drittel verurteilt", wobei diese Strafe 1935 auch in der Instanz bestätigt wurde.

Emil Schindler ${ }^{128}$ war Kreisgerichtspräsident in Wiener Neustadt und hatte „im Laufe des Jahres 1933 an den damaligen nat.soz. Landesleiter Österreichs, Proksch, ein Schreiben gerichtet, in dem er diesen aufforderte, der deutschen Reichsregierung nahezulegen, auf die österreichische Bundesregierung Druck auszuüben, um sie von der Verfolgung national gesinnter Beamter abzuhalten“. Schuschnigg habe, so das BMJ 1946, „um das peinliche Aufsehen zu vermeiden, das ein Einschreiten gegen einen aktiven Kreisgerichtspräsidenten hervorrufen mußte, beschlossen, von einer strafgerichtlichen oder disziplinären Verfolgung Dr. Schindlers abzusehen, falls er ohne Verzug sein Pensionsgesuch überreichen sollte“. Diese Aufforderung sei ihm vom damaligen OLG-Präsidenten telefonisch mitgeteilt worden, und er habe das Gesuch auch sofort unterschrieben. Schindler selbst gab im April 1945 an, er sei Ende Jänner 1934, nachdem dieser Brief in die Hände der Regierung gekommen war, "wegen seiner nat. Gesinnung in den dauernden Ruhestand versetzt" worden, obwohl der Brief aus der Zeit noch vor dem Parteiverbot datiere. Die „Maßregelung“ sei deshalb erfolgt, weil er sich in diesem Brief als „Anhänger der Partei bekannte und ihren Schutz für Untergebene, die von der Regierung Dollfuss wegen ihrer Gesinnung verfolgt wurden, angerufen" hatte. ${ }^{129}$

Eine weitere Zwangspensionierung fand im Fall des Halleiner Bezirksrichters Anton Jennewein

\footnotetext{
128 ÖStA, AdR, Justiz, BMJ, VP NA Schindler, Emil. ${ }^{129}$ Ende August 1939 trat er als LG-Präs. endgültig in den dauernden Ruhestand. Er verlegte seinen Wohnsitz nach Deutschland und kehrte 1946 nach Österreich zurück, wo die Einleitung eines Strafverfahrens wegen Illegalität erwogen wurde, ebd.
} 
statt, ${ }^{130}$ der seit 25. Juli 1934 „nicht mehr als Richter verwendet" wurde. Er war NSDAP-Mitglied seit 1930 und hatte sich als Parteiredner, Kreisleiter und Gauleiter in Salzburg betätigt. Wegen illegaler NS-Betätigung wurde er mit Erkenntnis des OLG Innsbruck als Disziplinargericht Ende März 1934 unter Kürzung der Bezüge auf zwei Drittel in den dauernden Ruhestand versetzt. Dem schloss sich 1935 die Disziplinarstrafe der Kürzung seines Ruhegenusses um weiter $10 \%$ (wegen Erschleichung des Armenrechts zugunsten seiner Ehefrau und „beleidigender Äusserungen über die Bundesregierung“) an. Ende 1935 wurde er vom LG Salzburg wegen des Vergehens der Geheimbündelei zu zehn Monaten strengen Arrest verurteilt. Er flüchtete in weiterer Folge nach Deutschland, wo er in Augsburg und München als Richter Beschäftigung fand. ${ }^{131}$

Darüber hinaus kam es aber auch zu Ruhestandsversetzungen von politisch exponierten Richtern auf eigenen Wunsch. ${ }^{132}$ So wurde mit 60 Jahren und aufgrund eigenen Ansuchens 1934 Theodor Heyn ${ }^{133}$ pensioniert, Parteianwärter ab 1938 und Vorsteher am BG Bad Aussee, wo er nach eigenen Angaben „unter den schwierigsten Verhältnissen tätig und vielfachen Quertreibereien des gewesenen jüdischen Rechtsan-

\footnotetext{
${ }^{130}$ Geb. 1894, vgl. ÖStA, AdR Justiz BMJ VP NA Jennewein, Anton.

${ }^{131}$ Nach dem „Anschluss“ kehrte er nach Österreich zurück, erhielt den „Blutorden“ und bekleidete den Rang eines SS-Untersturmführers. Er schied aus dem Justizdienst aus, wurde kurzzeitig Bezirkshauptmann in Hallein, dann Senatsrat der Stadt Wien und 1942 Generaldirektor des Dorotheums; siehe auch LÜTGENAU, SCHRÖCK, NIEDERACHER, Dorotheum 52ff. 1946 wurde er zu zwei Jahren verschärften Kerkers wegen Hochverrats und Illegalität nach dem Verbotsgesetz verurteilt.

132 Über Ansuchen nach Art. I Abs. 3 und § 791 BDG. ${ }^{133}$ Geb. 1875; ÖStA, AdR Justiz RJM PA Heyn, Theodor.
}

waltes Dr. Weishut ausgesetzt" war. ${ }^{134}$ Auch Richard Techner, ${ }^{135}$ NSDAP-Mitglied seit 1933, wurde (ebenfalls 60jährig) auf eigenen Wunsch in den Ruhestand versetzt. ${ }^{136}$

Eine eindeutige NS-Vorgeschichte liegt im Fall von Guntram Wenger, seit 1930 Richter am LG für Strafsachen Wien, ${ }^{137}$ vor. Er war, so die Beurteilung 1953, „seinerzeit Anhänger der Großdeutschen Volkspartei“ sowie seit 1923 Mitglied im „Deutschen Klub“138, einem geistigen Zentrum der deutschnationalen Bewegung, gewesen und habe sich „während der Verbotszeit ganz der ns. Bewegung zugewendet" ${ }^{\prime 139}$ Er war zwar nicht illegales NSDAP-Mitglied, wurde aber „wegen seiner politischen Äusserungen gegen die Systemregierung im Juli 1934 zuerst wegen Verdachtes des Hochverrates in Verfolgung gezogen“. Er habe nämlich „vor Beginn des Juliputsches Äusserungen [gemacht], die auf eine Mitwisserschaft schließen liessen“. Nach der Einstellung des Verfahrens kam es zu einem Disziplinarverfahren gegen ihn, infolge dessen er an einen anderen Dienstort versetzt "und so gemassregelt" wurde. Unter diesen Umständen zog es Wenger vor, sich in den Ruhestand versetzen zu lassen. ${ }^{140}$

\footnotetext{
1341939 wurde er unter Anrechnung dieser Pensionszeit am Amtsgericht Klagenfurt wieder in Dienst gestellt, nach 1945 seine „Illegalität“ als nicht erwiesen angesehen, ÖStA, AdR Justiz BMJ VP Liqu Heyn, Theodor.

${ }^{135}$ Geb. 1874, ÖStA, AdR Justiz BMJ VP NA Techner, Richard.

${ }^{136}$ Sein Ruhensgenuss wurde allerdings laut Liquidatorbeschluss mit 31. 6. 1945 wegen Illegalität eingestellt, ebd.

${ }^{137}$ Geb. 1889, ÖStA, AdR Justiz RJM PA Wenger, Guntram.

138 Ebd.

139 ÖStA, AdR Justiz BMJ VP Liqu Wenger, Guntram.

${ }^{140}$ Ebd. Nach dem "Anschluss“ wurde er „im Wege der Wiedergutmachung wieder in den Dienst gestellt."
} 


\subsubsection{Versetzungen an ein anderes Gericht}

Erheblich häufiger als zwangsweise oder politisch motivierte freiwillige Ruhestandsversetzungen erfolgten - dem bisherigen Recherchestand zufolge - Versetzungen an einen anderen Dienstort. Ein solcher Fall war (neben dem schon genannten Guntram Wenger) etwa Richard Eberstaller, ${ }^{141}$ Schwiegersohn des bekannten Jugendstilmalers Carl Moll, der 1934 vom Posten des Leiters des Präsidialsekretäriats des Wiener LG für Zivilrechtssachen (ZRS) wegen seiner Zugehörigkeit zur NSDAP (seit 1931) „,als unverlässlich" enthoben und einem Berufungssenat am LG für Strafsachen II zugeteilt wurde. Noch 1934 trat er der VF bei und gehörte seit 1936 deren „Führerrat" an. Im Dezember 1938 avancierte er zum Senatsvorsitzenden des LG für Strafsachen II, und der Reichskommissar für die Wiedervereinigung Österreichs mit dem Deutschen Reich bescheinigt ihm im März 1939, als er im Gespräch für den Posten des Wiener LG-Vizepräsidenten war, dass er „insbesondere die ganze Verbotszeit über sich einwandfrei als Nationalsozialist erwiesen" habe. Die Ortsgruppe Döbling berichtete überdies im Mai 1938, dass Eberstaller einen näheren „Verkehr mit dem [jüdischen] Schriftsteller Werfel, der mit einer Stiefschwester der Frau Eberstaller's verheiratet" sei, ${ }^{142}$ "geflissentlich" meide. Seyß-Inquart sprach sich dennoch gegen Eberstaller und für Ferdinand Fuhrmann aus, der ,,in der juristischen Gesellschaft, in der wir unseren nationalsozialistischen Juristenbund getarnt hatten, an

${ }^{141}$ Geb. 1887, er verübte in der Nacht vom 12. auf den 13. 4. 1945 mit seiner Ehefrau Maria und dem Schwiegervater gemeinsam Selbstmord durch Vergiftung; http://www.wladimir-aichelburg.at/kuenstler-

haus/mitglieder/opfer/; folgende Zitate und Angaben, wenn nicht anders vermerkt: ÖStA, AdR, Justiz, RJM, PA Eberstaller, Richard.

142 Eberstaller übernahm 1940 auch die Verwaltung einer Alma Mahler-Werfel gehörigen Liegenschaft in Wien. maßgeblicher Stelle tätig war" ${ }^{\prime 143}$ und dessen Söhne alle „illegal“ gewesen seien, während Eberstaller ,sich mit Nachdruck in den vollkommen verjudeten Fußballkreisen der Systemzeit [bewegt]" habe. ${ }^{144}$

Erwin Saurwein ${ }^{145}$ war seit April 1932 Bezirksrichter in Rattenberg in Tirol, seit August 1932 Mitglied der NSDAP und angesichts der „Unterdrückung" des Nationalsozialismus in seinem Bezirk „1933/34 auch aktiv in der SA tätig“ sowie SS-Anwärter. Die VF habe - Saurwein zufolge - „immer wieder" Anzeigen gegen ihn erstattet und ihm besonders übel genommen, dass er seinen Freund, den Kramsacher NSDAP-Ortsgruppenleiter, bei dessen „Überstellung nach Wöllersdorf" an den Bahnhof begleitet habe. Auch sei er selbst im Juli 1934 in Schutzhaft gekommen, aber nach einigen Tagen ${ }^{146}$ wieder freigelassen worden. Wegen dieser Verhaftung wurde eine Disziplinaruntersuchung gegen ihn eingeleitet, die zuerst zu einer Suspendierung durch Beschluss des OLG Innsbruck wegen NSEinstellung führte, dann aber zu einer Zwangsversetzung ins Burgenland (Oberpullendorf) nach dem V-ÜG. Seit 1935 versuchte er (vergeblich), „in die Berge zurückzukommen“, aber erst, als „sich schon das Abkommen des 11. Juli auswirkte", also das Deutsch-österreichische Verständigungsabkommen von 1936, habe er

${ }^{143}$ Auch die NSDAP-Gauleitung bestätigte 1942, dass dieser sich im „illegalen Rechtswahrerbund i.S. der ns-Bewegung betätigt" hatte und in seiner Wohnung

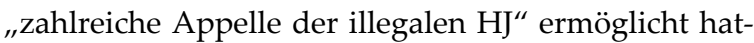
te. Auch wegen der für „NatSoz möglichst günstigen Erledigungen von Straf- und Dienststrafsachen wurde er wiederholt anfeindet" , ÖStA, AdR, Justiz, BMJ, VP Liqu Fuhrmann, Ferdinand.

1441944 wurde Eberstaller als mittlerweile anerkannter „Alter Kämpfer“ schließlich im März 1944 doch noch zum Vizepräsidenten ernannt.

${ }^{145}$ Geb. 1902, folgende Zitate und Angaben, wenn nicht anders vermerkt: ÖStA, AdR, Justiz, RJM, PA Saurwein, Erwin.

${ }^{146}$ Die Akten sprechen von 7 oder 4 Tagen, ÖStA, AdR, Justiz, BMJ, VP Liqu Saurwein, Erwin. 
den Gerichtsvorsteherposten in Schruns erhalten können. ${ }^{147}$

Ebenfalls wegen NS-Betätigung zunächst nur suspendiert wurde 1934 Josef Raunig, ${ }^{148}$ der seit Mai 1933 der NSDAP angehörte und am BG Rosegg tätig war. Nach eigenen Angaben hatte er sich, als in Rosegg die VF "aufgezogen“ wurde, geweigert, derselben beizutreten, weil unter der Leitung des ,jüdischen Notar[s] Dr. Egon Weissberger" stand. Sein Ersuchen an die Landesleitung, ihn „dem Juden Dr. Weissberger aus rassischen, völkischen und dienstlichen Gründen nicht zu unterstellen", sei nicht nachgekommen worden, vielmehr habe dieser begonnen, ihn zu

1471940 wurde er als „Alter Kämpfer" anerkannt, wenngleich seine Ehefrau dies 1946 (Saurwein war zu diesem Zeitpunkt verschollen) als „Gefälligkeitsbestätigung der Ortsgruppe Schruns" bezeichnete. Er wurde nach dem "Zusammenbruch 1945 [...] zunächst nicht in dienstliche Verwendung genommen " und in den dauernden Ruhestand versetzt. Das OLG-Präsidium Innsbruck erachtete 1949 seine Wiedereinstellung in diesem Sprengel „für gänzlich untunlich“, weil er „sowohl während der Verbotszeit als auch nach der Begründung der nat.soz. Herrschaft in Österreich prominenter Vertreter und Werber dieser Bewegung war und als solcher galt“. Weil er aber jener "Gruppe ehemaliger Nationalsozialisten zuzuzählen sein [dürfte], die ehrlich einsehen, einen Irrweg gegangen zu sein“, wurde er 1952 reaktiviert (LG Feldkirch), ÖStA, AdR, Justiz, BMJ, VP NA Saurwein, Erwin. 1968 erfolgte die Auszeichnung mit dem "Goldenen Ehrenzeichen für Verdienste um die Republik Österreich“, und zwar mit der Begründung, dass er sich „als Richter nahezu in allen Sparten der Rechtspflege [...] bewährt" habe, und den „Typ des bewährten älteren Streitrichters mit allseitiger Ausbildung und umfassenden Kenntnissen“ darstelle, der sich „durch Zuvorkommenheit und einen ausgeprägten, jedoch mit größter Güter gepaarten Gerechtigkeitssinn" auszeichne. Gestrichen wurde allerdings von BM Klecatsky die Zeile im Entwurf, dass er als „unerschütterlicher Diener des Rechtes [...] sein ganzes Berufsleben dem Wohl des Staates und seiner Würde gewidmet" habe, ebd.

${ }^{148}$ Geb. 1887, folgende Zitate und Angaben, wenn nicht anders vermerkt: ÖStA, AdR, Justiz, RJM, PA Raunig Josef. schikanieren und beim LG-Präsidium Klagenfurt eine Dienststrafanzeige wegen illegaler NSBetätigung erstattet. Raunig wurde im November 1934 vom Dienst unter Kürzung der Bezüge enthoben. Diese Suspendierung dauerte bis März 1935, dann erfolgte in Vollziehung des vom OGH bestätigten Disziplinarerkenntnisses des OLG Graz wegen Dienstvergehens seine Versetzung vom BG Rosegg zum BG Winklern. ${ }^{149}$ Nach seiner Darstellung $1946^{150}$ sei er 1933 ,infolge des verschärften Eischreitens der österr. Regierung gegen Nat.Soz. und Soz.Dem. in Widerstreit zu deren Tendenzen gekommen, die sich durch persönliche Differenzen mit dem zuständigen Bezirksleiter der VF. noch verschärften“. So sei er „immer mehr ins Lager der NSDAP. getrieben worden, ohne ihr beizutreten", und habe sich auch in Winklern dann nicht mehr politisch betätigt. ${ }^{151}$

Ludwig Pauer, ${ }^{152}$ ein „eifriger Verfechter der nationalsozialistischen Belange" (und Parteimitglied seit Anfang Mai 1938), wurde wegen sei-

149 Nach dem "Anschluss" erfolgte seine Ernennung zum Vorsitzenden des Anerbengerichtes Winklern, nach dem Krieg seine Anklage vor dem Volksgericht Graz.

150 ÖStA, AdR, Justiz, BMJ, VP Liqu Raunig, Josef.

${ }^{151}$ Auch habe er sich erst nach dem "Anschluss" um die Aufnahme in die NSDAP beworben und sei „rückwirkend auf 1.5. 1933 unter Verleihung einer freigewordenen niedrigen Mitgliedsnummer in die Partei aufgenommen worden“. 1945 wurde er als „Illegaler" eingestuft, zunächst entlassen. Im Zusammenhang mit einem Antrag auf Dienstzeitenanrechnung für die Ruhestandszahlung fasste 1957 der Vizepräsident des VfGH Gustav Zigeuner aus Anlass einer Intervention zugunsten Raunigs dessen politische Vergangenheit so zusammen: Raunig sei "stets ein ausgezeichneter Jurist aber ein Eigenbrötler gewesen, immer gegen die jeweilige Regierung eingestellt. In der Monarchie Sozialdemokrat, in der Republik dann ganz rechtsstehend, später Nationalsozialist, schließlich erbitterter Gegner derselben", ÖStA, AdR, Justiz, RM, NA Raunig, Josef.

${ }^{152}$ Geb. 1880; folgende Zitate und Angaben, wenn nicht anders vermerkt ÖStA, AdR, Justiz, RJM, PA Pauer, Ludwig. 
ner NS-Einstellung von Friesach zunächst nach Rosegg und dann nach Obervellach versetzt, und zwar auf Grund eines Disziplinarerkenntnisses des OLG Graz vom Februar 1936, in dem davon die Rede war, dass er "nach dem Verbot der NSDAP vorwiegend mit ns. eingestellten Personen Verkehr pflog, solche Gaststätten besuchte und im Dezember 1935 öffentl[lich] im Kino mit einem bekanntlich aus Deutschland zurückgekehrten Nat. Soz. sich unterhielt und ihm die Hand drückte". ${ }^{153}$ Nach eigenem Bekunden war er von „extrem Vaterländischen ,wegen feindlicher Einstellung' gegenüber dem (Starhemberg-)Heimatschutz beim Sicherheitsdirektor und beim Präsidium angezeigt" worden. Man habe ihm seinen Austritt aus dem Heimatschutz, dem er seit 1919 als Gründer und erster Ortsgruppenführer ununterbrochen angehört hatte, "schwer angekreidet". 1937 erfolgte schließlich auf eigenes Betreiben seine Versetzung nach Paternion, wo er nach Angaben der dortigen Gendarmerie im Mai „bei Verhandlungen seine Urteile nach politischen Gesichtspunkten gefällt und Antifaschisten beschimpft" habe. In einer "politischen Beurteilung vom Gemeinderat in Paternion“ wurde er auch „als politisch untragbar" beschrieben. ${ }^{154}$

Parteimitglied bereits seit Februar 1934 war Walter Rabe, ${ }^{155}$ Richter am BG Poydorf 1932 bis 1935. Er hatte nach eigenen Angaben 1931 an der Universität „die Gedenkrede anlässlich der Todestagsfeier Horst Wessels gehalten" und zählte es zu seinen „erhebendsten Lebenserinnerungen, einer der wenigen Freunde Horst Wessels während seiner Wiener Studentenzeit gewesen zu sein“.156 In der „Verbotszeit" stand er ",als

\footnotetext{
153 ÖStA, AdR, Justiz, BMJ, VP Liqu Pauer, Ludwig. 1541945 wurde er aus dem Staatsdienst entlassen, nach der NS-Amnestie 1957 wieder in Dienst gestellt, ÖStA, AdR, Justiz, RM, NA Pauer, Ludwig.

155 ÖStA, AdR, Justiz, RJM, PA Rabe, Walter; auch STADLER, Verfahren 347.

156 ÖStA, AdR, Justiz, BMJ, VP Liqu Rabe, Walter.
}

bekannter illegaler NS. eine Zeitlang unter Polizeiaufsicht", 157 auch wurde gegen ihn ein Disziplinarverfahren geführt, weil er weder das Abzeichen der VF noch auch Trauerflor nach der Ermordung Dollfuß' getragen hatte. Während seiner Zeit in Poysdorf sei er nach Mitteilung der NSDAP nach dem "Anschluss" an den Generalstaatsanwalt beim OLG Wien „von der VF. sehr angefeindet und mehrmals seine Entlassung begehrt" worden. Als Begründung für die Polizeiaufsicht gab Rabe an, dass „er als ,Nazirichter' bekannt war", sich aber dennoch "stets zum Nationalsozialismus bekannt und aus seiner Gesinnung kein Hehl gemacht" habe. ${ }^{158}$ So war er seit Februar 1934 Mitglied des Nationalsozialistischen Rechtswahrerbundes (NSRB) sowie Oberscharführer und Rechtsreferent beim Nationalsozialistischen Kraftfahrkorps. ${ }^{159}$ Im Jänner 1937 wurde er der Staatsanwaltschaft Korneuburg zugeteilt. ${ }^{160}$ Nach einer politischen Beurteilung der Gauleitung Niederdonau aus dem Jahr 1939 wurde er in der "illegalen Zeit" wegen seiner "nationalsozialistischen Einstellung als Richter sehr angefeindet", weshalb "mehrmals seine Entlassung begehrt" worden sei. ${ }^{161}$ Nach dem Krieg bestritt er allerdings, illegal gewesen zu sein und bezeichnete sich als "politisch uninteressiert". Als Strafrichter in Poysdorf sei er "von der Heimwehr grundlos angegriffen" worden. ${ }^{162}$ Nach dem Verbot der NSDAP in Poysdorf hätte nämlich eine neu aufgestellte Heimwehrformation „wiederholt mit politischen Gegnern Zusammenstöße" gehabt und von diesen Heimwehrlern sei er im Zuge

\footnotetext{
157 ÖStA, AdR, Justiz, BMJ, VP NA Rabe, Walter. 158 ÖStA, AdR, Justiz, RJM, PA Rabe, Walter. 159 ÖStA, AdR, Justiz, BMJ, VP Liqu Rabe, Walter. ${ }^{160}$ Er avancierte in der Staatsanwaltschaft 1944 zum OStA beim OLG Wien, ÖStA, AdR, Justiz, BMJ, VP NA Rabe, Walter.

${ }^{161}$ Ebd.

162 Ebd.
} 
der damit verbundenen Strafverfahren wegen Befangenheit abgelehnt worden. ${ }^{163}$

Josef Dölzl war Mitglied der NSDAP seit 1933, der SS seit 1936 sowie der VF von 1934 bis zu seinem Ausschluss aus derselben 1937. Er führte im Juni 1938 in einem Fragebogen über seine bisherigen Tätigkeiten für die NS-Bewegung weiters aus: „Ermöglichung und Förderung der illegalen Betätigung der Pg. [Parteigenossen] in Oberpullendorf; Wahrung der Rechte der Pg. in der Rechtsprechung; seit 1936 als SS-Mann Einholung und Uebermittlung von Nachrichten und Verrichtung anderer fallweise übertragener Aufgaben". Überdies gab er an, dass hinsichtlich seiner Person ein Verbot der Verwendung als Strafrichter ergangen sei.164 Die Begründung dafür sah er - seiner "Lebensbeschreibung" von 1938 zufolge - darin, dass er mehrere Heimatschützer „wegen tätlicher und wörtlicher Beleidigung von Nationalsozialisten" verurteilt habe, was Anlass für Beschwerden bei den Heimwehrführern Starhemberg und Fey gewesen sei. Man habe ihm gedroht, "nicht mehr lange Richter" zu sein und ihn "wegen seiner politischen Einstellung am 26. Juli durch mehrere Stunden angehalten. Er sei dann bis 1936 tatsächlich nicht mehr als Strafrichter verwendet worden. In weiterer Folge habe er veranlasst, dass gegen Gendarmen ein Strafverfahren eingeleitet worden sei, die "Heil-Hitler" rufende Burschen in einer Amtshandlung „mit Ochsenziemern schwer verprügelt" hatten. Darauf hätten Heimatschützer und „sämtliche jüdische Rechtsanwälte von

\footnotetext{
${ }^{163}$ ÖStA, AdR, Justiz, BMJ VP Liqu Rabe, Walter. Er wurde nach dem "Anschluss" als "Altparteigenosse" anerkannt und nach dem Krieg nicht nur als „Illegaler" eingestuft, sondern 1945 wegen seines Verhaltens in den Apriltagen 1945, als er versuchte, die Enthaftung von Gefangenen beim LG für Strafsachen zu verhindern, vom Volksgericht zu vier Jahren schweren Kerkers verurteilt. 1953 wurde er als LG-Rat reaktiviert, ÖStA, AdR, Justiz, BMJ, VP NA Rabe, Walter. ${ }^{164}$ Geb. 1902, ÖStA, AdR Justiz BMJ VP NA Dölzl, Josef.
}

Oberpullendorf" gegen ihn gehetzt, auch seien "Anzeigen an die Kammer und Aufsichtsbeschwerden" erhoben worden, was seinen Ausschluss aus der VF ${ }^{165}$ zur Folge hatte. Begründet wurde sein Ausschluss von der VF allerdings damit, dass er durch sein Verhalten in einem namentlich genannten Gasthaus, wo er ",angeblich den Gastwirt [...] wegen Tragens des Frontabzeichens und wegen seiner Zugehörigkeit zur Frontmiliz ganz grob beschimpft" und ein Kruzifix im Gasthauszimmer angespuckt hatte, nicht nur "den Anstand verletzt, sondern auch offensichtlich bekundet" habe, dass seine "Gesinnung und Einstellung mit den Grundsätzen der Vaterländischen Front und des erneuerten christlichen Österreich unvereinbar sind ". ${ }^{166}$ Es folgte die "strafweise Versetzung" an Wiener Gerichte. ${ }^{167}$

Ein besonders streitbarer und selbstherrlicher Richter scheint der Tiroler Karl Grüner ${ }^{168}$ gewesen zu sein, gegen den mit der Versetzung vorgegangen wurde, nachdem der Versuch einer Ruhestandsversetzung gescheitert war, wobei sich dann seine Wege mit Josef Dölzl in Oberpullendorf kreuzten. Grüner war zunächst Bezirksrichter und Bezirksvorsteher in Taxenbach seit 1930, seit 1934 Mitglied der VF und seit 24. Februar 1938 Mitglied der NSDAP. Er hatte sich 1932 nach eigenen Angaben (vom Mai 1938) "durch Vorträge in öffentl. Versammlungen und Sprechabenden in verschiedenen Orten des Landes Salzburg" ausgezeichnet, dann in weiterer Folge durch „hauptberufliche Förderung der Be-

\footnotetext{
${ }^{165}$ Offenbar erfolgte auch eine Anzeige durch einen Gastwirt, dessen Lokal in weiterer Folge von den Gerichtsbeamten gemieden wurde, ÖStA, AdR BKA-I Parteiarchive VF Gensekt 514-1-920, Kart. 149. 166 Ebd. 1671946 wurde Dölzl entlassen, 1955 wieder reaktiviert, ÖStA, AdR Justiz RJM PA Dölzl, Josef; ÖStA, AdR Justiz BMJ VP Liqu Dölzl, Josef.

${ }^{168}$ Geb. 1899; folgende Zitate und Angaben, wenn nicht anders vermerkt ÖStA, AdR, Justiz, RJM, PA Grüner, Karl.
} 
wegung“. Einen „formellen Beitritt“ zur NSDAP habe er ablehnen müssen, da er andernfalls „mangels einer geeigneteren Persönlichkeit sofort die Ortsgruppenleitung in Taxenbach übernehmen hätte müssen“. Dies sei ihm nicht nur „zu konjunkturell“ erschienen, sondern hätte ihn auch „später als Einzelgerichtsvorsteher in eine ganz unmögliche Lage gebracht", da er damals "schon viele Straf- und Streitsachen mit politischem Hintergrund $\mathrm{zu}$ entscheiden hatte" und sich "ohnedies schon öfters gegen Ablehnungsanträge wegen Befangenheit zur Wehr setzen“ habe müssen. Seit dem Frühjahr 1933 sei er „selbstverständlich den offenkundigen Rechtsbrüchen und Rechtsbeugungen der damaligen Bundesregierung innerhalb der Grenzen der richterlichen Unabhängigkeit, jedoch unter voller Ausnützung dieser Sonderstellung, entgegengetreten“ und habe sich "mit aller Kraft [...] dafür eingesetzt, den anständigen Teil der Bevölkerung vor dem Ansturm schlechter Charaktere und übelsten Konjunkturgesindels $\mathrm{zu}$ schützen“. Er habe deshalb „viele offene Anfeindungen und geheime Angebereien sogenannter vaterländischer Kreise zu erdulden" gehabt, was letztlich Ende Juli 1935 zu seiner „Pensionierung (als Gerichtsvorst. in Taxenbach)" mit nur 36 Jahren geführt habe. Diese "Zwangsversetzung" erfolgte nach §28 V-ÜG, also, wie Grüner betonte, „ohne Disziplinarverfahren“. Grund dafür war, dass er in den mit den Beschuldigten aufgenommenen Protokollen nicht deren tatsächliche Verantwortung aufgenommen habe, sondern "vielmehr seine eigene Meinung über die gegen die Beschuldigten erhobenen Anschuldigungen und seine persönlichen Anschauungen über die Verhältnisse in Österreich, sowie seine Stellungnahme gegenüber der Regierung und deren Maßnahmen zum Ausdrucke bringen wollte und tatsächlich auch gebracht" hatte. Seine Zwangspensionierung wur- de in weiterer Folge auf Grund eines Erkenntnisses des BGH aufgehoben, ${ }^{169}$ was er nach eigenen Angaben dessen Präsident Ernst Durig zu verdanken hatte, bei dem er zeitweise Präsidialsekretär während dessen OLG-Präsidentschaft in Innsbruck gewesen war. Der BGH erblickte in dem Umstand, dass Grüner "Gedanken zu Protokoll gebracht hatte, die die Beschuldigten überhaupt nicht vorbrachten, nur eine grobe Ungehörigkeit" und erachtete die Frage, ob Grüner "staatstreu oder staatsfeindlich eingestellt" sei, zwar als „entscheidend“, aber „zu wenig geklärt" ${ }^{\prime \prime}{ }^{170}$ Die Pensionierung wurde in weiterer Folge in eine Beurlaubung umgewandelt, die bis November 1937 andauerte, dann wurde er in Oberpullendorf erneut in Dienst gestellt. Nach Grüners Angaben hatte die Versetzung ihren Grund darin, dass er „während seiner Tätigkeit als Gerichtsvorsteher in Taxenbach aus seiner grossdeutschen Einstellung heraus Sympathien mit dem Nationalsozialismus in auffälliger Weise bekundete".171 Man habe ihn mit dieser "Zwangsversetzung“ ins Burgenland, so klagte er 1938, von seiner im Innsbrucker Raum lebenden Familie trennen wollen. In Oberpullendorf habe er die Bewegung jedoch weiter gefördert, etwa als Kreispresseamtsleiter sowie Kreisredner der NSDAP, obwohl er sowohl von der Gendarmerie als auch der VF überwacht worden sei - wie auch die VF attestierte, die 1937 vorschlug, der "derzeitige Gerichtsvorsteher von Oberpullendorf" möge aus dem Burgenland versetzt werden, weil er am „Verhalten der Richter und Gerichtsbeamten", die sich mit dem aus der VF wegen nationalsozialistischer Betätigung ausgeschlossenen Richter Josef Dölzl solidarisierten, "nicht schuldlos sein soll“. ${ }^{172} 1946$ behauptete

\footnotetext{
${ }^{169}$ Erkenntnis 8.5.1936, GZ. A 1116/35, ÖStA, AdR, Justiz, BMJ, VP NA Grüner, Karl.

170 ÖStA, AdR, Justiz, BMJ, VP NA Grüner, Karl.

171 Ebd.

172 ÖStA, AdR BKA-I Parteiarchive VF Gensekt 514-1920, Kart. 149.
} 
Grüner dann, er habe „die verfassungsrechtlichen Vorgänge 1933/34 als rechtlich denkender Mensch und aus Heimatliebe unmöglich billigen können“, seine "Ablehnung“ sei „mittelbar allerdings einer Begünstigung der ehemaligen Opposition in Österreich, von der die demokratischen Verfassungsrechte verteidigt wurden, gleichgekommen“. Seine "damaligen Rechtsbedenken“ wären jedoch „von fast allen Richtern in Österreich, soweit sie nicht an den Umsturz parteipolitisch gebunden waren, geteilt worden“. ${ }^{173}$ Als nach dem Ende der NS-Herrschaft Grüners Reaktivierung zur Diskussion stand, wurde allerdings von einem Ministerialbeamten, der vor 1938 als „Referent in dieser Leidensangelegenheit" im BMJ tätig gewesen war und daher also dem Regime wohl nahe gestanden hatte, in einer Stellungnahme festgehalten, dass Grüner ein besonders „eklatanter Fall des Treuebruchs gegenüber der Republik" gewesen sei. Schon vor dem Verbot der NSDAP habe er sich "höchst ungeschickt benommen“, indem er "mit Gott und der Welt" und insbesondere dem Gendarmerieposten verfeindet war und im NSTurnverein „regierungs- und staatsfeindliche Reden" gehalten habe. Auch hätte der damalige Leitende Staatsanwalt von Salzburg seine Urteile "als Skandal bezeichnet", ${ }^{174}$ und nach dem Verbot der NSDAP habe Grüner „aus dem Gerichtsgefängnis Taxenbach ein Fledermausmuseum gemacht für Nationalsozialisten". Diese

173 ÖStA, AdR, Justiz, BMJ, VP Liqu Grüner, Karl. Nach dem „Anschluss" erfolgte die Zurückversetzung Grüners nach Tirol; als „Wiedergutmachung der ihm wegen seiner ns. Einstellung widerfahrenen Massregelung" wurden ihm schließlich die Vertretungskosten vor dem BGH bewilligt. Laut Bestätigung der NSDAP-Leitung vom April 1939 war er als "alter Kämpfer" anzusehen und wurde im Juni zum OLG-Rat ernannt. 1948 erfolgte Grüners dauernde Pensionierung, 1955 wurde er reaktiviert, ÖStA, AdR, Justiz, BMJ, VP Komm Grüner, Karl.

${ }^{174}$ Nach der Gerichtssaalberichterstattung in der Reichspost bezeichnete die Staatsanwaltschaft das Urteil als „erschütternd“, RP, Nr. 48 v. 17. 2. 1935, 14. „konnten sich in dem Hof aufhalten, erhielten durch seine Mitwirkung von der ganzen Bevölkerung von Taxenbach Unterstützung durch Lebensmittelsendungen, Musikinstrumente bekamen sie ins Gefangenenhaus, und als der [LG-]Präsident [...] überfallsartig in Taxenbach erschien, glaubte er sich in eine andere Welt versetzt“. Im Zuge der von Grüner geführten Verfahren habe dieser den Beschuldigten "Verantwortungen etc. in den Mund gelegt", die diese, "einfache Bauernburschen“, „nie vorgebracht haben“ könnten, weil „ihnen das Rüstzeug hiezu fehlte“. In den Verfahren seien "ganze Polemiken mit der Regierung abgeführt", „die Rechtsgültigkeit der Verfassung in Zweifel gezogen" und "ganze Abhandlungen über die Verfassungsmässigkeit des Regimes durchgeführt" worden, weshalb auch die Entscheidung des BGH als „unbegreiflich" bezeichnet werden müsse. Grüner habe auch nach seiner Versetzung "seine destruktive Tätigkeit fortgesetzt" und den damals in Haft befindlichen illegalen Gau-Funktionär Dr. Tobias Portschy begünstigt, „wodurch dieser imstand war, als Gerichtshäftling die illegale Parteiarbeit für die NSDAP von der Zelle aus [...] zu leiten“. ${ }^{175}$ Grüner verteidigte sich freilich damit, ${ }^{176}$ dass seine Regimegegnerschaft von grundsätzlichen rechtlichen Überlegungen getragen gewesen sei und er im Sinne einer "demokr[atischen] Rechtspflege“ gehandelt habe. Er sei in allen Verfahren gegen Angehörige damals verbotener Parteien "gleichartig vorgegangen“, habe also „keineswegs Anhänger der NSDAP begünstigt, sondern ebenso auch die Rechte sozialdemokr[atischer] und kommunistischer Parteigänger zu wahren gesucht ${ }^{\prime \prime}{ }^{177}$

\footnotetext{
${ }^{175}$ Für „einen solchen Menschen“ sei daher insgesamt „kein Platz in der österreichischen Justiz".

176 ÖStA, AdR, Justiz, BMJ, VP NA Grüner, Karl.

177 Auch sei er kein "Illegaler" gewesen, und die NSDAP habe ",anscheinend alle Opfer der Rechtsentwicklung zum autoritären Regierungssystem als , alte Kämpfer anerkannt, sofern diese nur überhaupt na-
} 
Ein ebenfalls recht ungewöhnlicher Fall ist Otto Lutz, ${ }^{178}$ der nicht nur durch seine NS-Betätigung, sondern insbesondere auch durch geringe Befähigung bei gleichzeitiger Überheblichkeit hervorstach. Lutz, Sohn eines Senatspräsidenten des OGH, war schon seit Jänner 1932 Mitglied der NSDAP und seit 1933 Mitglied des NSRB. Er wurde - nachdem gegen ihn schon 1929 wegen seiner Prozessführung gegen sozialdemokratische Angeklagte ein mit einer Versetzung endendes Disziplinarverfahren geführt worden war - Ende August 1934 aus disziplinarrechtlichen Gründen an einen anderen Dienstort versetzt. In seinen eigenen Worten 1939 wurde er „über Anzeige der Vaterländischen Schuschnigg-Front und der Starhemberg-Heimwehr wegen nationalsozialistischer Gesinnung und Begünstigung nationalsozialistischer Bevölkerungskreise strafweise von Kirchberg am Wagram in das damals als Strafkolonie für Richter geltende Burgenland versetzt" und ihm "für die Zukunft die Ausübung der Strafjustiz untersagt ${ }^{\prime \prime}{ }^{179}$ Aber auch in Neusiedl sei er „überaus aktiv für die Bewegung gewesen". Von Seiten des "Stellvertreters des Führers“ wurde im März 1940 jedenfalls hervorgehoben, dass sich Lutz ,jederzeit restlos in den Kampf gegen das Schuschniggregime gestellt und bewährt" sowie für

tional eingestellt waren“. Er beklagte sich - in durchaus einseitiger Interpretation der seinerzeitigen Vorgänge -, dass „das seinerzeit durch [s]ein Verhalten betroffene autoritäre Regierungssystem in [s]einem Vorgehen niemals eine Veranlassung auch nur zur Einleitung eines Disziplinarverfahrens, geschweige denn irgendeine strafbare Handlung erblickt" habe, während er nun von einer von ihm "stets hochgehaltenen demokratischen Rechtspflege zum verbrecherischen Hochverräter gestempelt würde“. Durch sein Verhalten habe sich „höchstens das autoritäre Regierungssystem betroffen fühlen können, niemals aber eine objektive demokratische Rechtspflege“, für die er auch dann noch eingetreten sei, "als dies schon schwerste persönliche Nachteile nach sich ziehen konnte".

178 Geb. 1899, ÖStA, AdR, Justiz, RJM, PA Lutz, Otto. ${ }^{179} \mathrm{Ebd}$ „seine Treue zu unserer Bewegung viele Niederträchtigkeiten hinnehmen" habe müssen, während das Reichjustizministerium (RJM) trotz dieser Verdienste seine extrem deutlich negative Dienstbeschreibung ins Treffen führte. ${ }^{180}$

${ }^{180}$ ÖStA, AdR, Justiz, BMJ, VP Liqu Lutz, Otto. Da nach dem "Anschluss", nach dem er bis zur Versetzung nach Krems u.a. Vorsitzender des Anerbengerichts in Wolkersdorf gewesen war, keine ihm adäquat scheinende Beförderung erfolgte, drohte Lutz, sich im Fall einer ,tatsächlich weiter andauernden Benachteiligung“ seiner Person „als alter Kämpfer der NSDAP“ dazu veranlasst zu sehen, diese „in unserem heutigen Staate untragbare Behandlung eines der ältesten Parteimitglieder unter den österreichischen Richtern und des einzigen Parteimitgliedes aus der Verbotszeit des hiesigen Land- und Amtsgerichtes [Krems an der Donau] den zuständigen Parteistellen bekanntzugeben“. Vom OLG-Präs. Wien wurde er allerdings als "mässige Kraft” eingestuft, „von seinem Wissen sehr eingenommen, unbelehrbar und halsstarrig", in der "Ausübung seines Dienstes [...] sehr bequem", auch halte er die Arbeitszeit "selbst bei grösster Belastung" nicht ein, was zur einer "großen Schleuderhaftigkeit und Flüchtigkeit in der Erledigung der ihm zugewiesenen Arbeiten“ führe. Er zeige sich aber "gegen Belehrungen und Weisungen völlig einsichtslos, ja sogar überheblich“. Dies zeige sich auch darin, dass er in seinen Rechtsmittelvorlageberichten die Rechtsmittelrichter darüber belehre, „dass und warum eine seiner Entscheidung zuwiderlaufende Rechtsmittelentscheidung dem nationalsozialistischen Rechtsempfunden widersprechen müsste“. Eine solche "sachlich und rechtlich vollständig verfehlte Belehrung über das richtige nationalsozialistische Rechtsempfinden“ habe er auch „in sehr unhöflicher Form“ dem Reichskommissar auf eine „höfliche Anfrage" desselben erteilt. Er lege darüber hinaus ein Verhalten den Parteien gegenüber an den Tag, „das den Pflichten eines Beamten im nationalsozialistischen Staat nicht entspricht". Schließlich intervenierte die NSDAP Niederdonau im September 1939 für eine Beförderung, da er „in der Verbotszeit diszipliniert und geschädigt" " worden sei. Im Gegensatz dazu wies das RJM freilich darauf hin, dass Lutz eine "geradezu vernichtende Dienstbeschreibung" aufweise und sich „den Rechts suchenden Volksgenossen gegenüber in einer Weise (benehme), die von ns. Gesichtspunkte aus nicht gebilligt werden könne“. Seine verhaltensauffällige Art änderte Lutz offenbar auch in weiterer Folge nicht und wurde 1945 nicht mehr in den neuen 
Zu einer Versetzung wegen NS-Betätigung aufgrund des V-ÜG kam es weiters im Fall Eugen Hufnagls, 181 der ",schon vor dem Umbruch als Nationalsozialist [galt]", wenngleich er unbestrittener Maßen erst seit Juni 1938 der NSDAP angehörte. ${ }^{182}$ Er wurde im November 1934 vom BG Lilienfeld, wo er unter Polizeiaufsicht stand, zunächst vorübergehend nach Freistadt und dann nach Mattersburg transferiert, und zwar (nach Angaben aus 1945) im Zuge der Feststellung seiner "Illegalität" „ohne Disziplinarverfahren oder drgl., weil Anzeigen des faschistischen Heimatschutzes gegen ihn erfolgt seien. “183

Mit einer Versetzung gemäß dem V-ÜG ging die Regierung auch gegen den Steirer Franz Rainer vor, ${ }^{184}$ nach eigenen Angaben Mitglied der NSDAP seit Februar 1937. Er wurde Anfang November 1934 vom BG Deutschlandsberg nach Bad Aussee versetzt, und zwar nach eigener Aussage, weil zwei seiner Söhne am Juliputsch beteiligt gewesen waren. Er selbst habe Juliputschisten in seiner Wohnung mit Lebensmitteln und auch Gewehrmunition versorgt sowie versucht, seinen beiden „nach Jugoslavien geflüch-

Personalstand übernommen, wobei seine „Alkoholexzesse" ebenfalls eine Rolle spielten, ÖStA, AdR, Justiz, BMJ, VP NA Lutz, Otto.

${ }^{181}$ Geb. 1902, ÖStA, AdR, Justiz, RJM, PA Hufnagl, Eugen.

182 ÖStA, AdR, Justiz, BMJ, VP Liqu Hufnagl, Eugen.

${ }^{183}$ Ebd. 1938 wurde er als Amtsgerichtsrat zum Amtsgericht Wien versetzt, https://www.findbuch.at/tl_files/data/adressbuecher/1937_bsoe_bgl_abak/10_Justizwesen.pdf, nach 1945 als „Minderbelasteter" eingestuft, ÖStA, AdR, Justiz, BMJ, VP NA Hufnagl, Eugen; ÖStA, AdR, Justiz, BMJ, VP Komm Hufnagl, Eugen. Nach der NS-Zeit wurde er als „Belasteter“ nach dem Nationalsozialistengesetz qualifiziert und musste sich einem Volksgerichtsverfahren stellen, in dem er wegen seiner Unterstützung des Juliputsches zu einer Kerkerstrafe von 15 Monaten verurteilt wurde.

${ }^{184}$ Geb. 1887; ÖStA, AdR, Justiz, RJM, PA Rainer, Franz. teten Jungen Kleider und Geld nachzusenden", was zu einer Anzeige führte. ${ }^{185}$

Ungewöhnlich, insbesondere hinsichtlich seines Verlaufes nach dem "Anschluss" 1938, ist der Fall Karl Otto Thies, ${ }^{186}$ der seit Jänner 1932 NSDAP-Mitglied war, und zwar nach den (auf Thies' Angaben aus $1945^{187}$ beruhenden) Ausführungen des BMJ 1956 „vermutlich auf Veranlassung seiner ersten Ehegattin, die eine eifrige Anhängerin und Verfechterin der ns-Idee" gewesen sei. 188 Er hatte sich in der "Verbotszeit" in vielfacher Weise für die NSDAP engagiert, wofür er als Zeugen einerseits Paul Lux anführte, der nach dem "Anschluss“ zeitweise stellvertretender Gauführer des NSRB war, ${ }^{189}$ und andererseits Erich Führer, ${ }^{190}$ den Anwalt des DollfußMörders Otto Planetta, Leiter des illegalen NSJuristenbundes und Vizepräsident der Anwaltskammer Wien 1938 bis 1943. Er wurde Anfang Oktober 1935 vom BG Landstraße an das BG Leopoldstadt mit Ausschluss von der Strafgerichtsbarkeit versetzt, weil er laut einer Denunziation aus Anlass der Neu-Zuteilung eines Richters als Schriftführer angeblich gesagt hatte: „Achtung! Vorsicht! Maul halten! Ein Vaterländischer!“191 Im Juli 1936 erfolgte dann „wegen

${ }^{185}$ ÖStA, AdR, Justiz, BMJ, VP Liqu Rainer, Franz. Nach dem "Anschluss" wurde er als "Altparteigenosse“ anerkannt, im August 1938 Vorsitzender des Anerbengerichts Deutschlandsberg und war als Kreisamtsleiter der NSDAP in der Kommunalpolitik tätig. Wegen Illegalität wurde er 1945 entlassen und verurteilt, 1951 seine Entlassung aufgehoben und er in den Ruhestand versetzt, ÖStA, AdR Justiz BMJ VP NA Rainer, Franz.

${ }^{186}$ Geb. 1900 ÖStA, AdR, Justiz, RJM, PA Thies, Karl Otto.

${ }^{187}$ ÖStA, AdR, Justiz, BMJ, VP NA Thies, Karl Otto.

${ }^{188}$ Sie war auch "nach der Annexion hauptberuflich bei der Gauleitung Wien angestellt", ebd.

$189 \mathrm{Vgl}$. zu ihm STADLER, Verfahren 334f.

${ }^{190} \mathrm{http}: / / w w w . d o e w . a t / e r k e n n e n / r e c h t s e x t r e m i s m u s /$ neues-von-ganz-rechts/archiv/september-2001/erichfuehrer.

${ }^{191}$ ÖStA, AdR, Sonderarchiv Moskau, Kart. 109, Konv. 347. 
verschiedener [...] im Jahre 1933 und 1934 gegen das damalige Regime gemachter Äußerungen “192 seine Versetzung nach Poysdorf gemäß dem V-ÜG. Anfang 1937 erfolgte auch hier der Entzug der Strafsachen. Sodann wurde ihm - in den Worten der „Kanzlei des Führers der NSDAP“ 1939 - seine Pensionierung gemäß VÜG infolge seiner "staatsuntreuen Handlungen“ angekündigt. Er sei jedoch „pardoniert" (also nicht pensioniert), dafür aber aufs Land versetzt worden, und zwar „in eine der schwärzesten Gemeinden Niederdonaus“. Diese Zeit, "(18 Monate), die er hier verbrachte“, sei "für ihn wohl die qualvollste" gewesen, er habe aber selbst diese Zeit "standhaft überwunden“.193 Auch das BMJ vermerkte 1956 (Thies' Angaben folgend), dass "seine angeblich wegen fanatischer Äusserungen für den Nationalsozialismus strafweise geplante Pensionierung“ 1936 „dahin gemildert" worden sei, dass man ihn nach Poysdorf versetzte. Danach hätten keine weiteren "schwerwiegenden“ Tatsachen gegen Thies mehr festgestellt werden können, da er sich der "Einflußnahme" seiner Ehefrau "fast zur gleichen Zeit" (1935) durch Scheidung entzogen habe. ${ }^{194}$ Trotz seines (zumindest anfänglichen) Engagements für die NSDAP wurde ihm 1938 allerdings seine nicht-,,arische“ Herkunft zum Verhängnis. ${ }^{195}$

\footnotetext{
192 ÖStA, AdR, Justiz, BMJ, VP NA Thies, Karl Otto. 193 ÖStA, AdR, Justiz, RJM, PA Thies, Karl Otto. 194 ÖStA, AdR, Justiz, BMJ, VP NA Thies, Karl Otto. 195 Seine Mutter war vor ihrer Heirat 1899 „Jüdin“ im Sinne der NS-Rassegesetze. Die „Tragik“ lag also, in den Worten der NS-Behörde, „bei diesem bestimmt wertvollen Menschen in seinem starken jüdischen Bluteinschlag". Thies musste aus der NSDAP austreten, konnte aber infolge der Ausnahmegenehmigung des Berufsbeamtengesetzes mit Genehmigung des Stellvertreters des Führers im Staatsdienst verbleiben, jedoch nicht als (Spruch-)Richter oder Staatsanwalt, denn „Mischlinge 1. Grades“ durften nur mehr als "Grundbuchrichter oder in ähnlicher Stellung" tätig werden. So wurde Thies nach seiner zeitweiligen Enthebung ab Februar in den Reichsjustizdienst überge-
}

\subsubsection{Disziplinarverweis}

Eine mildere Maßregelung stellte der Verweis durch das Disziplinargericht dar. Allerdings kam es oft auch nur zur Einleitung von Verfahren ohne Schuldspruch. So erteilte etwa das OLG Wien bereits Ende Juni 1932 Adolf Bayer einen Verweis, weil er eine abfällige Bemerkung gegen die Regierung Dollfuß getätigt hatte. ${ }^{196}$

Abfällige Bemerkungen gegen die Regierung waren auch der Grund für das Disziplinarverfahren 1935 gegen Norbert Schebesta, Richter am BG Favoriten und erst seit dem "Anschluss" Parteianwärter bzw. seit 1940 Parteimitglied. ${ }^{197}$ Schebesta, der "der ns. Bewegung schon vor der Verbotszeit sympathisierend gegenüberstand" und "mit ihr auch in der Verbotszeit [sympathisierte]", hatte, so der gegen ihn erhobene Vorwurf,, 198 im Mai 1934 und Anfang Juli 1934 „abfällige Äusserungen über das Verhältnis Österreichs zu Deutschland gemacht“, "am Tag der Ermordung des Bundeskanzlers Dr. Dollfuß geäussert, es werden sich noch andere Dinge ereignen", sich "gelegentlich des Leichenbegängnisses des Bundeskanzlers Dr. Dollfuss über die Trauerbeleuchtung abfällig geäußert" (nämlich, dass es „um das viele Geld schade sei, das man für die vielen Kerzen [...] zur Beleuchtung der Fenster des Gerichtsgebäudes ausgeben müsse“), am Tag der Hinrichtung „des Kanzlermör-

leitet, auch blieb er Mitglied im NSRB. Er wurde 1945 außer und 1948 wieder in Dienst gestellt. In Hinblick auf eine vorgeschlagene Beförderung erschien es dem BMJ 1950 allerdings als „besondere Charakterlosigkeit", "dass er in doch wohl genauer Kenntnis der Diffamierung des Judentums durch den Nationalsozialismus sich offenbar unter absichtlicher Verschweigung seiner Abstammung diesem anschloss“. Dass er dann „selbst diffamierend ausgeschlossen wurde, kann er sich daher nicht als Verdienst buchen“, ebd. 196 STADLER, Verfahren 303.

197 ÖStA, AdR Justiz BMJ VP Komm Schebesta, Norbert.

${ }^{198}$ Dienststrafsache Norbert Schebesta Zl. Jv 922111R/35, 22f, ÖStA, AVA JM Wien P 6+Vz 1935, Kart. 4391. Daraus die folgenden Zitate. 
ders Planetta abfällige Äusserungen über die Rechtsprechung der Militärgerichte und die Behandlung der Angeklagten durch den Verhandlungsleiter gemacht ${ }^{\prime \prime}{ }^{199}$, sich nach der Ermordung Dollfuß` „, an Gesprächen mit Beamten des BG. Favoriten beteiligt, welche den Verdacht rechtfertigen, dass sich die Teilnehmer trotz dem Verbote für die NSDAP. betätigen“. Ein Dienststrafverfahren gegen Schebesta wurde im August 1935 eingestellt, im Disziplinarverfahren wurde er in den meisten Punkten freigesprochen, aber hinsichtlich folgender Äußerung für schuldig erkannt: „Ich hätte die Militärgerichte nicht eingeführt, die Standgerichte hätten genügt. Ich würde politische Verbrecher erschießen“. Es wurde über ihn die Ordnungsstrafe des Verweises verhängt (und diese in der Instanz auch bestätigt), weil er hierdurch der Pflicht, "sowohl in und ausser dem Amte alles zu unterlassen, was die Achtung vor dem Stande, welchem er angehört, zu vermindern geeignet wäre", sowie sich durch das "Verhalten in und ausser dem Amte der Achtung und des Vertrauens, die sein Beruf erfordert, nicht unwürdig zu zeigen“ (§ 2 RDG), zuwidergehandelt habe. ${ }^{200}$

Die Strafe des Disziplinarverweises wegen einer Ordnungswidrigkeit erhielt auch Walter Dillersberger, nach eigenen Angaben NSDAP-Mitglied „aus ideellen Gründen“ seit September 1931 (mit Unterbrechung in der Verbotszeit ${ }^{201}$ ) und

199 „Wenn man die Leute zum Tode verurteilen wolle, so solle man ihnen einen ehrenvollen Tod gönnen und sie erschiessen lassen. Das Hängenlassen bedeute eine ganz überflüssige Demonstration oder Demagogie und eine unangebrachte Härte gegenüber diesen armen Teufeln."

${ }^{200}$ Da Schebesta seit dem „Anschluss“ der NSDAP zunehmend kritisch gegenüberstand und auch keine Funktionen in der NSDAP bekleidete, wurde er im Dienst belassen, ÖStA, AdR Justiz BMJ VP Komm Schebesta, Norbert; ÖStA, AdR Justiz BMJ VP NA Schebesta, Norbert.

${ }^{201}$ Und zwar eigenen Angaben zufolge nicht erst seit dem Parteiverbot, sondern bereits seit dem Verbot der Mitgliedschaft von Beamten in der NSDAP, so ein
SS-Untersturmführer (SS-Führer im Stabe des SS-Abschnittes XXXVI, Innsbruck), Richter seit 1930 (zuerst am BG in St. Johann im Pongau und dann in Feldkirch, seit 1936 am LG Innsbruck). Der Verweis erfolgte im Jänner 1934 durch Disziplinarerkenntnis des OLG Innsbruck wegen „Beleidigung der Regierung Dollfuss“.202 Im September 1933 war Dillersberger bereits verwaltungsstrafrechtlich wegen „öffentl. Beleidigung der Bundesregierung" von der Bezirkshauptmannschaft St. Johann zu 1.500 Schilling und drei Tagen Arrest verurteilt worden, ${ }^{203}$ weil er als Obmann des „Deutsch-Völkischen Turnvereins" am 7. Juni 1933, also noch vor dem Verbot der NDSAP, in einem Schreiben an der Bundesregierung "abfällige Kritik" geäußert hatte. ${ }^{204}$ Die Kritik bestand in dem Vorwurf, dass „der österreichische Heimatschutz [...] jede von der derzeitigen Regierung unternommene Maßnahme zur Unterdrückung völkischer Menschen und einer gesamtdeutschen Politik deckt und weitgehend unterstützt" ${ }^{\prime 205} \mathrm{Zu}$ seinen Aktivitäten für die NSDAP gab Dillersberger nach dem "Anschluss" an, dass er bis zum Parteiverbot Mitglied der Bezirksleitung der NSDAP Pongau gewesen sei. Nach dem Parteiverbot habe er sich bis zu seiner Versetzung nach Feldkirch als „Obmann des dv. Turnvereins i.S. der ns. Bewegung“ betätigt und „fallweise [den] österr. Beobachter verbreitet". Außerdem sei er "Organisator des Widerstandes gegen die Schuschnigg-

Schreiben Dillersbergers an das OLG-Präs. Innsbruck im Mai 1946 (Dank an Dr. Günther Stanonik für die Zurverfügungstellung).

${ }^{202}$ Geb. 1904, ÖStA, AdR Justiz RJM PA Dillersberger, Walther.

${ }^{203}$ Wobei die Freiheitsstrafe im Berufungsweg nachgesehen und die Geldstrafe im Gnadenweg auf nur 650 Schilling reduziert wurde, ebd.

${ }^{204}$ ÖStA, AdR Justiz BMJ VP NA Dillersberger, Walther.

205 Ebd. 
wahl unter den Richtern u. Staatsanwälten etc., etc. " 206 gewesen.

Ein Beispiel für ein erfolgloses Disziplinarverfahren ist hingegen Anton Rolleder, ${ }^{207}$ seit Jänner 1931 NSDAP-Mitglied, der im Zuge des Juliputsches seitens des Schutzkorps der VF morgens verhaftet und „im Konzentrationslager Notarrest Löfler-Keller, Wien, XIII., bis 18 Uhr angehalten" wurde. ${ }^{208}$ Er gehörte von (vermutlich) 1931 bis 1933 dem NS-Juristenbund an, hatte allerdings nach seinen Angaben 1946 in der „Aera Dollfuß" bzw. „der ganzen Verbotszeit keinerlei Funktion" innegehabt. ${ }^{209}$ Gegen ihn wurde 1935 ein Disziplinarverfahren „wegen brieflicher Grüße an einen nach Deutschland [zur Österreichischen Legion] geflüchteten Funktionär" geführt, das allerdings mit Freispruch endete. Es folgten mehrere Hausdurchsuchungen - alle (nach seinen eigenen Angaben) wegen der NS-Tätigkeiten seiner Söhne - und Ablehnungen von Beförderungsgesuchen.210

${ }^{206}$ Wiewohl er offenbar bereits vor dem Parteiverbot aus der NSDAP ausgetreten war, wurde er nach dem "Anschluss" als „Alter Kämpfer" anerkannt. Er war dann Gaugruppenwalter (Richter und Staatsanwälte) im NSRB, 1939 wurde er OLG-Rat in Innsbruck. Im Jänner 1943, damals Chef des SS- und Polizeigerichts VII in Wien, bot er dem RJM seine "vorbehaltlose Bereitschaft zur Mitarbeit“ an der Justizreform an und bekundete sein Interesse an den „Fragen des richterlichen Nachwuchses und seiner Ausbildung", da er gerade „,auf diesen Gebieten einige Erfahrung gewonnen und das Interesse an der Neugestaltung dieser Sachgebiet nie verloren" habe. Im November 1943 erfolgte seine Beförderung zum SS-Sturmbannführer der Waffen-SS. Darüber hinaus ersuchte der Chef der Sicherheitspolizei Ernst Kaltenbrunner persönlich um Versetzung Dillersbergers von der Allgemeinen SS zum Reichssicherheitshauptamt. $\mathrm{Zu}$ diesem Zeitpunkt war Dillersberger Untersuchungsführer beim Chef der Sicherheitspolizei und des SD. 1946 wurde er aus dem Justizdienst entlassen.

${ }^{207}$ ÖStA, AdR, Justiz, BMJ, VP NA Rolleder ,Anton.

${ }^{208}$ ÖStA, AdR, Justiz, BMJ, VP NA Rolleder ,Anton.

209 ÖStA, AdR, Justiz, BMJ, VP Liqu Rolleder Anton.

${ }^{210}$ ÖStA, AdR, Justiz, BMJ, VP NA Rolleder, Anton. Nach dem „Anschluss" wurde Rolleder als „Alter
1945 bescheinigte diesem "geistige[n] Vater der Methode der erbbiologischen Abstammungsgutachten“211 der OLG-Präsident, dass er „ein harmloser Idealist" gewesen sei, „der aus ehrlicher Begeisterung und nicht etwa aus Konjunkturgründen zur NSDAP gestoßen ist und ihr auch während der Verbotszeit weiter angehört hat". Seine Interessen hätten sich v.a. auf Rasse-, Abstammungs- und Erbgesundheitsfragen" bezogen, „von deren Lösung im Sinne der n.s. Auffassung er sich die überstiegensten Hoffnungen auf eine Regeneration des deutschen Volkes machte". ${ }^{212}$

\subsubsection{Anhaltung}

"Angehalten" bzw. interniert wurden außer Rolleder und Saurwein auch noch andere Richter, so etwa im Zusammenhang mit dem Juliputsch für einige Stunden Josef Dölzl, ${ }^{213}$ Richter am BG Oberpullendorf. Ebenfalls zu einer Anhaltung kam es im Fall vom Johann Schwandtner, seit 1932 Richter am LG für ZRS214 und Mitglied der NSDAP seit 1930,215 den am 25./26. Juli 1934 die Heimwehr in Weidlingau inhaftierte.

Der Richter des BG Eberstein, Franz Hradetzy, wurde den MRP zufolge ${ }^{216}$ hingegen schon lange vor dem Juliputsch, nämlich bereits in der Nacht von 30. auf 31. Jänner 1934, verhaftet und in das Anhaltelager Wöllersdorf abgegeben, und

Kämpfer" anerkannt, war Vorsitzender eines Sondersenates des Obersten Parteigerichts, seit Mai 1939 Mitglied des Gau-Ehrengerichts des NSRB und seit 1940 Vorsitzender des Erbgesundheitsgerichts.

${ }^{211}$ So hieß es in einem Antrag auf Verleihung des Österreichischen Ehrenkreuzes für Wissenschaft und Kunst nach dem Ende der NS-Herrschaft, ebd.

${ }^{212}$ Er wurde zunächst als Belasteter, 1948 dann aber schließlich als Minderbelasteter eingestuft, infolgedessen auch seine Entlassung aufgehoben werden konnte, ebd.

${ }^{213}$ STADLER, Verfahren 306f, siehe auch weiter oben.

214 Ebd. 358.

215 ÖStA, AdR Justiz BMJ VP NA Schwandtner, Josef. ${ }^{216}$ MRP 919 1. 2. 1934, NECK, WANDRUSZKA, Protokolle $480 \mathrm{ff}$. 
zwar weil er Mitglied der NSDAP gewesen sei, mit Parteigängern der NSDAP „Fühlung“ gehabt und sich eine von ihm verfügte Verhaftung von zwei Mitgliedern des Kärntner Heimatschutzes (die im Zusammenhang mit einer vorgeblichen Verhinderung nationalsozialistischen Umtriebe in eine Schießerei verwickelt waren) als "Sabotageakt" dargestellt habe. Staatssekretär Glas kritisierte im MR allerdings, dass die Anhalteverfügung „offenbar wegen seiner Ausübung des Richteramtes erfolgt" sei, weshalb gegen diese "die schwersten Bedenken verfassungsrechtlicher Natur bestünden", denn die wegen der Verhaftung der Heimatschützer vorgenommene "Abschiebung des Dr. Hradetzky" - richtig natürlich Anhaltung - verstoße eindeutig gegen die verfassungsrechtlich garantierte Unabhängigkeit und Unversetzbarkeit der Richter. Fey führte hingegen aus, dass Hradetzky eine Verhaftung nur „im Weg eines staatsanwaltschaftlichen Funktionärs" veranlassen hätte dürfen und somit seine Befugnisse überschritten habe. Er sei verhaftet worden, weil er "als Staatsbürger, nicht in seiner Eigenschaft als richterlicher Funktionär staatsfeindliche Handlungen gefördert" habe. Außerdem sei er "schon lange der Behörde und der heimattreuen Bevölkerung missliebig aufgefallen“, weil er als "einer der wildesten nationalsozialistischen Agitatoren in der Gegend“" gelte.

\subsubsection{Sonstige Maßnahmen}

Manche Richter wurden zeitweilig auch unter Polizeiaufsicht gestellt, so etwa Eugen Hufnagel und Walter Rabe. Weiters wurde das politische Verhalten der Richter im Karriereverlauf berücksichtigt. So wurde etwa bei Karl Piska, ${ }^{217}$ seit Oktober 1931 beim LG für ZRS Wien, wegen seiner Zugehörigkeit zur NS-Betriebszellenorganisation (NSBO) angeordnet, dass vor jeder Betrauung mit einem verantwortlichen Posten

217 Ebd. 344. oder Auszeichnung eine „besonders sorgfältige Prüfung“ stattzufinden habe. Darüber hinaus fanden auch bei mehreren Richtern Hausdurchsuchungen statt, so z.B. neben Anton Rolleder ${ }^{218}$ auch bei Ernst Österreicher 1934, LG-Rat und NSDAP-Mitglied seit 1930, ${ }^{219}$ und Ludwig Koloseus, ${ }^{220}$ der seit September 1931 Parteigenosse und SA-Obertruppführer war. ${ }^{221}$

\subsection{Richterliche Unabhängigkeit und "Staatsnotstand"}

Gerechtfertigt wurden die Eingriffe der Regierung in die Verfassung und den Rechtsstaat mit der Rettung der Unabhängigkeit Österreichs bzw. der Abwehr des Nationalsozialismus, also letztlich dem Vorliegen eines Ausnahmezustandes bzw. Staatsnotstandes. So äußerte etwa Richard Schmitz im Parteivorstand nach der „Selbstausschaltung“ des Nationalrats: „Gott hat uns noch einmal eine Gelegenheit geschickt, das Land und die Partei zu retten [...] der Staatsnotstand ist zweifellos gegeben, der verfassungsmäßige Apparat ist durch seine eigene Schuld gehemmt. Die nationalsozialistische Bewegung ist mitten in der Partei und in der Katholischen Aktion. Wir können [...] nicht mehr sagen, wie die Partei denkt“ ${ }^{\prime 222}$ Für den katholischen Publizisten Alfred Missong war der Verfassungsbruch des März 1933 ein „Schönheitsfehler des neuen Regimes“, der allerdings „mit dem gewiß gegebenen Notstand kaum vollgültig zu rechtfertigen" war. ${ }^{223}$ Der katholische Publizist Ernst Karl Winter sprach in den „Wiener Politischen Blättern“ im August 1933 allerdings sehr deut-

\footnotetext{
${ }^{218}$ ÖStA, AdR, Justiz, BMJ, VP NA Rolleder, Anton.

219 STADLER, Verfahren 343.

${ }^{220}$ Ebd. 325f; ÖStA, AdR, Justiz, BMJ, VP Liqu Ludwig, Koloseus.

${ }^{221}$ Er gehörte seit 1942 dem Sondergericht Wien an und wurde nach 1945 als "Illegaler" eingestuft (1947 reaktiviert).

${ }^{222}$ Parteivorstand 7.3.1933, GoldingER, Protokolle 133

${ }^{223}$ MisSONG, Leben 31.
} 
lich davon, ${ }^{224}$ dass sich die Regierung mit der „Opposition nicht verständigen wollte" und sich daher "gezwungen [sah ...], die rechtlichen Grundlagen ihres Bestandes in sehr anfechtbarer Weise zu überspannen“, wodurch sie sich aber „des Rückhaltes der Legalität [beraubte]“. Dies habe in weiterer Folge zu der "nicht gerade ausdrücklichen, aber doch mehr minder konkludent-faktischen Proklamierung des Staatsnotrechtes, dem Handeln aus Staatsräson" geführt, „gleichgültig ob nun im einzelnen Falle im Rahmen oder außerhalb der gesetzlichen und verfassungsmäßigen Schranken“. Für Winter war allerdings ,jede Abweichung vom Wege der Legalität [...] unerträglich“, , wenn die Maßnahme nicht die Überzeugung ihrer absoluten Notwendigkeit erweckt“, und er fragte: „Mit welchem Rechte wehrt man dem Unrecht und der Gewalt, wenn man selbst das Recht und Rechtsbewußtstein kränkt? [...] Mit welchem Rechte proklamiert man das Notrecht des Staates, wenn man selbst nicht daran glaubt oder den Glauben daran nicht zu verbreiten versteht?" Und er folgerte: „Wenn sich eine Partei wirklich mit Bombenwerfern, Brandstiftern und sonstigen Verbrechern identifiziert, wenn sie wirklich hochverräterischer Umtriebe gegen den Bestand des Staates überwiesen ist und wenn diese Gruppe einen solchen Umfang annimmt, daß sie wirklich eine ernste Bedrohung der Ruhe und Ordnung im Staat darstellt; dann kann es doch nicht zweifelhaft sein, daß zur Abwehr dieser Gefahr alle [Hervorhebung im Original] ohne Unterschied der geistigen Weltauffassung zusammenwirken müssen“. Es dürfe aber „über einen Punkt [...] keine Meinungsverschiedenheit geben: über das Prinzip der Legalität“.

Dass der proklamierte Staatsnotstand in Wahrheit freilich nur ein Regierungsnotstand war, der sich mit - für die Christlichsozialen allerdings vernichtenden - Neuwahlen möglicher-

\footnotetext{
${ }^{224}$ WINTER, Demokratie 129f.
}

weise hätte beheben lassen, wurde durch geschickte Propaganda der Christlich-Sozialen überspielt. Für Vizekanzler Franz Winkler handelte es sich retrospektiv auch „keineswegs um Staatsnotstand, sondern nur um einen Notstand der am Ruder befindlichen Regierung ",225 die nach der Durchführung von Wahlen keine Mehrheit mehr erreichen hätte können. Dollfuß sprach dies im Mai 1933 noch klarer aus: „Wenn wir diesen Weg nicht benützt hätten, wären wir gefressen worden“.226 Die Maßnahmen der Regierung dienten daher nach Winkler nicht - wie von der Regierung behauptet - der Verteidigung der staatlichen Unabhängigkeit Österreichs gegen die "Staatsfeinde“, sondern es "galt vielmehr alles Tun und Lassen der Aufrichtung der austrofaschistischen Diktatur“.227 Daher erhielt auch die sozialdemokratische Führung, die bis zum Ausbruch des „offenen Bürgerkrieges“ auf einen Ausgleich im Verhandlungsweg hingearbeitet hatte und "wenn nicht eine gemeinsame Front, so doch wenigstens ein erträgliches Verhältnis zwischen den Christlichsozialen und den Sozialdemokraten" angestrebt hatte, $228 \mathrm{im}$ mer ",die gleiche Antwort": „für das, was ihr uns anbietet, ist es zu spät”. 229 Der Antimarxismus und die Durchsetzung eigener politischer Ziele hatten für die Regierung Dollfuß letztlich Vorrang vor einer gemeinsamen Bekämpfung des Nationalsozialismus.

Der "Staatsnotstand“, der im März 1933 proklamiert wurde, war also, wie es Gerhard Senft zusammenfasste, ,,in Wahrheit ein Notstand der an den Hebeln der Macht befindlichen Regierungsparteien", und „,jede der beteiligten Gruppen

\footnotetext{
225 WINKLER, Diktatur 61.

226 Parteivorstand 3.5.1933, GolDINGER, Protokolle 248.

227 WINKLER, Diktatur 89, 93.

${ }^{228}$ LEICHTER, Schwarzbuch 92.

${ }^{229}$ So erinnerte sich der ehemalige christlichsoziale Parteiobmann Emmerich Czermak, RP, Nr.97 v. 10. 4. 1934, 3.
} 
hatte triftige Gründe, das staatsstreichartige Manöver zu unterstützen“: „Der Christlichsoziale Dollfuß konnte sich im Parlament nur auf eine hauchdünne Mehrheit stützen, eine Mehrheit, die von der Seite der Heimwehrfraktion aber immer wieder gefährdet war. Der Ausweg, das Glück in Neuwahlen zu versuchen, war für die Christlichsozialen ebenso wie für den Landbund verunmöglicht, da die Befürchtung bestand, zur Bedeutungslosigkeit herabzusinken. Der Heimwehr, deren politische Stellung einen internen ,Alles-oder-Nichts'-Standpunkt erzeugte, half die relative außenpolitische Isolierung, in der sich Österreich befand. Mussolinis ,Hilfsbereitschaft' ermöglichte es der Heimwehr, ihr Gewicht in der politischen Waagschale zu erhöhen, so dass es ihr gelang, sich mit der autoritären Strategie in weiten Bereichen durchzusetzen. ${ }^{230}$ Die Anschläge der Nationalsozialisten im Juni 1933 verschärften in weiterer Folge die Situation, und BMJ Schuschnigg231 drohte im Juli 1933 ebenfalls unmissverständlich, vom Notstandszum Notwehrbegriff übergehend: „Wir wollen Ruhe und werden sie uns mit bedeutend weniger grausamen Methoden verschaffen, als dies anderwärts geschieht. Man soll uns aber nicht zum letzten zwingen, sonst müssten wir zur Notwehr greifen und auch in Österreich entsprechende Mittel anwenden, wie man sie anderswo schon länger anwendet."

Für den Fall von Bedrohungen des Staates, wie etwa durch eine Störung der öffentlichen Ordnung und Sicherheit, sahen und sehen Verfassungen immer wieder Regelungen für einen Ausnahmezustand im Sinne eines Staatsnotrechtes vor. ${ }^{232}$ Als derartiges (allgemeines) Staatsnotrecht definierte Gottfried Boldt 1937 „positiv rechtlich eingefangene, verfassungsmäßig festgelegte Einrichtungen, wie Kriegs- und Belage-

\footnotetext{
230 SENFT, Vorfeld 180.

${ }^{231}$ RP, Nr. 198 v. 19. 7. 1933, 2.

${ }^{232} \mathrm{Vgl}$. FOLZ, Staatsnotstand 33ff.
}

rungszustand, Notverordnungsrecht und Ermächtigungsgesetzgebung, als außerordentliche Mittel für die vorhergesehenen Fälle staatlicher Notbekämpfung“. ${ }^{233}$ Historisch gesehen hatte sich der Ausnahmezustand ${ }^{234}$ zunächst auf äuBere Gefahren beschränkt (Belagerungszustand, Kriegsrecht) und wurde erst in weiterer Folge auch auf innere politische Konfliktlagen und sogar wirtschaftliche Krisen ausgeweitet. Typischerweise können im Ausnahmezustand zeitweilig die Verfassung oder einzelne ihrer Bestimmungen außer Kraft gesetzt werden, wobei dann ein Kompetenzübergang v.a. von der Legislative auf die Exekutive stattfindet; weiters finden Einschränkungen von Grundrechten statt oder diese werden überhaupt vorübergehend außer Kraft gesetzt (etwa Pressefreiheit, Vereinsund Versammlungsfreiheit, Briefgeheimnis, Schutz des Hausrechts). Zentrales Merkmal eines Ausnahmezustandes ist somit eine vorübergehende Aufhebung der Gewaltenteilung zum Zweck einer Effizienzsteigerung der Regierungspraxis.

Ein derartiges Staatsnotrecht hatte in Österreich schon die Dezemberverfassung 1867 mit ihrem kaiserlichen Notverordnungsrecht (§ 14) sowie der Möglichkeit der Suspendierung der Grundrechte und Schwurgerichtsbarkeit normiert. In der Ersten Republik, in der die Suspendierung von Grundrechten nicht zulässig war, fungierte zunächst das KwEG als Staatsnotrecht. Ein darüber hinausgehendes offenbares Autoritätsbedürfnis der konservativen Parteien knüpfte allerdings schon früh an der „ohnmächtigen Position des Bundespräsidenten “235 nach der Bundesverfassung 1920 an. So verlangte der christlichsoziale Parteiobmann Ignaz Seipel anlässlich der Bundespräsidentenwahl 1928, „die Stellung des Bundespräsidenten in einigen wichtigen

\footnotetext{
${ }^{233}$ BOLDT, Staatsnotwehr 186.

${ }^{234}$ Vgl. BOLDT, Rechtsstaat; TROTTER, Ausnahmezustand.

${ }^{235}$ WITTMAYER, Verfassungsreform 451.
} 
Punkten abzuändern, wobei die deutsche Reichsverfassung als Vorbild dienen könnte". ${ }^{236}$ Auch der Landbund forderte im August 1929237 ein Staatsoberhaupt ähnlich dem im Deutschen Reich, das „unabhängig von den Parteien, unabhängig von jedermann, gewählt in freier Volksabstimmung" das Recht haben sollte, „die Staatsmaschine in Ordnung $\mathrm{zu}$ halten, auch dann, wenn das Parlament versage“. Dieses Ansinnen wurde zwar von den Christlichsozialen unterstützt, von den Sozialdemokraten, die für die erforderliche Zweidrittelmehrheit gebraucht wurden, aber abgelehnt:238 „Im bürgerlichen Lager spukt der Gedanke, dem Bundespräsidenten ein Notverordnungsrecht zu geben, damit er dekretiere, wenn das Parlament eine Aufgabe nicht zu bewältigen vermag; aber eine solche Rückkehr zur §-14-Schande wäre eine durch und durch undemokratische Lösung. Nicht ein einzelner Mensch, sondern das Volk in seiner Gesamtheit soll zur letzten Entscheidung berufen sein, wenn ein Gesetz von größerer Bedeutung im Parlament Gegenstand heftiger Kämpfe ist." Die Sozialdemokraten würden ihre „ganze Kraft jedem Versuch entgegenwerfen, die Verfassung rechtswidrig, durch einen Putsch von unten oder einen Staatsstreich von oben, zu ändern", und sich, „wenn man die Verfassung der Republik, der wir Treue gelobt haben, gewaltsam umstürzen will, mit aller unserer Kraft um die Verfassung scharen."

In seiner Regierungserklärung sprach sich auch Bundeskanzler Johann Schober Ende September 1929 dafür aus, dass die Befugnisse des Bundespräsidenten erweitert werden müssten, insbesondere auf Ernennung und Abberufung der Regierung, Auflösung des Nationalrates sowie auf ein Notverordnungsrecht, und postulierte: „Die Vorkommnisse der letzten Jahre haben er-

\footnotetext{
236 SEIPEL, Kampf 121.

${ }^{237}$ ULM, Verfassungsreform 106.

${ }^{238}$ AZ, Nr. 255 v. 15. 9. 1929, 2.
}

wiesen, daß die Staatsgewalt die Möglichkeit haben muß, bei erheblichen Unruhen einen ,Ausnahmezustand' zu verhängen“. ${ }^{239}$ Die B-VGNovelle 1929, „ein Kind ihrer Tage“, brachte dann schließlich, dem NS-Staatsrechtler Norbert Gürke zufolge, eine Angleichung der Kompetenzen des Bundespräsidenten , an die des deutschen Reichspräsidenten", insbesondere durch Einräumung einer „Ausnahmegesetzgebung im Verordnungswege“. ${ }^{240}$ Dieses 1929 eingeführte Notverordnungsrecht des Bundespräsidenten war allerdings aufgrund seiner „Konstruktion gerade im Notstand nicht handhabbar", weil diese Befugnis mit so vielen Beschränkungen versehen ist, „daß ihre Praktikabilität im Ernstfalls fraglich“ erschien. „Raschheit, Einfachheit, Zweckmäßigkeit fanden keinen normativen Ausdruck, obwohl gerade im Notfall die Zeitfrage im Vordergrund steht". ${ }^{241}$ Gerade die Ereignisse 1933 zeigten, dass das für parlamentarische Krisensituationen gedachte Instrument der Notverordnung einfach dann nicht zum Zug kam, wenn die Bundesregierung den notwendigen Antrag nicht stellte, weil sie den Nationalrat nicht handlungsfähig machen wollte und der Bundespräsident - aus welchen Gründen auch immer - in der Art einer "Selbstausschaltung des Bundespräsidenten" die Regierung eben nicht entließ. ${ }^{242}$

Im August 1933 sprach sich dann Ernst Karl Winter $^{243}$ für die Möglichkeit einer (auf zwei Jahre) „befristeten Legaldiktatur" durch den Bundespräsidenten als „Kompromiß zwischen Diktatur und Parlamentarismus" in Form einer „parlamentarische Ermächtigung zu einer kontrollierten Diktatur" aus. Für die konkrete Situation bedeute dies einen „Kompromiß zwischen

\footnotetext{
${ }^{239}$ BERCHTOLD, Verfassungsreform, Nr. 39, 119; UlM, Verfassungsreform 146.

${ }^{240}$ GÜRKE, Verfassungsreform 403.

${ }^{241}$ WELAN Bundespräsident 70.

242 Ebd.

${ }^{243}$ WINTER, Demokratie 136.
} 
der geltenden Bundesverfassung und der tatsächlichen Machtausübung durch die Bundesregierung", um „künftig die Maschen des Netzes der Legalität enger [...] zu wirken“. Im Herbst 1933 übermittelte Karl Renner einen Rohentwurf für eine "Notstands-Verfassungsnovelle" in Form einer Privatarbeit an die Präsidentschaftskanzlei, die zwar noch nicht mit den Parteigenossen besprochen sei, sich aber in Richtung dessen bewege, „was bei unseren Leuten so ziemlich feststeht". ${ }^{244}$ Dieses Staatsnotstandsgesetz sollte an die Stelle des KwEG treten und sah Regelungen für die Erklärung des Staatsnotstandes vor. In dieser Zeit sollte ein aus den Präsidenten des Nationalrates und weiteren 22 von Nationalrat und Bundesrat zu bestellenden Mitgliedern bestehender Staatsrat die Aufgaben der gesetzgebenden Körperschaft ausüben. ${ }^{245}$

Über diese Konzepte hinaus ist jedoch eine grundsätzliche intensive Auseinandersetzung mit dem Phänomen des Ausnahmezustandes bzw. eines durch einen Staatsnotstand bedingten überpositiven Notstandsrechtes in Österreich in 1920er und 1930er Jahren im Unterschied zu Deutschland nicht feststellbar.

In Deutschland waren bereits unmittelbar nach Gründung der Weimarer Republik drei von der Nationalversammlung und fünf vom Reichstag beschlossene Ermächtigungsgesetze ergangen, mit denen der Reichspräsident ermächtigt wurde, gesetzesvertretende Verordnungen zu erlassen. Die Weimarer Reichsverfassung (WRV) hatte schließlich dem Reichspräsidenten, insbesondere in Art. 48, eine Fülle von Kompetenzen gegeben, die durch ihre Kombinationsmöglichkeiten eine Gefahr für die parlamentarische Demokratie bedeuteten (und schließlich auch zu ihrer Zerstörung führen sollten). Er hatte das

\footnotetext{
${ }^{244}$ Brief Renners an den Kabinettsdirektor der Präsidentschaftskanzlei Josef Löwenthal, zit.n. ZAVADIL, Ausschaltung 156.

${ }^{245} \mathrm{Ebd}$.
}

Recht, Maßnahmen gegen die Länder des Reichs (Reichsexekution) zu setzen, Grundrechte zu suspendieren und außerdem weitere Kompetenzen für den Ausnahmezustand. Die Verfassung sah zwar für die Konkretisierung der Ausnahmebefugnisse die Erlassung eines Ausführungsgesetzes vor, da dieses aber nie erging, blieben die Befugnisse des Reichspräsidenten weit und unbestimmt. Die „staatsrechtliche Begleitmusik zur Handhabung des verfassungsrechtlich zumindest fragmentarisch geregelten Ausnahmezustandes des Art. 48 WRV durch den Reichspräsidenten“246 war dementsprechend vielfältig. Art. 48 mag zwar nicht als „Reserveverfassung“ für den Ausnahmefalle intendiert gewesen sein, die Staatsrechtslehre machte ihn jedoch dazu.

Eine erste monographische theoretische Auseinandersetzung mit dem Thema des Ausnahmezustandes wurde bereits in den 1920er Jahren von Carl Schmitt vorgelegt (insbes. „Die Diktatur" 1921). ${ }^{247}$ Er unterschied zwei wesentliche Ausprägungen der Diktatur: die „kommissarische“ bzw. verfassungsmäßige und die "souveräne" bzw. nichtverfassungsmäßige Diktatur. Während bei der typisch rechtsstaatlichen Regelung der kommissarischen Diktatur, wie im Fall von Art. 48 WRV, der Diktator zwar von rechtlichen Schranken befreit, aber an den Diktaturzweck gebunden erschien, nämlich die geltende Verfassung zu verteidigen oder wiederherzustellen bzw. ihren Bestand zu schützen, äußerte sich Schmitt zufolge die souveräne Diktatur hingegen darin, dass der Diktator nicht an die suspendierte Verfassung gebunden ist, sondern eine neue Ordnung etablieren will. „Souverän ist, wer über den Ausnahmezustand entschei$\operatorname{det}^{\prime \prime}, 248$ lautete Schmitts These, und der von Schmitt propagierte "Führerstaat" war dann auch „von Anfang bis Ende Herrschaft durch

\footnotetext{
${ }^{246}$ GROH, Staatsrechtslehrer 535.

${ }^{247}$ Ausführlich NeUMANN, Schmitt 30ff.

248 SCHMITT, Politische Theologie 1922.
} 
Ausnahmegesetzgebung [...], die sich an keine Verfassungseinschränkungen hielt “. ${ }^{249}$ Zahlreiche weitere Publikationen verschiedener Staatsrechtler folgten, die Schmitt entweder weitgehend folgten oder im Unterschied $\mathrm{zu}$ ihm ein überpositives Staatsnotstandsrecht ablehnten.

Die positivistischen Staatsrechtslehrer hielten nämlich „unisono an der Legalität und Normativität der parlamentarischen Reichsverfassung als gültiger Norm auch für den Not- und Ausnahmezustand" fest. Sie beharrten auf der Erfüllung der Verfassung und verfochten den „Vorrang des demokratischen Geistes des Verfassungsrechts vor Staatsnotwendigkeiten".250 So meinte Richard Thoma 1930 explizit, dass es „ein Staatsnotrecht über das verfassungsrechtlich regulierte hinaus im geordneten republikanischen Verfassungsstaat nicht geben " könne, ${ }^{251}$ und trat für präventive Verfassungsregeln für den Notstand ein. Staatliches Handeln, „,das sich nur auf einen Notstand stützen könnte, sei rechtsverletzend“, es könne daher kein Staatsnotrecht geben, und was ,jenseits dieser Normierungen geschähe, wäre Staatsunrecht ${ }^{\prime \prime}{ }^{252}$ Gerhard Anschütz beschwor "den ,Geist” der parlamentarisch-demokratischen Verfassung gegenüber der Staatsraison“. Es kam allerdings nicht zu einer „Parlamentarisierung des Ausnahmezustandes“, sondern vielmehr zur „Entparlamentarisierung der Reichsgesetzgebung" und zur permanenten „Diktatur“ des Reichspräsidenten. ${ }^{253} \mathrm{Da}$ "konsequentes rechtsstaatliches Denken das Bestehen eines derartigen Notrechtes leugnen" muss, ja Staatsnotrecht und Rechtsstaatsprinzips in einem Widerspruch stehen,254

\footnotetext{
249 BRACHER, Diktatur 232.

250 Siehe dazu GROH, Staatsrechtslehrer 534f.

251 THOMA, Handbuch 231f.

252 Zit.n. WOLTER, Staatsnotrecht 43.

${ }^{253}$ GROH, Staatsrechtslehrer 545.

${ }^{254}$ Vgl. SIEGERS, Staatsnotrecht 89.
}

erschien folglich dem „liberalen Rechtsstaat jeder Fall der Staatsnot als Rechtsnotstand“. ${ }^{255}$

An diesem Diktaturdiskurs nahm auch der "Architekt $^{\prime 256}$ der österreichischen Bundesverfassung von 1920, Hans Kelsen, teil. Er verwarf das überpositive "Staatsnotrecht", das „etwa in der Weise [argumentiert]: der Staat muß eben leben, und wenn dies auf rechtmäßigem Wege unmöglich ist, sind die höchsten Organe des Staates [...] verpflichtet alles $\mathrm{zu}$ tun, um den Staat zu erhalten“. Für ihn handelte es sich dabei „natürlich nur um ein politisch-naturrechtliches Räsonnement, das sich - wie gewöhnlich - als positives Recht zu geben versucht". Hinter der "treuherzigen Versicherung, dass der Staat ,leben' müsse, verbirgt sich meist nur der rücksichtslose Wille, daß der Staat so leben müsse, wie es diejenigen für richtig halten, die sich der Rechtfertigung eines ,Staatsnotrechtes' bedienen. “257 Von diesem "Staatsnotrecht" zu unterscheiden sei freilich die in manche Verfassungen aufgenommene Möglichkeit, den „Belagerungs- oder Ausnahmezustand“ zu verhängen. Jedenfalls müsse der Staat, da er im Sinne der Kelsenschen Identitätstheorie eine Rechtsordnung ist, auch unter den Umständen des Ausnahmezustands eine Rechtsordnung bleiben und sei weiterhin an die Prinzipien der Rechtsordnung und damit an das Rechtsstaatsprinzip gebunden. ${ }^{258}$

Gerade dem Rechtspositivismus wird freilich manchmal vorgeworfen, durch die Kelsensche Alternativermächtigungstheorie eine Rechtfertigung für den Verfassungsbruch der Regierung zur Verfügung gestellt zu haben. Das Recht selbst stelle nämlich den staatlichen Organen, die es formal zur Setzung von Normen ermächtigt, die Entscheidung frei, "ob sie sich in ihrer normsetzenden Tätigkeit inhaltlich rechts-

\footnotetext{
255 BOLDT, Staatsnotwehr 187.

${ }^{256}$ OLECHOWSKI, Beitrag 228.

${ }^{257}$ KELSEN, Staatslehre 157.

${ }^{258}$ ZWITTER, Gedanken 156.
} 
konform verhalten wollen oder nicht", womit die „inhaltliche Rechtskonformität scheinbar keine notwendige Bedingung der gültigen Ausübung von Staatsgewalt mehr" mehr ist, bzw. „es ist nicht einmal mehr klar" ist, „ob die Organe des Staates wenigstens der Pflicht unterliegen, in ihren Akten eine möglichst vollständige inhaltliche Rechtskonformität anzustreben. ${ }^{259} \mathrm{In}$ dieser Argumentation könnte freilich die Position eines Putschisten durch die Alternativermächtigungstheorie insofern gestärkt werden, als sie ihm "einen Persilschein in die Hand" gebe, „fordert die Kelsensche Grundnorm doch, daß man auch dem Usurpator gehorcht". Damit vermöge die Reine Rechtslehre nicht einmal mehr "die scheinbar offenkundigen Unterschiede zwischen Staatsstreich und verfassungsmäBiger Änderung der Rechtsordnung zumindest in begrifflicher Weise aufrecht zu erhalten." ${ }^{260}$ Allerdings ist die Anwendung der Alternativermächtigungstheorie Kelsen zufolge doch nur auf Rechtsordnungen (oder solche Teile von Rechtsordnungen) beschränkt, „die Garantien der Legalität bereitstellen“, findet doch ein Staat, „der die Autorität in Anspruch nimmt, sich nach eigenem Gutdünken über das Recht hinwegzusetzen, [...] in der Theorie der autorisierenden Norm als Alternativbestimmung keinerlei ideologischen Rückhalt “. ${ }^{261}$

Stellt man die Frage nach der Rechtfertigung dieser massiven Eingriffe freilich nicht aus zeitgenössischer Sicht, sondern aus aktueller Perspektive, so ist auch heute nicht ausgeschlossen, dass ein Staat in staats- oder verfassungsgefährdende Situationen geraten kann, „die mit den Bindungen der Verfassung nicht - oder zumindest nicht in der gebotenen Eile - zu bewältigen sind (Staatsnotstand)“. Regelungen für einen derartigen Notstand (Notstandsrecht oder

\footnotetext{
${ }^{259}$ VINX, Indentitätsthese 63.

${ }^{260}$ GRAF, Rechtslehre 65.

${ }^{261}$ VINX, Indentitätsthese 67.
}

Staatsnotstandsrecht) müssen daher die Effektivität der staatlichen Maßnahmen sicherstellen, aber auch gegen deren Missbrauch schützen. ${ }^{262}$ Notstandsrecht wird heute definiert als "das Recht des Staates, besonders seiner obersten Vollzugsorgane, in äußersten Notfällen, in denen das Bestehen oder die Sicherheit des Staates in dringender Gefahr sind (Staatsnotstand), zur Bekämpfung der Notlage auch ohne gesetzliche Ermächtigung (u.U. entgegen der Rechtsordnung) die notwendigen Maßnahmen zu treffen und hierzu besonders in Freiheit und Eigentum, aber auch in sonstige Grundrechte des Einzelnen einzugreifen“. Es "darf nicht zum Umsturz des Staates oder der Verfassung angewandt werden“. ${ }^{263}$ So bewahrt etwa die "streitbare" 264 bzw. "wehrhafte" Demokratie, 265 wie sie in der BRD in der im Zuge des "Deutschen Herbstes“ 1968 eingeführten Notstandsverfassung definiert wurde, die BürgerInnen „vor dem politischen Selbstmord" und verwehrt ihnen die "Freiheit zur Beseitigung der Freiheit". ${ }^{266}$ Dies kommt im Bonner Grundgesetz in der sogenannte Ewigkeitsklausel zum Ausdruck, welche die „elementarsten Grundsätze der Verfassung“ schützt, ${ }^{267}$ und zwar mit den Mitteln des Parteienverbots, der Verwirkung von Grundrechten, wenn diese zum Kampf gegen die freiheitlichdemokratische Grundordnung missbraucht werden, und der Staatsschutzdelikte. Zu diesen geschützten Grundsätzen, die sich weitgehend mit dem Begriff der "freiheitlichen demokratischen Grundordnung" decken, gehört das Rechtsstaatsprinzip und damit auch die Unab-

\footnotetext{
${ }^{262}$ JAKAB, Grunddilemma 323f.

${ }^{263}$ Wo eine „Verfassung für solche Notfälle einen Ausnahmezustand (Belagerungs-, Kriegszustand) vorsieht", wie etwa aktuell in Deutschland (Notstandsverfassung), „ist für das Staatsnotrecht kein Raum mehr", vgl. DUDEN, Recht.

${ }^{264}$ LAMEYER, Demokratie.

${ }^{265} \mathrm{Vgl}$. THIEL, Demokratie.

266 STOHLMANN, Begriffe 12.

${ }^{267}$ BACKHAUS, Richter 88.
} 
hängigkeit der Gerichte. Eingriffe in die Judikative sind daher nicht erlaubt, ein Fehlverhalten von Richtern ist allein mit dem Disziplinarrecht zu ahnden.

Die Verordnungen des Dollfuß-Schuschnigg-Regimes richteten sich freilich nicht nur gegen diejenige Opposition, die das Ende der Unabhängigkeit Österreichs und den totalitären Staat wollte, sondern auch gegen die Sozialdemokraten, die nach der "Machtergreifung“ der Nationalsozialisten im Deutschen Reich die "Anschluss"-Idee auf Eis gelegt hatten und die parlamentarische Republik verteidigten. Die von Sozialdemokraten und Nationalsozialisten verlangten Wahlen hätten zweifellos zu erheblichen Mandatsgewinnen der Nationalsozialisten geführt, wobei dieser Krise - wenn überhaupt nur mit einer parlamentarisch-demokratischen Lösung beigekommen hätte werden können, nicht aber mit einer "fortschreitenden Aufzehrung der Verfassungssubstanz". ${ }^{268}$ Dies hätte aber sowohl dem Mussolini-Kurs einer rigiden Verfolgung der Sozialdemokratie als auch Dollfuß' radikalem Antimarxismus widersprochen. „Keine Freiheit für die Feinde der Freiheit“269 galt also in dieser Zeit des behaupteten Staatsnotstandes eben nicht nur für die Feinde der Freiheit und Demokratie, sondern auch für die Feinde der faschistischen bzw. autoritären Bestrebungen Mussolinis und Dollfuß’. Im „Notstand" wurde der Rechtsstaat preisgegeben, nicht zuletzt durch die undifferenzierte Aufgabe der Unabsetzbarkeit- und Unversetzbarkeit der Richter. Wiewohl die konkreten Maßnahmen gegen einzelne Richter - soweit bisher festgestellt durchwegs Nationalsozialisten oder NS-Sympathisanten trafen, mussten sie dadurch, dass sie nicht auch normativ nur auf diese als Feinde der Freiheit beschränkt waren, auf Ablehnung seitens der Sozialdemokraten stoßen, die sich wie-

268 Vgl. BLOMEYER, Notstand 451.

${ }^{269}$ Vgl. DenNinger, Grundordnung 33. derum so mit ihrer Kritik am ausnahmerechtlichen Regime weitgehend im Einklang mit den Nationalsozialisten befanden. Dass richterliche Kritik an der mangelnden Verfassungsdeckung des Notstandsregimes zur Ab- oder Versetzung führen konnte, festigte wohl auch die durch Carl von Schmitt und weiteren Vertreter der Weimarer Staatslehre ohnedies geschlagene Schneise für überpositives, naturrechtliches Denken, wie es auch der NS-Rechtslehre immanent war.

Die vielfältigen Unterminierungen des Rechtsstaats in Österreich vor dem "Anschluss“ mündeten schließlich in den Nationalsozialismus, der die „Unabhängigkeit" der Richter dann überhaupt aus der liberal-rechtsstaatlichen Tradition löste und neu definierte.

\section{Richterliche Unabhängigkeit im Nationalsozialismus und "Anschluss" 1938}

Schon 1932 hatte Robert Kempner ${ }^{270}$ unter dem bezeichnenden Titel „Justizdämmerung“ vor der "Zertrümmerung der deutschen Justiz" gewarnt und prophezeit, dass ",im faschistischen Staatswesen begrifflich eine unabhängige Justiz nicht denkbar" sei und die Nationalsozialisten „in einer unabhängigen deutschen Justiz eine Gefahr für ihre Machtpläne“ sähen.271 Die „Machtergreifung" der Nationalsozialisten in Deutschland 1933 wurde daher seitens der Richterschaft auch mit einer "gewissen Besorgnis" gesehen, fürchtete man doch, es könnten „Maßnahmen

\footnotetext{
${ }^{270} \mathrm{Da}$ er damals Oberregierungsrat im preußischen Innenministerium war, verfasste er diese Schrift unter dem Pseudonym „Eike von Repkow“. Er wurde im Jänner 1933 aus politischen und rassistischen Gründen entlassen und floh aus Deutschland. Nach Ende der NS-Herrschaft fungierte er als stellvertretender Hauptankläger der Vereinigten Staaten beim Nürnberger Prozess gegen die Hauptkriegsverbrecher.

${ }^{271}$ Zit.n. WROBEL, Richterbund 326.
} 
ergriffen werden, die die Unabsetzbarkeit der Richter und die Unabhängigkeit der Justiz in Frage stellten“, 272 bzw. dass "die unaufhaltsame revolutionäre Sturmflut zusammen mit den sonstigen Einrichtungen des liberalen Rechtsstaates auch dieses Bollwerk der bisherigen Verfassung zum Einsturz bringen und hinwegschwemmen" würde. ${ }^{273}$

„Reichsjuristenführer“ Hans Frank versicherte allerdings den Richtern immer wieder, dass die "Gleichschaltung" sich nicht auf die Unabhängigkeit der Richter erstrecken, sondern vielmehr die "nationale Regierung" mit ",aller Kraft an der Unabhängigkeit des Richtertums festhalten“" werde. Allerdings dürfe sich diese niemals mehr "gegen die letzten Werte des Deutschtums auswirken". ${ }^{274}$ Dementsprechend wurde die Unabhängigkeit der Richter formell nach der „Machtergreifung" nicht beseitigt, die $\S \S 1$ und 8 des Gerichtsverfassungsgesetzes ${ }^{275}$ blieben in Geltung. "Die richterliche Gewalt" wurde daher gem. §1 weiterhin „durch unabhängige, nur dem Gesetz unterworfene Gerichte ausgeübt", und kein Richter konnte wegen einer Entscheidung mittels Verwaltungsakt aus dem Amt entfernt werden $(\S 8) .276$

Wiewohl im positiven Recht also noch die Gesetzesbindung festgeschrieben war, wurden in der NS-Ideologie freilich Volkswille und Führerwille als identisch erachtet, womit die Unterscheidung zwischen Gesetz, Verordnung und

${ }^{272}$ Karl Linz, Zeitspiegel, DRiZ 1933, 121, zit.n. WROBEL, Richterbund 326.

${ }^{273}$ HENKEL, Unabhängigkeit 7.

${ }^{274}$ So am 21. 5. 1933 vor dem Verein Sächsischer Richter und Staatsanwälte in Chemnitz, FRANK, Richter 162; siehe allgemein SIMON, NS-Richter 102ff.

275 RGBl. 1877, S. 74.

$276 \S 8$. (1) Richter können wider ihren Willen nur kraft richterlicher Entscheidung und nur aus den Gründen und unter den Formen, welche die Gesetze bestimmen, dauernd oder zeitweise ihres Amts enthoben oder an eine andere Stelle oder in Ruhestand versetzt werden.
Führerbefehl zur Bedeutungslosigkeit verkam: "Gesetz ist was der Führer befiehlt", so brachte es Friedrich Schaffstein 1934 auf den Punkt. ${ }^{277}$ Überdies stand den Richtern seit 1935 mit dem Gesetz zur Änderung des Strafgesetzbuches und dem Gesetz zur Änderung von Vorschriften des Strafverfahrens und des Gerichtsverfassungsgesetzes, beide vom 28. Juni 1935, 278 die Möglichkeit offen, nicht nur für eine Tat, „, die das Gesetz für strafbar erklärt", sondern auch für eine solche eine Strafe zu verhängen, die nach dem „Grundgedanken eines Strafgesetzes und nach gesundem Volksempfinden Bestrafung verdient". Dies bedeutete das Ende des Analogieverbots und des Legalitätsprinzips, ${ }^{279}$ anstelle des Grundsatzes der Bindung an das Gesetz galt hinfort der einer Bindung an die NS-Ideologie. Davor waren bereits im Zuge des Reichstagsbrands im Februar 1933 die Grundrechte suspendiert und die polizeiliche Praxis der Schutzhaft aufgenommen sowie das nulla poena sine lege-Prinzip durch die rückwirkende Einführung der Todesstrafe für bestimmte Delikte aufgeben worden.

Hinsichtlich der Unabhängigkeit der Richterschaft stellte Hitler in seiner Regierungserklärung vor dem Reichstag am 23. März 1933 klar, dass das „Rechtswesen in erster Linie der Erhaltung der Volksgemeinschaft dienen" und daher der „Unabsetzbarkeit des Richters [...] eine Elastizität der Urteilsfindung zum Zweck der Erhaltung der Gesellschaft entsprechen müsse“.280 Am 7. April versicherte er beim Empfang einer Delegation des "Deutschen Richterbundes", dass „er die Unabhängigkeit der Richter aufrecht erhalten werde“, wenngleich "auch gewisse Maßnahmen notwendig seien ", ${ }^{281}$ also in concreto die "Säuberung" der Justiz von ,jüdi-

\footnotetext{
277 SCHAFFSTEIN, Strafrechtswissenschaft 24.

${ }^{278}$ RGBl. 1935 I, S. 839 und S. 844ff.

279 RÜPING, Nullum crimen.

280 Zit.n. ebd. 131.

${ }^{281}$ Zit.n. ebd. 131f.
} 
schen" und politisch "unzuverlässigen" Richtern und Staatsanwälten. Diese hatte bereits im März seitens der Landesjustizverwaltungen begonnen und erfolgte schließlich auf der Grundlage des Gesetzes zur „Wiederherstellung des Berufsbeamtentums" vom 7. April 1933. Wenngleich Hans Frank Anfang Juni 1933 in Aussicht stellte, dass „[n]ach der Säuberung [...] die Freiheit des Rechtsberufs, besonders die Unabhängigkeit des deutschen Richters, sichergestellt" würde, ${ }^{282}$ so galt dieses Gesetz letztlich unbefristet, womit auch die persönliche Unabhängigkeit des Richters aufgehoben blieb. ${ }^{283}$

Richter hatten als Beamte nach dem Gesetz zur "Wiederherstellung des Berufsbeamtentums" "jederzeit rückhaltlos für den nationalen Staat" einzutreten ${ }^{284}$ bzw. nach dem Beamtengesetz 1937 sogar „Vollstrecker des Willens des von der Nationalsozialistischen Arbeiterpartei getragenen Staates" zu sein. ${ }^{285}$ Das RJM wollte aber gleichzeitig die Unabhängigkeit der Richter im Beamtengesetz 1937 absichern. So gab das Beamtengesetz 1937 dem „Führer und Reichskanzler" zwar das Recht, Beamte in den Ruhestand zu versetzen, wenn sie „nicht mehr die Gewähr" boten, ,jederzeit für den nationalsozialistischen Staat" einzutreten, die Zwangspensionierung durfte jedoch nur durch das RJM nach einem detailliert geregelten Verfahren erfolgen, um den Beamten vor unbegründeten Anschuldigungen zu schützen. Außerdem durfte sie im Sinne der "sachlichen Unabhängigkeit" ${ }^{\prime 286}$ ausdrücklich nicht „auf den sachlichen Inhalt einer in Ausübung der richterlichen Tätigkeit getroffenen Entscheidung gestützt werden“.

Diese Regelungen waren Hitler allerdings zu wenig weitreichend, und Hans Frank stellte be-

\footnotetext{
282 Zit.n. WROBEL, Richterbund 340.

${ }^{283}$ GRUCHMANN, Justiz 124ff.

${ }^{284}$ RGBl. 1933 I, S. 175.

${ }^{285}$ RGBl. 1937 I, S. 39.

${ }^{286} \mathrm{Vgl}$. STEINLECHNER, Richter 50.
}

reits im Juni 1938 klar, dass der „Führer und Reichskanzler [...] oberster Gerichtsherr der Nation“ sei, und es daher „im Staatsrechtsraum des Dritten Reiches keine von diesem elementaren Führerwillen unabhängige Position“ geben könne. ${ }^{287}$ Hitler hielt es in weiterer Folge auch für notwendig, die $\mathrm{Ab}$ - und Versetzungsmöglichkeiten betreffend die Richter deutlich zu erweitern. ${ }^{288}$ Die Reichskanzlei verkündete so im Juli 1938 Hitlers Auffassung, ${ }^{289}$ dass eine Zwangspensionierung eines Richters nicht nur dann stattfinden könne, wenn er "die nationalsozialistische Weltanschauung bewußt ablehnt", sondern auch dann, wenn er "durch die Art seiner Amtstätigkeit, im besonderen durch die von ihm getroffenen Entscheidungen, oder durch seine dienstliche oder außerdienstliche Führung erkennen" lasse, dass er dieser Weltanschauung "gefühls- oder verstandesmäßig fremd gegenübersteht". Das Gebot der sachlichen Unabhängigkeit des Beamtengesetzes schließe nicht aus, dass "auch eine gerichtliche Entscheidung zum Anlaß genommen" werde, einen Richter in den Ruhestand zu versetzen, „da unsachliche und verletzende Ausdrücke in den Entscheidungsgründen" dadurch nicht gedeckt seien. - Die Unversetzbarkeit eines Richters durch die Verwaltung fiel hingegen erst mit den Verwaltungsvereinfachungsmaßnahmen im Krieg, als Richter nun - unter Beibehaltung ihrer Planstelle beim bisherigen Gericht - „abgeordnet“ werden konnten. 290

Entsprechend diesem NS-Richterbild ${ }^{291}$ stellte etwa auch Wilhelm Stuckart, Staatssekretär im RIM, 1939 fest, ${ }^{292}$ dass der Richter in der Rechts-

\footnotetext{
${ }^{287}$ Rede Hans Franks vor der Akademie für Deutsches Recht 18. 6. 1938, zit.n. SCHMID, Erinnerung 264.

${ }^{288}$ GRUCHMANN, Justiz 197.

${ }^{289}$ Rundschreiben der Reichskanzlei 12. 7. 1938, zit.n.

GRUCHMANN, Justiz 199f.

${ }^{290}$ GRUCHMANN, Justiz 202.

${ }^{291}$ ReITER-ZATLOUKAL, Richterbild.

292 STUCKART, Geleit IV.
} 
findung zwar "naturgemäß frei von Weisungen“ sei, „es besteht aber seine Verantwortlichkeit gegenüber dem Führer". Von der Unabhängigkeit „in dem alten liberalen Sinn“ könne „nicht mehr gesprochen werden“, denn der "Führer" selbst "gewährleistet die Sicherung der Rechtsfindung gegen wesensfremde Einflüsse“. Da „er dem Richter den Auftrag erteilt, muß er ihn auch zur Verantwortung ziehen können“. Aus der richterlichen Unabhängigkeit "liberaler Prägung“ werde „so höchste nationalsozialistische Verantwortung des Richters vor Volk, Führer und Reich".

Auch verstummte weiterhin die Kritik an der Justiz trotz personellen „Säuberungen“, v.a. von Seiten der SS, nicht, und immer wieder wurden, insbesondere nach Kriegsbeginn, richterliche Entscheidungen und die nationalsozialistische Gesinnung der Richter in Frage gestellt. ${ }^{293}$ Joseph Göbbels notierte im März 1942 in sein Tagebuch: „Bis jetzt ist ein Richter selbst dem Führer gegenüber unabsetzbar". ${ }^{294}$

Aus Anlass eines „,volksfremden“ Urteils ${ }^{295}$ übte dann Hitler in seiner Rede in der (letzten) Sitzung des Großdeutschen Reichstags am 26. April 1942 Kritik an der Justiz, die verstehen müsse, „daß nicht die Nation ihretwegen, sondern daß sie der Nation wegen da ist $[\ldots]$, daß Deutschland leben muß, ganz gleich wie immer auch formale Auffassungen der Justiz dem widersprechen mögen." Er werde „von jetzt ab in diesen Fällen eingreifen und Richter, die ersichtlich das Gebot der Stunde nicht erkennen, ihres

\footnotetext{
293 ANGERMUND, Richterschaft 246.

${ }^{294}$ GRUCHMANN, Generalangriff 513.

${ }^{295}$ Hitler nahm das aus seiner Sicht zu milde Straferkenntnis im Fall „Schlitt“ (Tötung einer Frau durch ihren Ehemann) zum Anlass für die geplante Aktion gegen die Justiz. Er erklärte dem RJM, er „werde die gesamte Justiz zum Teufel jagen, wenn dieses Urteil nicht umgehend revidiert wird! Umgehend!" - was auch innerhalb von zehn Tagen geschah, zit.n. BRUPPACHER, Hitler 339; vgl. ausführlich SCHÄDLER, Justizkrise 22.
}

Amtes entheben.“296 $\mathrm{Zu}$ diesem Zweck ließ er sich vom Reichstag bevollmächtigen, missliebige Richter aus ihren Ämtern zu entfernen bzw. (in Hitlers Worten) „Juristen, die Schädlinge seien, am Schlaffitchen zu kriegen“, denn bisher hätten „sich solche Gesellen ja nur vor ihren Disziplinargerichten verantworten brauchen, bei denen der alte Grundsatz gegolten habe, eine Krähe hacke der anderen kein Auge aus". ${ }^{297}$ Damit war die Unabsetzbarkeit der Richter und damit ihre Unabhängigkeit auch in formeller Hinsicht beendet. ${ }^{298}$

Von einem "Generalangriff gegen die Justiz" bzw. von ihrem „Totenschein“ ${ }^{\prime 299}$ zu sprechen, ist Lothar Gruchmann ${ }^{300}$ zufolge allerdings irreführend, denn dieser Reichstagsbeschluss richtete sich einerseits keineswegs nur gegen die Justiz, sondern gegen ,jeden Deutschen“ in staatlicher bzw. parteilicher Funktion, und stellte andererseits auch inhaltlich keinen Wendepunkt für die deutsche Justiz dar, war doch die Aufforderung an die Justiz, das Recht im Sinne der NS-Ideologie zu beugen, keineswegs eine Novität. Was die Umsetzung des Reichstagsbeschlusses in der

${ }^{296}$ Zit.n. SCHÄDLER, Justizkrise 14.

${ }^{297}$ PICKER, Tischgespräche 451.

298 „Es kann keinem Zweifel unterliegen, daß der Führer in der gegenwärtigen Zeit des Krieges, in der das deutsche Volk in einem Kampf um Sein oder Nichtsein steht, das von ihm in Anspruch genommene Recht besitzen muß, alles zu tun, was zur Erringung des Sieges dient oder dazu beiträgt. Der Führer muß daher - ohne an bestehende Rechtsvorschriften gebunden zu sein - in seiner Eigenschaft als Führer der Nation, als Oberster Befehlshaber der Wehrmacht, als Regierungschef und oberster Inhaber der vollziehenden Gewalt, als oberster Gerichtsherr und als Führer der Partei jederzeit in der Lage sein, nötigenfalls jeden Deutschen [...] zur Erfüllung seiner Pflichten anzuhalten und bei Verletzung dieser Pflichten [...], ihn im besonderen ohne Einleitung vorgeschriebener Verfahren aus seinem Amte, aus seinem Rang und seiner Stellung zu entfernen", dRGBl. I, S. 247. ${ }^{299}$ So Hans Hattenhauer 1977, vgl. GruCHMANN, Generalangriff 509.

${ }^{300}$ GRUCHMANN, Generalangriff 512ff. 
Praxis anbelangt, so musste sich Hitler tatsächlich, „wenn auch zähneknirschend“, damit zufrieden geben, "gegenüber Richtern die Verfahrensbestimmungen des Deutschen Beamtengesetzes selbst dann zu beachten, wenn die Amtsenthebung von ihm gefordert wurde". Es wurde also ein Untersuchungsverfahren mit ",gewissenhafter Prüfung" aller Umstände durch die Ministerialbürokratie durchgeführt, inklusive der Möglichkeit einer eidlichen Vernehmung und Anhörung des Betroffenen. Hitler scheute „offenbar", so Gruchmann, "davor zurück, das nach langjährigen Beratungen von ihm unterzeichnete und erst vor kurzem in Kraft getretene nationalsozialistische Beamtengesetz zu desavouieren“. ${ }^{301}$ Dies führte in der Praxis dazu, dass in der Ära Gürtner nur in drei von sechs Fällen die Zwangspensionierung eines Richters erfolgte, denn das RJM wollte verhindern, dass „nun wahllos Richter" aufgrund von Zeitungsmeldungen oder Wünschen der Gauleiter abgesetzt würden. ${ }^{302}$ Dem Reichstagsbeschluss kam also nach Gruchmann ${ }^{303}$ „für die Maßregelung der Richter durch Hitler keine Bedeutung" zu, und selbst in der Ära Thierack wurden „unfolgsame Richter nicht unter Anwendung des Beschlusses kassiert, sondern auf gesetzlicher Grundlage in den Ruhestand versetzt". In der Praxis entsprach daher die Wirkung des Beschlusses der Einschätzung Göbbels, der in seinem Tagebuch wenig später vermerkte, dass dieser „den Richtern $[\ldots]$ gegenüber aus psychologischen Gründen notwendig war", "in den betroffenen Kreisen einen richtigen Schock ausgelöst" und „eine außerordentlich heilsame Wirkung gehabt" habe. ${ }^{304}$ Auch auf Seiten der Richterschaft wurde vermeldet, ${ }^{305}$ dass „starke Besorgnis“ herrsche,

\footnotetext{
301 Ebd. 512.

302 Ebd. 513, 515.

${ }^{303}$ Ebd. 518, 515f.

304 Ebd. 519.

${ }^{305}$ Lagebericht des OLG-Präs. Köln 2. 7. 1942, zit.n. ebd. 519.
}

„weil die Richter u.U. ihre Absetzung fürchten müßten, wenn sie nach Recht und Gesetz urteilten“, sie seien aber bemüht, "nach besten Kräften die gestellten Erwartungen zu erfüllen“.

Zu diesem Zweck setzte ebenfalls 1942 auch die direkte Lenkung der Rechtspflege ${ }^{306}$ durch vertrauliche sogenannte "Richterbriefe" des RJM ein, die eine "Anschauung" davon zu geben hatten, „wie sich die Justizführung nationalsozialistische Rechtsanwendung denkt" und „auf diese Weise dem Richter die innere Sicherheit und Freiheit geben [sollten], die richtige Entscheidung zu finden.“ ${ }^{307}$ Darüber hinaus gab es weitere Maßnahmen zur Indoktrinierung der Richter, etwa Schulungen zu neuen Gesetzen bzw. Rechtsmaterien in Arbeitsgruppen, auf Tagungen oder in Schulungslagern. Des Weiteren ergingen diverse "Richtlinien“ des RJM, Urteile wurden in der "Deutschen Justiz" besprochen und mit Lob bzw. Kritik versehen sowie bestehende Berichtspflichten verschärft bzw. neue eingeführt. ${ }^{308}$ Als weiteres Mittel der Justizlenkung dienten die „Urteilsvor- und Nachschauen", bei denen sowohl vor als auch nach der Verhandlung eine Besprechung des Prozesses erfolgte, ${ }^{309}$ sowie die „Fühlungnahme“, die darin bestand, dass bereits vor Prozessbeginn mit dem RJM das Urteil abgesprochen wurde. ${ }^{310}$

Die „Wiedervereinigung“ Österreichs mit dem Deutschen Reich brachte hinsichtlich der Garantien der Unabsetzbarkeit und Unversetzbarkeit der Richter letztlich keinen Umbruch, musste doch schon 1933/34 den Richtern „bewußt ge-

\footnotetext{
306 Ausführlich GRUCHMANN, Justiz 1091ff.

307 Zit.n. STAFF, Justiz 70; vgl. auch BOBERACH, Richterbriefe.

308 SCHÄDLER, Justizkrise $197 \mathrm{ff}$.

${ }^{309}$ So bat etwa der Vorgesetzte einen Richter, trotz Schwierigkeiten in der Beweisführung „nicht zu subtile Bedenken" bei der Urteilsfindung zu haben, vgl. STAFF, Justiz 104.

310 SCHÄDLER, Justizkrise 162f., 171f.; BOBERACH, Richterbriefe XVIII.
} 
worden“ sein musste, "daß der rechtliche Rahmen eines liberal-demokratischen ,Rechtsstaates' nicht mehr galt“. ${ }^{311}$ Nach Mulley bedeuteten die NS-Maßnahmen nur mehr einen weiteren radikalen Schritt „vom ständestaatlichen ,UnRechts- $^{-}$zum nationalsozialistischen ,UnStaat'."312 Die Verfassung 1934, die noch die Unabsetzbarkeit und Unversetzbarkeit der Richter normiert hatte, trat außer Kraft, die Gerichtsbarkeit ging auf das Deutsche Reich über, ${ }^{313}$ und es erfolgte innerhalb kürzester Zeit die Erfassung des politischen Verhaltens und der fachlichen Eignung des Justizpersonals. ${ }^{314}$ Bereits am 15. März 1938 wurden die nicht-,,jüdischen“ Richter und Staatsanwälte auf Adolf Hitler persönlich vereidigt. In weiterer Folge wurde nicht die Übernahme des reichsdeutschen Beamtenrechts für die Säuberung des Justizapparates abgewartet - tatsächlich trat das deutschen Gesetz zur Wiederherstellung des Berufsbeamtentums vom 7. April 1933 erst im September 1938 in Österreich in Kraft -, sondern am 31. Mai 1938 erging dessen österreichisches Pendant, die „Verordnung zur Neuordnung des österreichischen Berufsbeamtentums", das eine rasche „Säuberung“ der Richterschaft ${ }^{315}$ von „,fremdrassigen und unzuverlässlichen Elementen“316 ermöglichte, der mehr als 200 Richter zum Opfer fielen.

$\mathrm{Ab}$ 1. Mai 1938 waren die Justizbehörden im „Land Österreich“ Reichsbehörden, und auch die Richter im „Land Österreich“ wurden nun im Rahmen ihrer "sachlichen Unabhängigkeit" nicht nur dem Gesetz, „sondern mehr noch dem Recht der völkischen Rechtsidee unterworfen", und ihre "persönliche Unabhängigkeit" erfuhr durch das Reichsrecht „eine neue gesetzliche

\footnotetext{
311 MULLEY, Gleichschaltung 260.

312 Ebd. 260.

313 PfEIFER, Ostmark 21; MULLEY, Gleichschaltung 280.

${ }^{314}$ MULLEY, Gleichschaltung 273ff.

$315 \mathrm{Vgl}$. SCHWARZ, Kontinuität.

316 PFEIFER, Ostmark 71.
}

Formulierung und Wandlung ". ${ }^{317}$ So manchem Richter freilich, der sich in der "Systemzeit" auf die richterliche Unabhängigkeit berufen hatte und vom Dollfuß-Schuschnigg-Regime wegen NS-Aktivitäten gemaßregelt worden war, wurde nun das endgültige auch formale Ende seiner Unabhängigkeit mit dem ersehnten Karrieresprung und Anerkennung als „Alter Kämpfer“ abgegolten. Die übrigen Richter passten sich großteils nicht nur rasch an die geänderten Verhältnisse an, sondern zeichneten sich, so Mulley, "durch Übereifer und Beflissenheit" sowie „inhaltliche Akzeptierung der NS-Ideologie" aus. ${ }^{318}$

\section{Schlussbemerkung}

Die richterliche Unabhängigkeit steht in Österreich und Deutschland wie in den meisten europäischen Staaten nicht mehr zur Diskussion, wiewohl die Frage des Ausnahmezustandes bzw. „übergesetzlichen Notstandes“ seit den 1970er Jahren v.a. in der BRD angesichts der Terrorismusgefahr wieder verstärkt diskutiert wurde und in letzter Zeit auch wissenschaftlich durchaus wieder Hochkonjunktur hat. ${ }^{319}$ Der historische Befund stärkt jedoch die positivistische Position, dass „[a]lles Spekulieren mit einem ,überverfassungsgesetzlichen Notstand ' als eine Erlaubnis zu Maßnahmen, die nicht von der urkundlich Verfassung gerechtfertigt werden, [...] nicht anderes [ist] als eine verwerfliche Beschönigung des Verfassungsbruchs, des Verfassungsverrats“. ${ }^{320}$ Auch können der Rechtsstaat und die richterliche Unabhängigkeit auf Dauer

\footnotetext{
${ }^{317}$ Vortrag von Helfried Pfeifer, Verwaltungsrecht, im Rahmen der Verwaltungsakademie, zit. n. MulleY, Gleichschaltung 281.

${ }^{118}$ MuLLEY, Gleichschaltung 65; siehe aber etwa auch den Fall Eypeltauer SCHWARZ, NS-Richter 138ff.

${ }^{319}$ U.a. in Form des Folterdiskurses und der Frage des Rettungsabschusses, siehe etwa AGAMBEN, Ausnahmezustand; FRANKENBERG, Staatstechnik 145ff.

${ }^{320}$ Adolf Arndt zit.n. FRANKENBERG, Staatstechnik 178.
} 
nur in der parlamentarischen Demokratie gewährleistet werden, ${ }^{321}$ jedoch muss die Unabhängigkeit der Justiz als „Freiheit von allen äußeren Einflüssen bei der gerichtlichen Entscheidung immer neu erkämpft und abgesichert werden“. 322

\section{Korrespondenz:}

Ao. Univ.-Prof. Dr. Ilse Reiter-Zatloukal Institut für Rechts- und Verfassungsgeschichte Universität Wien

1010 Wien, Schottenbastei 10-16

ilse.reiter-zatloukal@univie.ac.at

\section{Abkürzungen:}

$\begin{array}{ll}\text { AZ } & \text { Arbeiter-Zeitung } \\ \text { BM } & \text { Bundesminister } \\ \text { BMI } & \text { Bundesminister/ium für Inneres } \\ \text { BMJ } & \text { Bundesminister/ium für Justiz } \\ \text { DRiZ } & \text { Deutsche Richterzeitung } \\ \text { GZ } & \text { Geschäftszahl } \\ \text { Komm } & \text { Kommission/Sonderkommission } \\ \text { KPÖ } & \text { Kommunistische Partei Österreichs } \\ \text { Liqu } & \text { Personalakten - „Liquidator } \\ \text { MR } & \text { Ministerrat } \\ \text { MRP } & \text { Ministerratsprotokolle } \\ \text { NA } & \text { Namensakte } \\ \text { NFP } & \text { Neue Freie Presse } \\ \text { NSBO } & \text { NS-Betriebszellenorganisation } \\ \text { NSKK } & \text { Nationalsozialistisches Kraftfahr- } \\ & \text { korps } \\ \text { NSRB } & \text { Nationalsozialistischer Rechtswah- } \\ \text { OSTA } & \text { rerbund } \\ \text { RDG } & \text { Oberstaatsanwalt/schaft } \\ \text { RIM } & \text { Richterdienstgesetz } \\ \text { RJM } & \text { Reichsinnenminister/ium } \\ \text { RP } & \text { Reichsjustizminister/ium } \\ \text { SDAPÖ } & \text { Reichspost } \\ \text { VF } & \text { Oozialdemokratische Arbeiterpartei } \\ \text { VP } & \text { Vaterländische Front } \\ \text { WrZ } & \text { Verwaltung und Personal } \\ \text { ZRS } & \text { Wiener Zeitung } \\ \text { Siechssachen }\end{array}$

Siehe auch das allgemeine Abkürzungsverzeichnis: [http://www.rechtsgeschichte.at/files/abk.pdf]

\footnotetext{
321 PeLINKA, Richter 41.

322 MARKEL, Sicherung 44.
} 


\section{Archivalien:}

ÖStA, AdR, Justiz, RJM, PA Dillersberger, Walther; Eberstaller, Richard; Rainer, Franz; Grüner, Karl; Heyn, Theodor; Hufnagl, Eugen; Lutz, Otto; Pauer, Ludwig; Rabe, Walter; Raunig, Josef; Saurwein, Erwin; Thies, Karl Otto; Wenger Guntram.

ÖStA, AdR, Justiz, BMJ, VP NA Dillersberger, Walther; Dölzl, Josef; Grüner, Karl; Herbert, Paul; Hufnagl, Eugen; Jennewein, Anton, Lutz, Otto; Pauer, Ludwig; Rabe Walter; Rainer, Franz; Raunig, Franz; Rolleder, Anton; Saurwein, Erwin; Schebesta, Norbert; Schindler, Emil; Schwandtner, Johann; Techner Richard; Thies Karl Otto.

ÖStA, AdR, Justiz, BMJ, VP Komm Grüner, Karl; Hufnagl, Eugen; Schebesta, Norbert.

ÖStA, AdR, Justiz, BMJ, VP Liqu Fuhrmann, Ferdinand; Grüner, Karl; Heyn, Theodor; Koloseus, Ludwig; Kraus Friedrich; Lutz, Otto; Pauer Ludwig; Raunig, Josef; Rolleder Anton; Schindler, Emil; Wenger, Guntram.

ÖStA, AdR, Sonderarchiv Moskau, Kart. 109, Konv. 347.

ÖStA, AdR BKA-I Parteiarchive VF Gensekt. 514-1920, Kart. 149.

ÖStA, AVA, JM, Allgemein Pers.Ger. Kart. 4465.

ÖStA, AVA, JM, Wien P 6+Vz 1935, Kart. 4391.

ÖStA, AVA, JM, OStA Wien 1938 Pers. Varia, Kart. 5045.

\section{Gedruckte Quellen und Literatur:}

Ludwig ADAMOvicH, Grundriss des österreichischen Staatsrechtes (Wien 1935).

Giorgio AgAmBEN, Ausnahmezustand (Homo sacer II.1) (Frankfurt am Main 2004).

Ralph ANGERMUND, Deutsche Richterschaft 19191945. Krisenerfahrung, Illusion, politische Rechtsprechung (Frankfurt am Main 1990).

Gustav AuBIN, Die Entwicklung der richterlichen Unabhängigkeit im neuesten deutschen und österreichischen Rechte (Karlsruhe 1906).

Vera BACKHAUS, Der gesetzliche Richter im Staatsschutzstrafrecht. Zur Verfassungsmäßigkeit des §120 Abs. 2 GVG (Frankfurter kriminalwissenschaftliche Studien 121, Frankfurt am Main 2010).

Kurt BAUER, Elementar-Ereignis. Die österreichischen Nationalsozialisten und der Juliputsch 1934 (Wien 2003).

Klaus BERCHTOLD (Hg.), Die Verfassungsreform von 1929. Dokumente und Material zur BundesVerfassungsgesetz-Novelle von 1929, Teil I
(=Österreichische Schriftenreihe für Rechts- und Politikwissenschaften II/3, Wien 1979).

Bericht über die Rede des Bundesministers Dr. Kurt Schuschnigg am 15. März 1934, in: RZ 27/4 (1934) 65-67.

Heinz BOBERACH, Richterbriefe. Dokumente zur Beeinflussung der deutschen Rechtsprechung 19421944 (= Schriften des Bundesarchivs 21, Boppard 1975).

Gottfried BOLDT, Staatsnotwehr und Staatsnotstand, in: Zeitschrift für die gesamte Strafrechtswissenschaft 56/1 (1937) 183-226.

Hans BOLDT, Rechtsstaat und Ausnahmezustand. Eine Studie über den Belagerungszustand als Ausnahmezustand des bürgerlichen Rechtsstaates im 19. Jahrhundert (=Schriften zur Verfassungsgeschichte 6, Berlin 1967).

Gerhard Bотz, Gewalt in der Politik. Attentate, Zusammenstöße, Putschversuche, Unruhen in Österreich 1918-1938 (München 1976).

Gerhard BотZ, Strukturwandlungen des österreichischen Nationalsozialismus (1904-1945), in: Isabella ACKERL, Walter HuMMELBERger, Hans MoMMSEN (Hgg.), Politik und Gesellschaft im alten und neuen Österreich (Wien 1981) 163-193.

Gerhard BотZ, Zum Verhältnis von Politik und Rechtswesen in der Ersten Republik, in: Erika WEINZIERL, Karl STADLER (Hgg.), Justiz und Zeitgeschichte I. Symposion am 22. und 23. Oktober 1976 (Wien 1977) 144-168, auch in: Erika WEINZIERL u.a. (Hgg.), Justiz und Zeitgeschichte, Bd. 1 (Wien 1995) 99-113.

Karl Dietrich BRACHER, Die deutsche Diktatur. Entstehung, Struktur, Folgen des Nationalsozialismus (Köln 1993).

Paul BRUPPACHER, Adolf Hitler und die Geschichte der NSDAP. Eine Chronik, Teil II (Norderstedt 22013).

Erhard DENNINGER (Hg.), Freiheitliche demokratische Grundordnung. Materialien zum Staatsverständnis und zur Verfassungswirklichkeit in der Bundesrepublik, I. Teil (Frankfurt am Main 1976).

Duden Recht A-Z. Fachlexikon für Studium, Ausbildung und Beruf (Berlin ${ }^{32015)}$.

Otto ENDER, Die neue Österreichische Verfassung mit dem Text des Konkordates (= Der neue Staat 1, Wien-Leipzig 1934).

Otto ENDER, Die Übergangsbestimmungen zur neuen österreichischen Verfassung (= Der neue Staat 4, Wien-Leipzig 1934).

Hans-Ernst FolZ, Staatsnotstand und Notstandsrecht (Köln u.a. 1962). 
Hans FRANK, Der Richter im neuen Reich, in: DRiZ 1933, 162.

Günter FrANKENBERG, Staatstechnik. Perspektiven auf Rechtsstaat und Ausnahmezustand (Berlin 2010).

Erich FRÖsCHL, Helge ZoITL (Hgg.), Der 4. März 1933. Vom Verfassungsbruch zur Diktatur, Beiträge zum wissenschaftlichen Symposium des Dr.-KarlRenner-Instituts abgehalten am 28. Februar und 1. März 1983 (Wien 1984).

Winfried R. GARSCHA, Nationalsozialisten in Österreich 1933-1938, in: Emmerich TÁLOS, Wolfgang Neugebauer (Hgg.), Austrofaschismus. Politik Ökonomie - Kultur 1933-1938 (Politik und Zeitgeschichte 1, Wien ${ }^{52005)}$ 100-120.

Geheimer Briefwechsel Mussolini-Dollfuß. Mit einem Vorwort von Vizekanzler Dr Adolf Schärf, erläuternder Text von Karl Hans SAILER (Wien 1949).

Franz GOLDNER, Dollfuss im Spiegel der US-Akten. Aus den Archiven des Secretary of State, Washington - bisher veröffentlichte Berichte der US-Botschaften Wien-Berlin-Rom-London-ParisPrag (St. Pölten 1979).

Walter GOLDINGER (Hg.), Protokolle des Klubvorstandes der Christlichsozialen Partei 1932-1934 (= Studien und Quellen zur österreichischen Zeitgeschichte 2, Wien 1980).

Georg GRAF, Reine Rechtslehre und schmutzige Verfassungstricks - Rechtstheoretische Überlegungen zu einigen Verordnungen aus dem Jahre 1933, in: Kurt R. FISCHER, Franz Martin WIMMER (Hgg.), Der geistige Anschluß. Philosophie und Politik an der Universität Wien 1930-1950 (Wien 1993) 5968.

Kathrin GROH, Demokratische Staatsrechtslehrer in der Weimarer Republik. Von der konstitutionellen Staatslehre zur Theorie des modernen demokratischen Verfassungsstaats (Tübingen 2010).

Lothar GRUCHMANN, „Generalangriff auf die Justiz?“ Der Reichstagsbeschluß vom 26. April 1942 und seine Bedeutung für die Maßregelung der deutschen Richter, in: Vierteljahreshefte für Zeitgeschichte 51 (2003) 509-520.

Norbert GÜRKE, Die österreichische „Verfassung 1934", in: Archiv des öffentlichen Rechts NF 25/2 (1934) 178-255.

Norbert GÜRKE, Österreichs Verfassungsreform, in: Schweizerische Monatshefte für Politik und Kultur 9 (1929-1930) 399-404.

Charles A. GuLICK, Österreich von Habsburg zu Hitler, Bd. 4 (Wien 1948).

Karl HAAS, Industrielle Interessenpolitik in Österreich zur Zeit der Weltwirtschaftskrise, in: Jahrbuch für Zeitgeschichte (1978) 97-126.
Dirk HÄNISCH, Wahlentwicklung und Wahlverhalten in der Ersten Republik, in: Emmerich TÁLOS, Herbert DACHS, Ernst HANISCH, Anton STAUdinger (Hgg.), Handbuch des politischen Systems Österreichs 1918-1933 (Wien 1995) 488-503.

Heinrich HENKEL, Die Unabhängigkeit des Richters in ihrem neuen Sinngehalt (Hamburg 1934).

Barbara HELIGE, Richteramt und Gesellschaftspolitik Wie politisch muss ein Richter sein, in: Erika WeINZIERL, u.a. (Hgg.), Richter und Gesellschaftspolitik. Symposion Justiz und Zeitgeschichte, 12. und 13. Oktober 1995 in Wien (=Veröffentlichungen des Ludwig-Boltzmann-Instituts für Geschichte und Gesellschaft 28, Innsbruck-Wien 1997) 138-148.

Everhard HOLTMANN, Zwischen Unterdrückung und Befriedung. Sozialistische Arbeiterbewegung und autoritäres Regime in Österreich 1933-1938 (Wien 1978).

Everhard HolTMANN, Autoritätsprinzip und Maßnahmegesetz. Zur verfassungsgeschichtlichen Stellung der Justiz im österreichischen Ständestaat, in: Protokoll des Symposiums in Wien am 19. Oktober 1977 (= Veröffentlichungen. Wissenschaftliche Kommission des Theodor-KörnerStiftungsfonds und des Leopold-Kunschak Preises zur Erforschung der Österreichischen Geschichte der Jahre 1927 bis 1938 6, Wien 1980) 210-222.

Peter Huemer, Sektionschef Robert Hecht und die Zerstörung der Demokratie in Österreich. Eine historisch-politische Studie (Wien 1975).

Gerhard JAGschitz, Der Putsch. Die Nationalsozialisten 1934 in Österreich (Graz u.a. 1976).

Ludwig JeDLICKA, Rudolf NeCK (Hgg.), 12. Februar. Protokoll des Symposiums in Wien am 5. Februar 1974 (Wien 1975).

Johannes LAMEYER, Streitbare Demokratie - eine verfassungshermeneutische Untersuchung (=Schriften zum Öffentlichen Recht 336, Berlin 1978).

Stefan August LÜTGENAU, Alexander SCHRÖCK, Sonja NiEDERACHER, Zwischen Staat und Wirtschaft. Das Dorotheum im Nationalsozialismus (Wien u.a. 2006).

Thomas OlechOWsKI, Der Beitrag Hans Kelsens zur österreichischen Bundesverfassung, in: Robert WALTER, Werner OGRIS, Thomas OLECHOWSKI (Hgg.), Hans Kelsen: Leben - Werk - Wirksamkeit (= Schriftenreihe des Hans Kelsen-Instituts 32, Wien 2009) 211-230.

Hans KELSEN, Allgemeine Staatslehre (Berlin 1925).

Gerald KOHL, Zur Entwicklung der richterlichen Unabhängigkeit bis zum Bundes-Verfassungsgesetz 1920, in: Barbara Helige, Thomas OlechOWs- 
KI (Hgg.), 100 Jahre Richtervereinigung. Beiträge zur Juristischen Zeitgeschichte (Wien 2007) 9-26.

Helmut KONRAD, Das Werben der NSDAP um die Sozialdemokraten 1933-1938, in: Rudolf G. ARDELT, Hans HautManN (Hgg.), Arbeiterschaft und Nationalsozialismus in Österreich. In memoriam Karl R. Stadler (Wien-Zürich 1990).

Felix KREISSLER, Von der Revolution zur Annexion. Österreich 1918 bis 1938 (Wien u.a. 1970).

[Otto LEICHTER], Schwarzbuch der österreichischen Diktatur. Recht und Gesetz unter Dr. Schuschnigg. Tatsachen, nichts als Tatsachen (Bruxelles 1934).

Otto LEICHTER, Glanz und Ende der Ersten Republik. Wie es zum österreichischen Bürgerkrieg kam (Wien u.a. 1964).

Wolfgang MADERTHANER, Michaela MAIER (Hgg.), „Der Führer bin ich selbst". Engelbert Dollfuß Benito Mussolini, Briefwechsel (Wien 2004).

Ernst MARKEL, Sicherung der richterlichen Unabhängigkeit, in: Alfred Noll (Hg.), Justiz unter Druck. Zur Rolle der dritten Gewalt in Österreich (WienNew York 1991) 43-57.

Siegfried MATTL, Beiträge zu einer Sozialgeschichte der österreichischen Richterschaft (1900-1924), in: Erika WeINZIERL, Karl R. STADLER (Hgg.), Justiz und Zeitgeschichte VI. Symposion. Zur Geschichte der richterlichen Unabhängigkeit in Österreich am 24. und 25. Oktober 1986 (Wien-Salzburg 1987) 359-396.

Siegfried MATTL, Zur Sozialgeschichte und Habitus österreichischer RichterInnen seit 1924, in: Barbara Helige, Thomas OlechowsKI (Hgg.), 100 Jahre Richtervereinigung. Beiträge zur Juristischen Zeitgeschichte (Wien 2007) 67-88.

AdOLF MERKL, Das Verfassungsübergangsgesetz, JBl. 63 (1934) 377-383.

Alfred MissonG, "Mein Leben und Arbeiten", in: DERS., Christentum und Politik in Österreich. Ausgewählte Schriften 1924-1950 (=Schriften zu Politik und Verwaltung 55, Wien-Köln-Graz 2006) 15-46.

Klaus-Dieter MulleY, Zur "Gleichschaltung“ der Justiz im Bereich des Oberlandesgerichtes Wien "Anschluß" Österreichs, in: Willibald ROSNER (Hg.), Recht und Gericht in Niederösterreich (St. Pölten 2002) 248-294.

Rudolf NeCK, Adam WANdruZsKa (Hgg.), Protokolle des Ministerrates der Ersten Republik VIII, Bd. 3-6 (Wien 1983-1985).

Wolfgang NeUgebAUER, Repressionsapparat und -maßnahmen 1933-1938, in: Emmerich TÁLOS, DERS. (Hgg.), Austrofaschismus. Politik - Ökono- mie - Kultur 1933-1938 (= Politik und Zeitgeschichte 1, Wien 52005) 298-319.

Wolfgang Neugebauer, Richter in der NS-Zeit. Politische und gesellschaftliche Rahmenbedingungen, in: Erika WeINZIERL u.a. (Hgg.), Richter und Gesellschaftspolitik. Symposion Justiz und Zeitgeschichte, 12. und 13. Oktober 1995 in Wien (=Veröffentlichungen des Ludwig-Boltzmann-Instituts für Geschichte und Gesellschaft 28, InnsbruckWien 1997) 56-68.

Wolfgang NeUGEBAUER, Richterliche Unabhängigkeit 1934-1945, unter Berücksichtigung der Standgerichte und der Militärgerichte, in: Erika WEINZIERL u.a. (Hgg.), Justiz und Zeitgeschichte, Bd. 2 (Wien 1995) 51-74.

Wolfgang Neugebauer, Politische Justiz in Österreich, in: Erika WEINZIERL u.a. (Hgg.), Justiz und Zeitgeschichte, Bd. 1 (Wien 1995) 114-138.

Volker NEUMANN, Carl Schmitt als Jurist (Tübingen 2015).

Engelbert NIEBLER, Richterliche Unabhängigkeit in der Bundesrepublik Deutschland, in: Richard FRANK (Hg.), Unabhängigkeit und Bindungen des Richters in der Bundesrepublik Deutschland, in Österreich und in der Schweiz. Ergebnisse einer internationalen Richtertagung (Basel-Frankfurt am Main 21997) 14-36.

Franz OswALD, Die Stellung von Major a. D. Emil Fey in der Politik der Ersten Republik und des Ständestaates (Diss. Univ. Wien 1964).

Anton PeLINKA, Wie unabhängig sind die Richter? Unabhängige Rechtsprechung im Demokratiebewusstsein des Österreichers, in: Alfred NolL (Hg.), Justiz unter Druck. Zur Rolle der dritten Gewalt in Österreich (Wien-New York 1991) 2742.

Helfried PfEIFER (Hg.), Die Ostmark. Eingliederung und Neugestaltung. Historisch-systematische Gesetzessammlung nach dem Stand vom 16. April 1941 (Wien 1941).

Henry PICKER, Hitlers Tischgespräche im Führerhauptquartier 1941-42 (Stuttgart ${ }^{31976) .}$

Wolfgang PUTSCHEK, Ständische Verfassung und autoritäre Verfassungspraxis in Österreich 19331938 mit Dokumentenanhang (Rechtshistorische Reihe 109, Frankfurt am Main 1993).

Oliver RATHKOLB, Anmerkungen zur Entnazifizierungsdebatte über Richter und Staatsanwälte in Wien 1945/46 vor dem Hintergrund politischer Obsessionen und Pressionen während des Nationalsozialismus, in: Erika WeINZIERL u.a. (Hg.), Justiz und Zeitgeschichte, Bd. 2 (Wien 1995) 75-99. 
Dieter Ross, Hitler und Dollfuß. Die deutsche Österreich-Politik 1933-1934 (Hamburg 1966).

Ilse ReITER-ZATLOUKAL, Parlamentarismus im Fadenkreuz. Demokratiekonzepte und (Anti-)parlamentarismus in Österreich 1918-1933/34, in: Parlamentsdirektion (Hg.), Staats- und Verfassungskrise 1933 (Wien u.a. 2014) 19-50.

Ilse ReIter-Zatloukal Der Bundesgerichtshof 19341938. Wendeexperte oder Verteidiger des Rechtsstaats? in: Clemens JABLONER u.a. (Hgg.), Gedächtnisschrift für Robert Walter (Wien 2013) 657678.

Ilse ReITER-ZATLOUKAL, Richterliche Unabhängigkeit im autoritären Ständestaat, in: Barbara HELIGE, Thomas OlechOWSKI (Hg.), 100 Jahre Richtervereinigung. Beiträge zur Juristischen Zeitgeschichte (Wien 2007) 89-111.

Ilse ReIter-Zatloukal, Politische Radikalisierung, NS-Terrorismus und „innere Sicherheit“ in Österreich 1933-1938. Strafrecht, Polizei und Justiz als Instrumente des Dollfuß-Schuschnigg-Regimes, in: Karl HärTER, Beatrice de GrAF (Hgg.), Vom Majestätsverbrechen zum Terrorismus: Politische Kriminalität, Recht, Justiz und Polizei zwischen Früher Neuzeit und 20. Jahrhundert (=Studien zur europäischen Rechtsgeschichte. Veröffentlichungen des Max-Planck-Instituts für europäische Rechtsgeschichte Frankfurt am Main 68, Frankfurt am Main 2012) 271-320.

Ilse Reiter-ZATLOUKAL, Richterbild und Richterausbildung im nationalsozialistischen Deutschen Reich, in: GERALD KOHL, ILSE REITER-ZATLOUKAL (Hgg.), RichterInnen in Geschichte, Gegenwart und Zukunft. Auswahl, Ausbildung, Fortbildung und Berufslaufbahn (Wien 2014) 83-107.

Anton RIEDLER, Die Ausnahmegesetzgebung in Österreich 1933-1936 (Berlin 1936).

Christiane ROTHLÄNDER, Vermögensbeschlagnahme und Liquidation des Republikanischen Schutzbundes 1933-1937, in: DÖW-Jahrbuch 2010, 212233.

Hinrich RÜPING, Nullum crimen sine poena. Zur Diskussion um das Analogieverbot im Nationalsozialismus, in: Rolf Dietrich HERZBERG (Hg.), FS für Dietrich Oehler (Köln 1985) 27-41.

Hans SAFRIAN, Standgerichte als Mittel der Politik im Februar 1934 in Wien, in: Karl R. STADLER (Hg.), Sozialistenprozesse. Politische Justiz in Österreich 1870-1936 (Wien-München-Zürich 1986) 269-302.

Sarah SCHÄDLER, ,Justizkrise“ und „Justizreform" im Nationalsozialismus. Das Reichsjustizministerium unter Reichsjustizminister Thierack (1942-1945) (= Beiträge zur Rechtsgeschichte des 20. Jahrhunderts 61, Tübingen 2009).
Friedrich SCHAFfSTEIN, Politische Strafrechtswissenschaft (Hamburg 1934).

Richard SCHMID, Erinnerung an den NS-Rechtswahrerbund, in: JZ 9 (1954) 263-264.

Ursula SCHWARZ, Zur Frage der personellen Kontinuität im Richtertum. Entlassungen und Weiterverwendungen von Richtern 1838 und 1945, in: Barbara Helige, Thomas OlechOWSKI (Hgg.), 100 Jahre Richtervereinigung. Beiträge zur Juristischen Zeitgeschichte (Wien 2007) 127-146.

Ursula SCHWARZ, NS-Richter in Österreich, in: Gerald KOHL, Ilse ReITER-ZATLOUKAL (Hgg.), RichterInnen in Geschichte, Gegenwart und Zukunft. Auswahl, Ausbildung, Fortbildung und Berufslaufbahn (Wien 2014) 125-144.

Kurt ScHusCHNIGG, Dreimal Österreich (Wien 1937).

Eva Maria SEDLAK, Politische Sanktionen gegen öffentliche Bedienstete im österreichischen Ständestaat (Diss., Univ. Wien 2004).

Ignaz SEIPEL, Der Kampf um die österreichische Verfassung (Wien-Leipzig 1930).

Gerhard SENFT, Im Vorfeld der Katastrophe. Die Wirtschaftspolitik des Ständestaates. Österreich 19341938 (= Vergleichende Gesellschaftsgeschichte und politische Ideengeschichte der Neuzeit 15, Wien 2002).

Elsbeth SIEGERS, Staatsnotrecht. Geschichte, Inhalt und Begründung (Diss., Univ. Köln 1969).

Dieter SIMON, Waren die NS-Richter „unabhängige Richter" im Sinne des § 1 GVG?, in: Rechtshistorisches Journal 4 (1985) 103-116.

Wolfgang STADLER, „... Juristisch bin ich nicht zu fassen." Die Verfahren des Volksgerichtes Wien gegen Richter und Staatsanwälte 1945-1955 (Wien 2007).

Ilse STAFF (Hg.), Justiz im Dritten Reich (Frankfurt am Main 1964).

Anton StAudinger, Christlichsoziale Partei und Errichtung des "Autoritären Ständestaates" in Österreich, in: Ludwig JEDLICKA, Rudolf NECK (Hg.), Vom Justizpalast zum Heldenplatz. Studien und Dokumentationen 1927-1938 (Wien 1975) 65-81.

Anton STAUdinger, Christlichsoziale Partei, in: Erika WEINZIERL, Kurt SKALNIK (Hg.), Österreich 19181938. Geschichte der Ersten Republik, Bd. 1 (Wien 1983) 249-276.

Herbert STEINER, Die Kommunistische Partei, in: Erika WEINZIERL, Kurt SKALNIK (Hg.), Österreich 19181938. Geschichte der Ersten Republik, Bd. 1 (Wien 1983) 317-329.

Wolfgang STEINLECHNER, Der Richter im Dritten Reich, Status - Unabhängigkeit - Persönlichkeit (Diss., Univ. Main 1974). 
Alfred STOHLMANN, Die Unbestimmtheit der Begriffe "Rechtsstaat" und "freiheitliche demokratische Grundordnung" in der Rechtsprechung des Bundesverfassungsgerichts (Diss., Univ. Münster 1965).

Wilhelm STUCKART, Zum Geleit, in: August JÄGER, Der Richter. Wesen und verfassungsrechtliche Stellung (Berlin 1939) III-V.

Viktor SzONTAGH, Die Richtervereinigung 1918-1938 im Spiegel der Richterzeitung, in: Barbara HELIGE, Thomas OleCHOWSKI (Hgg.), 100 Jahre Richtervereinigung. Beiträge zur Juristischen Zeitgeschichte (Wien 2007) 51-66.

Emmerich TÁLOS, Walter MANOSCHEK, Zum Konstituierungsprozess des Austrofaschismus, in: Emmerich TÁlos, Wolfgang Neugebauer (Hgg.), Austrofaschismus. Politik - Ökonomie - Kultur 1933-1938 (= Politik und Zeitgeschichte 1, Wien 52005).

Markus THIEL (Hg.), Wehrhafte Demokratie (Tübingen 2003).

Richard THOMA, Handbuch des deutschen Staatsrechts, Bd. 2 (Tübingen 1930).

Markus TrotTER, Der Ausnahmezustand im historischen und europäischen Rechtsvergleich (Diss., Univ. Heidelberg 1997).

Helmut UlM, Die Verfassungsreform von 1929 in der steirischen Öffentlichkeit (Diss., Univ. Wien 1968).

Lars VINX, Kelsens Indentitätsthese und das Problem der Rechtsstaatlichkeit, in: Tamara EHS (Hg.), Hans Kelsen und die europäische Union. Erörterungen moderner Staatlichkeit (Baden-Baden 2008) 57-74.

Christine VLCEK, Der Republikanische Schutzbund in Österreich. Geschichte, Aufbau und Organisation (Diss., Univ. Wien 1971).
Katharina WÄCHTER, Politik und Strafjustiz in den Jahren 1933 und 1934 mit besonderer Berücksichtigung des Landesgerichts für Strafsachen Wien I (Dipl.Arb., Univ. Wien 2013).

Manfried WELAN, Der Bundespräsident: Kein Kaiser in der Republik (= Studien zu Politik und Verwaltung 40, Wien 1992).

Erika WeINZIERL, Aus den Notizen von Richard Schmitz zur österreichischen Innenpolitik im Frühjahr 1933, in: Geschichte und Gesellschaft. FS für Karl R. Stadler zum 60. Geburtstag (Wien 1974) 113-141.

Franz WINKLER, Die Diktatur in Österreich (ZürichLeipzig 1935).

Ernst Karl WiNTER, Demokratie und Ermächtigung, in: Wiener Politische Blätter 1/3 (1933) 123-170.

Leo WiTTMAYER, Die österreichische Verfassungsreform von 1929, in: Zeitschrift für die gesamte Staatswissenschaft 88 (1930) 449-497.

Walter WiltschegG, Die Heimwehr. Eine unwiderstehliche Volksbewegung? (= Studien und Quellen zur österreichischen Zeitgeschichte 7, Wien 1985).

Helmut Wolter, Das Staatsnotrecht. Seine rechtliche Beurteilung in der Vergangenheit und seine Wandlung im völkischen Führerstaat (Düsseldorf 1937).

Hans Wrobel, Der Deutsche Richterbund im Jahre 1933, in: Kritische Justiz 15 (1982) 323-347.

Thomas ZAVADIL, Die Ausschaltung des Verfassungsgerichtshofs 1933 (Diss., Univ. Wien 1997).

Andrej ZWITTER, Rechtsstaat im Notstand. Rechtsstaatliche Gedanken zum Staatsnotstand in der liberalen Demokratie, in: Österreichisches Studienzentrum für Frieden und Konfliktlösung (Hg.), Demokratie im globalen Wandel. Eine Welt im demokratischen Aufbruch? (= Dialog 59, Wien 2010) 150-165. 